Portland State University

PDXScholar

Spring 6-8-2017

\title{
A Brief Intervention to Increase the Use of Precorrection and Praise by Elementary School Teachers
}

Dustin Bindreiff

Portland State University

Follow this and additional works at: https://pdxscholar.library.pdx.edu/open_access_etds

Part of the Educational Leadership Commons, and the Elementary Education Commons Let us know how access to this document benefits you.

Recommended Citation

Bindreiff, Dustin, "A Brief Intervention to Increase the Use of Precorrection and Praise by Elementary School Teachers" (2017). Dissertations and Theses. Paper 3640.

https://doi.org/10.15760/etd.5524

This Dissertation is brought to you for free and open access. It has been accepted for inclusion in Dissertations and Theses by an authorized administrator of PDXScholar. Please contact us if we can make this document more accessible: pdxscholar@pdx.edu. 
A Brief Intervention to Increase the use of Precorrection and Praise by Elementary School Teachers

by

Dustin F. Bindreiff

A dissertation submitted in partial fulfillment of the requirements for the degree of

\section{Doctor of Education}

in

Educational Leadership: Special and Counselor Education

Dissertation Committee:

Randall L. De Pry, Chair

Amy Donaldson

Randy Hitz

Sheldon Loman

Portland State University

2017 
(C) 2017 Dustin Bindreiff 


\begin{abstract}
There is an evidence base supporting the use of positive behavior supports in schools; however effectively and efficiently transferring these interventions into classroom settings remains a challenge. Precorrection is a highly-regarded behavior support strategy that relies on antecedent prompting to reduce problem behavior and teach socially appropriate skills. This study examined how a brief training in precorrection and praise paired with regular feedback impacted the behavior of four Title I elementary school teachers and students. As a result of the intervention, the four teachers increased use of precorrection and praise, while concomitantly reducing their use of reprimands. Limitations and suggestions for future research are provided.
\end{abstract}




\section{Table of Contents}

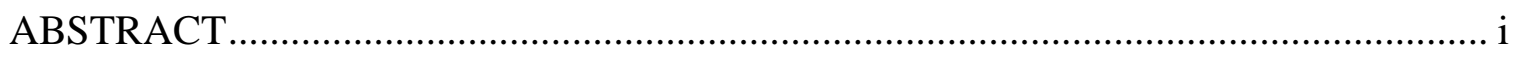

LIST OF TABLES .................................................................................... iv

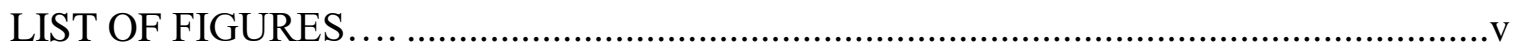

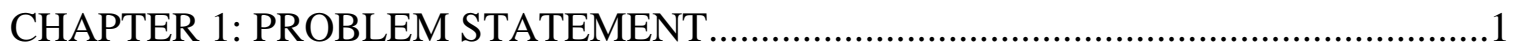

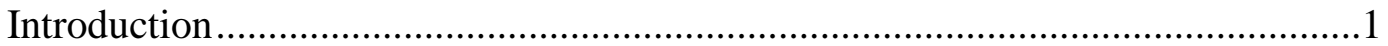

Background of the Problem .............................................................................2

School-wide positive behavior support..............................................4

Implementation of behavior supports ................................................

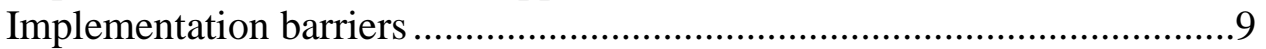

Statement of the Research Problem .................................................................... 12

Significance of the Research Problem ............................................................... 13

Impact of problem behavior...............................................................16

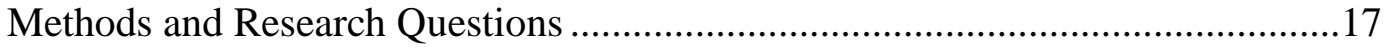

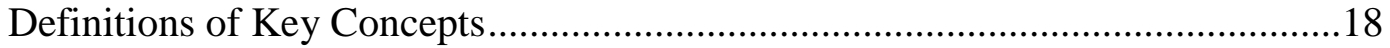

CHAPTER 2: LITERATURE REVIEW …............................................................. 19

Theoretical Framework ................................................................................ 19

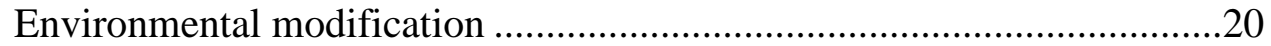

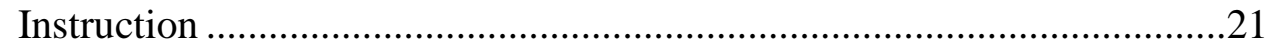

Review of the Research Literature ..................................................................2

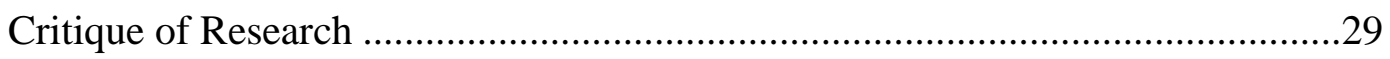

Review of the Methodological Literature ........................................................ 31

Summary of the Research literature and Application to Study ..............................35

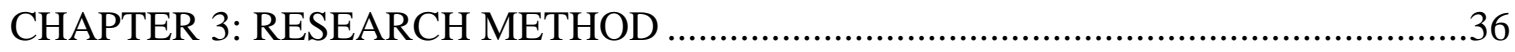

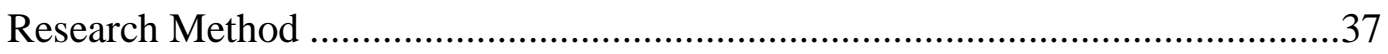

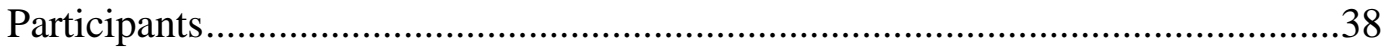

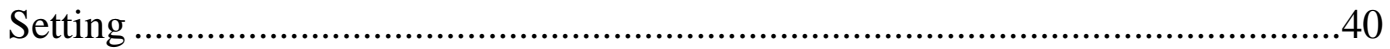

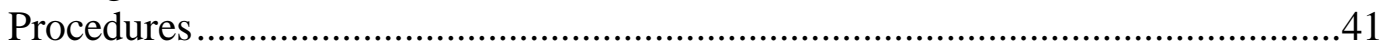

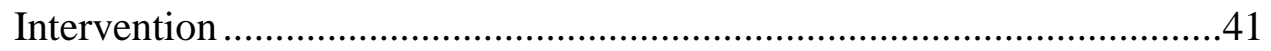

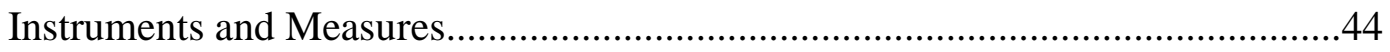

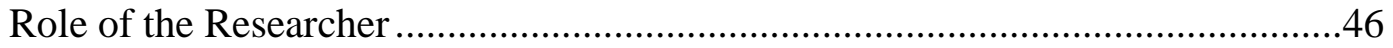

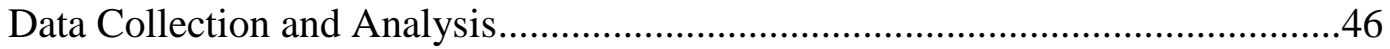

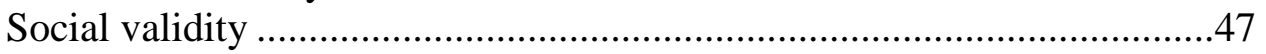

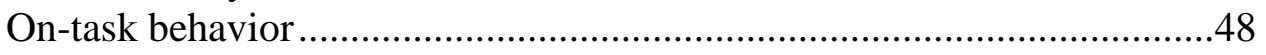

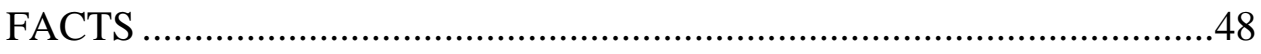

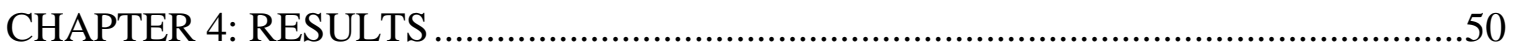

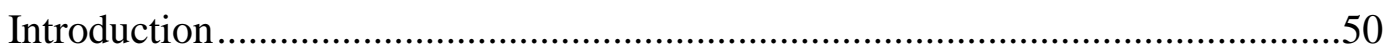




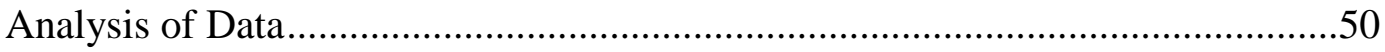

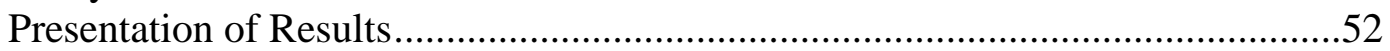

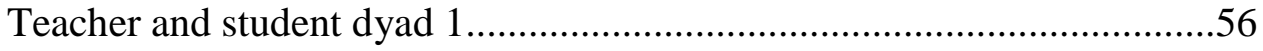

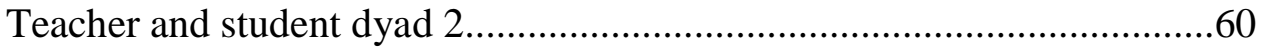

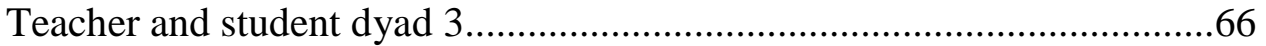

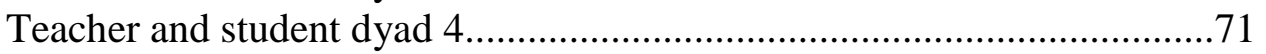

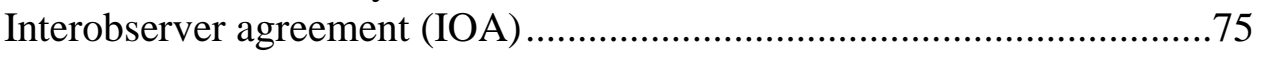

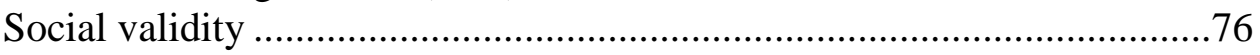

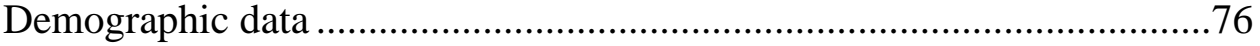

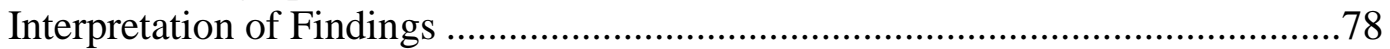

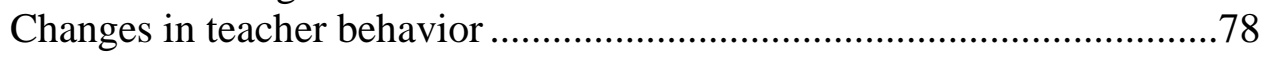

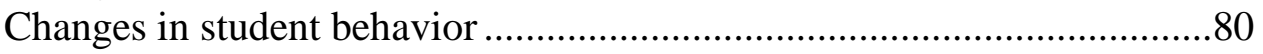

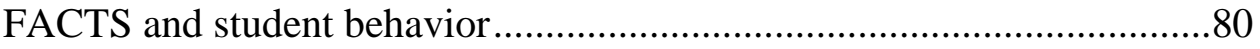

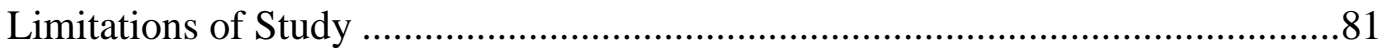

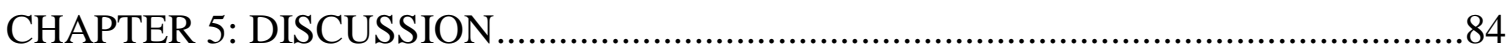

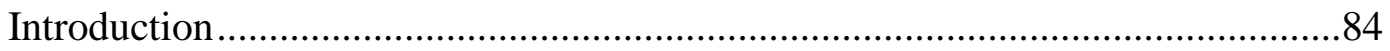

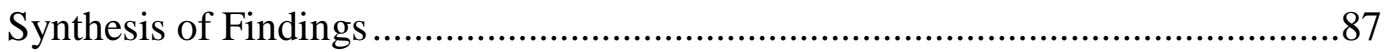

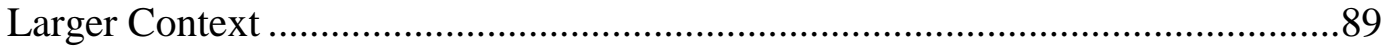

Replication findings ..................................................................99

Precorrection and prevention ...............................................92

Teacher training implications .....................................................93

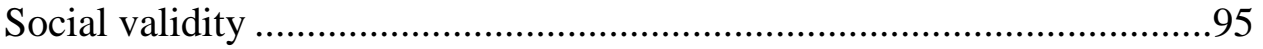

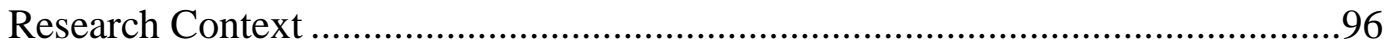

Evidence based practice potential ...................................................97

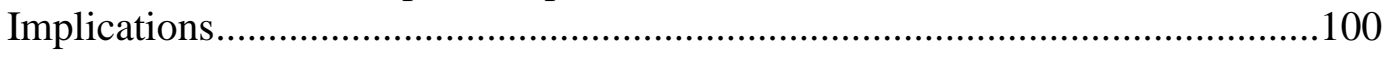

Predictable problem behavior ....................................................100

Implementation of supports ..........................................................101

Considerations for future research .................................................102

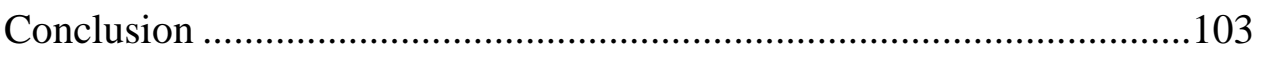

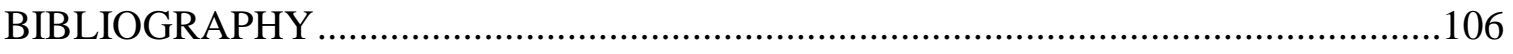

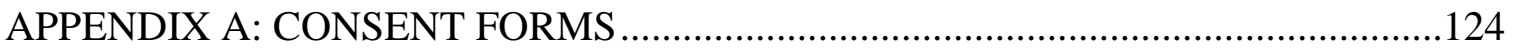

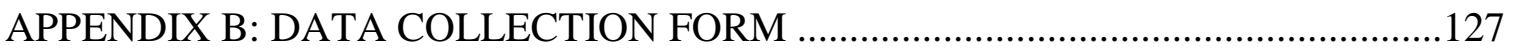

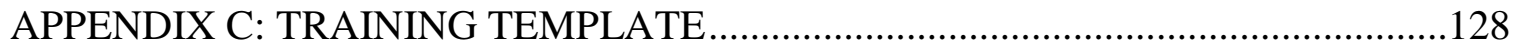




\section{LIST OF TABLES}

Table 1: Research Findings on Teacher Skills and Values Surrounding Behavior Interventions 12

Table 2: Sample Precorrection Plan. .18

Table 3: Comparing Procedures for Addressing Academic and Social Problems.23

Table 4: Comparison Between Correction and Precorrection Procedures.............25

Table 5: Methods Comparisons of Precorrection Training Research ....................34

Table 6: Comparing a Precorrection Plan with Teacher Training Model..............37

Table 7: Behavior Categories and Operational Definitions ................................45

Table 8: Mean use of Precorrection, Praise, Reprimands and Student On-task

(Question 1) ..........................................................................................53

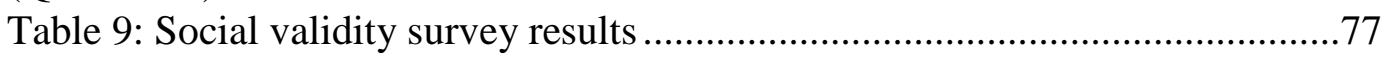

Table 10: Demographic Data of Participating Teachers....................................78

Table 11: Teacher precorrection-to-reprimand and praise-to-reprimand ratios ....79

Table 12: Comparison of FACTS results with changes in student behavior.........81

Table 13: Comparison between correction and precorrection procedures..............88

Table 14: Social validity survey results ........................................................96

Table 15: Precorrection research articles summaries........................................97 


\section{LIST OF FIGURES}

Figure 1: In Reference to research question 1, mean rate of Precorrection, Praise and Reprimands during baseline and intervention

Figure 2: In reference to question 2, mean percentage of observation focus student

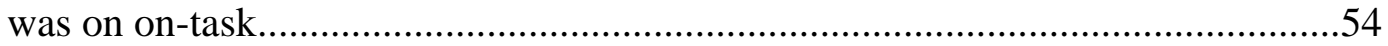

Figure 3: In reference to research question 2, daily percent of observation focus

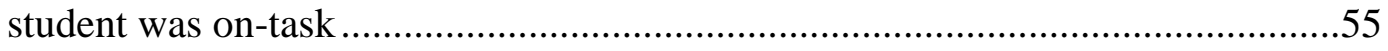

Figure 4: Observation results for teacher and student 1 ..................................57

Figure 5: Mean statements delivered by Mrs. Brown directly to the student of focus

.60

Figure 6: Observation results for teacher and student 2 ...................................63

Figure 7: Mean statements delivered by Mrs. Cook directly to the student of focus

Figure 8: Observation results for teacher and student 3

Figure 9: Mean statements delivered by Mrs. Sims directly to the student of focus

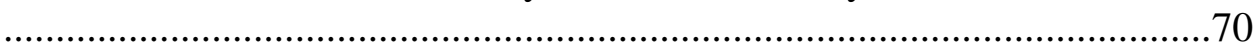

Figure 10: Observation results for teacher and student 4 ..................................73

Figure 11: Mean statements delivered by Mrs. Love directly to the student of focus 74 


\section{Chapter 1: Problem Statement}

\section{Introduction}

The challenge of managing the behavior of twenty to thirty or more students for six hours a day has long been recognized as one of the greatest concerns teachers face (Ayers, 2004; Rose \& Gallup, 1999; Stoughton, 2007; Wald \& Losen, 2003). Moreover, policy revisions have placed greater demand on educators to go beyond the academic needs of students and support their social emotional and behavioral needs as well (Crimmins, 2006; Losen, 2011). In response to these challenges and policy mandates, many schools are turning to the Technical Assistance Center for Positive Behavioral Interventions and Supports for guidance.

The Technical Assistance Center for Positive Behavioral Interventions and Supports was formed to define, develop, implement, and evaluate a multi-tiered approach to student behavior that supports the implementation of tiered systems of behavior support in education (Lewis, Barrett, Sugai \& Horner 2010). Initial implementation focuses on providing universal supports to ensure all students have access to a highquality learning environment (Collins \& Arthur, 2007; Cook, Wright \& Gale, 2007; Sugai et al., 2000). These interventions have been shown to reduce suspensions, improve academic engagement, and school climate (Bradshaw, Mitchell, Leaf, 2010; Horner, Sugai, Smolkowski, Todd, Nakasato, \& Esperanza, 2009). Unfortunately, to this point, research has shown that the ability of school sites to consistently provide support for students with more intensive behavior support needs has yet to be established (Cook et al. 2007; Van Acker, Boreson, Gable, \& Potterton, 2005). The purpose of this research is to 
examine whether a brief, individual training can help struggling teachers increase the ontask behavior of students in need of additional support. This training centered on elements of a precorrection plan; training these teachers to analyze a student's problem behavior, clearly define expected behaviors, to utilize prompts to teach this desired behavior, and finally to provide students with specific praise. As Colvin, Sugai and Patching (1993) explain: "Precorrection procedures are antecedent manipulations designed to prevent the occurrence of predictable inappropriate behavior and facilitate the occurrence of more appropriate replacement behavior" (p. 145). Precorrection has been shown to be an effective, low intensity, prevention-based support that builds on wellestablished instructional practices (Colvin \& Sugai, 1998; De Pry \& Sugai, 2002; Stormont \& Reinke, 2009). Before examining precorrection in detail, it is important to review the School-wide Positive Behavior Interventions and Supports (SW-PBIS) framework and the impact it has had on schools and students.

\section{Background of the Problem}

In the past, schools often took a passive approach to student behavior, expecting students to arrive at school with an acquired set of social competencies already in place (Kerr \& Nelson, 2006; Valenti, 2011). However, the 1997 reauthorization of the Individuals with Disabilities in Education Act (IDEA) required schools to focus on empirically based behavior supports and interventions (Cohen, McCabe, Michelli, \& Pickeral, 2009; Nelson, Mathur, Rutherford, 1999; Turnbull, Wilcox, Swoe, Raper \& Hedges, 2000; Sugai \& Horner, 2009; Yell \& Katsiyannis, 2000). Recognizing the complex interaction between behavior and disability, the federal government required 
educators to pay attention to situations where a child's behavior is impacting his/her learning (Nelson, Mathur \& Rutherford, 1999; Yell \& Katsiyannis, 2000). These revisions, coupled with the subsequent 2004 IDEIA revision and civil rights data reporting, have created an increased focus on behavior in schools.

These policies required schools to conduct a functional behavioral assessment of the problem behavior and develop a behavior intervention plan when (a) suspending or removing a student with a disability from their least restrictive environment for 10 days, (b) prior to changing a student's educational placement, and (c) adding behavior goals and objectives to a student's Individual Education Plan (IEP) (Allday, Nelson, \& Russel, 2011; Armstrong \& Kauffman, 1999; Yell \& Katsiyannis, 2000). Interestingly, as awareness of the utility of function-based behavior supports has expanded, the use of this process has increasingly been adopted for students beyond those defined in the policy. In fact, Solnick and Ardoin (2010) found that more than one-third of function-based behavior plans were for students without disabilities.

In the early 2000's the traditional practice of suspending students for problem behavior had more than doubled since the 1970's (Losen, 2011). As a result, schools experienced increased political, legal, and social pressure to reduce the use of suspensions for problem behavior. However, if these higher expectations are not accompanied with the support and training necessary to understand how to address student behavior, teachers may simply be overwhelmed. Fortunately, policy makers realized that in order for these laws to have the desired impact, educators would need support. One effort to ensure quality implementation following IDEA reauthorization in 
1997 was establishing the National Technical Assistance Center on Positive Behavioral Interventions and Supports (PBIS) (Lewis, Barrett, Sugai, \& Horner, 2010). This center is a collaboration of university and resource partners whose primary purpose is to "gather and disseminate evidence-based behavioral interventions and practices that enhance social behavior development, school climate and safety of all students, especially students who are at risk of or display problem behavior within the school context" (Lewis et al., p 2).

School-wide positive behavior support. The SW-PBIS framework has been implemented in over 24,000 schools and is often having a dramatic impact on school climates (see pbis.org). This framework has been shown to drastically reduce the need for suspensions and improve the school climate (Collins \& Arthur, 2007; Cook et al., 2007; Sugai et al., 2000). The adoption of the PBIS framework begins with the recognition that student behavior is a fundamental area of concern (Collins \& Arthur, 2007; Cook et al., 2007; Sugai et al., 2000). Building on this recognition, the PBIS Technical Assistance Center has developed resources that outline a process to aid schools in the development of an organizational structure which focuses on improving school culture and student conduct (Lewis et al., 2010).

These tiered supports are based on the premise that universal supports will prevent problem behavior for $80 \%$ of students school-wide. The second tier, sometimes referred to as targeted interventions, is designed to reduce the number of students exhibiting problem behavior with efficient and rapid responses. These interventions are meant to support approximately $15 \%$ of students with at-risk behavior. The third tier, or 
intensive intervention group, is aimed at addressing existing cases of problem behavior that are resistant to primary and secondary efforts. The pyramid structure helps schools remain responsive to the varying needs of all students, by supporting students performing well and providing targeted interventions to those that need more support.

The success of the PBIS framework at the universal level increases the capacity of schools to focus on those students with more persistent and pervasive problem behavior, which can be challenging. Changing a child's learned behavior is not a simple task. In many instances a particular problem behavior, such as physical aggression, may have served a useful function for a child for many years. Implementing supports to change this behavior often requires advanced behavior intervention skills and highly controlled environments (Gable, Hendrickson, \& Smith, 1999; Van Acker et al., 2005). This is, typically, different from the natural classroom setting and the skill level of most classroom teachers.

The contrast between a research-controlled setting and a general education classroom has raised concerns about the impact intensive behavior supports can have in classrooms (Allday et al., 2011; Ellis, 2004; Sugai et al., 2000). The complexity of a busy classroom can make it especially demanding for teachers to alter the environment, control antecedent variables, and consistently distribute consequences (Scott, Liauspin, Nelson \& Jolivette, 2003). For example, managing how peers respond to a student's problem behavior can be particularly challenging. Also, there will typically be a dramatic difference in the training and skill level of a classroom teacher, when compared to the skills of an experienced behavior therapist (Benazzi, Horner, \& Good, 2006; Reid 
\& Nelson, 2002). Combined, there is often a difference in environmental variables, instructor skills, and student demographics between the settings where many behavior supports were researched and the classrooms where they are often implemented.

Some of the interconnected concerns surrounding targeted behavior supports frequently discussed in research tend to revolve around three broad questions:

1. Can educators, with existing knowledge, conduct a high-quality, functional behavior analysis (Gresham \& Quinn, 1999; Nelson et al., 1999; O’Neill \& Stephenson, 2009; Reid \& Nelson, 2002; Solnick \& Ardoin, 2010; Van Acker et al., 2005)?

2. Are the resources available to implement research based behavior interventions (Hieneman, Dunlap, \& Kincaid, 2005; Nelson et al., 1999)?

3. Do educators have the skills necessary to implement behavior interventions (Allday et al., 2011; Conroy, Clark, Fox, \& Gable, 2000; Gresham \& Quinn, 1999; Reid \& Nelson, 2002)?

In particular, time is typically one of the most precious resources for teachers. The numerous competing demands on educators limits the time they have available to implement supports (Allday et al., 2011; Hieneman et al., 2005). As Bambara et al. (2009) found, issues related to time were identified as a key concern for $88 \%$ of those surveyed regarding behavior supports. Participants identified three time-related barriers in particular. The lack of available time for team members to meet regularly was the first barrier. The second barrier was the perception that behavior supports created extra burdens for school personnel, especially teachers. The third time-related barrier was that the entire process itself was often viewed as too time-consuming or labor-intensive. These time constraints can create a major deterrent to sustained teacher and administrative involvement. 
In classrooms, the result of these limiting factors can be low-quality supports and inconsistent implementation. Cook et al. (2012) evaluated 320 behavior plans, and concluded that nearly $90 \%$ of the plans developed by school site personnel were inadequate. Even the behavior plans written by the most experienced professionals were found lacking, with 35\% of their plans considered inadequate. A particular concern was that many of the plans were found to lack any proactive environmental manipulations and/or teaching strategies. These are the foundations of behavior change, so the inability of more than one-third of plans to include these fundamental pathways is concerning. This research confirmed the work of Van Acker et al. (2005), who evaluated 71 intervention plans following a statewide training program. The researchers concluded that the adequacy of the submitted plans was disappointing. Approximately half of the plans contained multiple shortcomings that would likely lead to poorly designed and ineffective behavior interventions (Van Acker et al., 2005). Nearly $70 \%$ of plans didn't identify a target behavior and $25 \%$ failed to identify a function of behavior; two fundamental aspects of behavior interventions.

Implementation of behavior supports. Implementation is a necessary precursor to success with any intervention plan. Unfortunately, evidence suggests that high fidelity of implementation of behavior interventions should not be assumed (Albin, Lucyshyn, Horner, \& Flannery, 1996; Benazzi, Horner, \& Good, 2006; O’Neill \& Stephenson, 2009; Reid \& Nelson, 2002). Heckaman, Conroy, Fox and Chait (2000) warned that in many instances, plans are not implemented or are done so in a haphazard manner. Implementation of behavior plans is a particularly important issue for educators to keep 
in mind when litigation is a risk. In these cases, one of the first questions mediators will ask is whether the interventions were implemented (Etscheidt, 2006). Additionally, if the plan is not implemented with a high degree of fidelity, the effectiveness of the plan can't be measured (Gresham \& Quinn, 1999). When this happens, critical placement and intervention decisions may be made based on inaccurate data. Addressing the implementation issue in behavior interventions is an important next step if schools are to make informed placement and service decisions, as well as to minimize legal risk.

While the failure to properly implement a behavior plan can put educators at legal risk, if they are able to implement behavior interventions the process can have exciting results. Cook et al. (2012) found that when quality plans were implemented with a high degree of fidelity, (a) identified problem behaviors are reduced, (b) general positive behaviors are increased, (c) appropriate replacement behaviors are increased, and (d) academic performance is improved. However, these researchers recognize that implementation is a major hurdle to behavior change. For this reason, they stress the importance of diligently monitoring and ensuring the fidelity of implementation.

In order for teachers to implement an intervention with fidelity, it will need to contain a strong fit with their classroom, as well as their skills and values (Crone \& Horner, 2003; Elliott, Witt, Kratochwill, \& Stoiber, 2002; O’Neill \& Stephenson, 2009). This is often referred to as the contextual fit between a support and the setting where it will be used (Albin et al., 1996). In Van Acker et al.'s (2005) review of behavior intervention plans throughout Wisconsin, the most popular interventions were changes to the physical setting (37\%), changes in teacher behavior (34\%) or curriculum changes 
(25\%). Each of these depends largely on the classroom teacher to manage. Additionally, changing a child's learned behavior in a busy classroom is a challenge that is impacted by factors such as the teacher's self-efficacy, their belief that the child's behavior can be altered, and their belief that the selected supports will result in change (Albin et al., 1996; Elliott et al., 2002).

Implementation barriers. Unfortunately, when responding to problem behavior, many teachers rely on ineffective procedures such as detention, suspension, or other consequence-based measures (Maag, 2001; Smart \& Igo, 2010; Valenti, 2011). Student problem behavior is a fundamental concern for teachers, yet many do not feel equipped to prevent or address the behavior (Allday et al., 2011). Teachers have consistently reported feeling under-educated and unprepared to manage challenging behaviors (Clunies-Ross, 2008; Martin, Linfoot, \& Stephenson, 1999). For example, when Baker (2005) surveyed teachers, nearly half of their sample felt ill-equipped to manage student behavior. Teacher frustration around student behavior is compounded by Baker's (2005) finding that more than one in five teachers were described as not willing to make managing student behavior an active part of their daily planning. This resistance and lack of confidence can create resentment toward students with challenging behavior and undermines the potential of any support efforts. In order to begin moving past this resistance and sense of helplessness, it is important that educators are exposed to training on behavior supports that have a strong contextual fit with their classroom, skills and values. 
Teacher confidence drops even further when facing more severe problem behavior. Under these circumstances, teachers perceived their management strategies to be largely ineffective and reported implementing them inconsistently (Baker, 2005; Main \& Hammond, 2008). Additionally, there is often a sharp drop in use, efficacy, and teacher confidence as they move from universal behavior intervention practices to individualized behavior support (Crimmins, 2006; Main \& Hammond, 2008; Smart \& Igo, 2010). This may explain why teachers are more likely to avoid or retreat from students with problematic behavior profiles than intervene (Abidin \& Kmetz, 1997; Abidin \& Robinson, 2002; Ratcliff, Jones, Costner, \& Savage-Davis, 2011).

Another factor that limits the efficacy of behavior supports is the numerous competing demands on educators. These competing demands can limit the ability of teachers to modify the classroom environment or control the other variables needed for behavior supports. In order to improve the implementation of behavior supports, it is important to understand the limitations and values of educators. As Kaff, Zabel and Milham (2007) concluded from their research into teacher perceptions of behavior supports, many of the supports commonly taught in teacher preparation programs are perceived by teachers to be too complex to implement, in some instances, ineffective. Kaff et al. (2007) explored the labor intensity, frequency of use, and perceived effectiveness of behavior interventions by special educators. They found, as the perceived labor intensity increased, the use of that intervention decreased. Similarly, as labor intensity increased, the perceived effectiveness of that intervention decreased. 
From an instructional perspective, the modern classroom can be a daunting place. According to Baker's (2006) description of an urban, high-poverty classroom, as many as 17 out of every 30 students need varying degrees of academic and/or behavior accommodations. The range of academic and behavioral accommodations needed in today's classrooms requires a great deal of time, confidence and a wider skill set than in the past. Unfortunately, in spite of the frequent support of differentiation, research suggests it is not a common instructional practice (Fuchs, Fuchs, \& Stecker, 2010; Gersten, 2009; Kapusnick \& Hauslein, 2001; Tomlinson, 1999).

As the field of PBIS continues to grow, it is important to remain focused on the implementation of supports by teachers with limited skills, confidence, and available time. Table 1 summarizes the research discussed earlier regarding the skills and attitudes of classroom teachers around behavior supports. The pattern emerging from this examination of the behavior support practices of teachers shows that many teachers initially rely on consequences and universal practices to address problem behavior (Couvillon, 2006; Smart \& Igo, 2010; Valenti, 2011). If problem behavior persists, teachers quickly lose confidence and resort to retreatism or discipline measures (Baker, 2005; Clunies-Ross, 2008; Ratcliff et al., 2011). Finally, there appears to be an inverse relationship between how effective teachers perceive a behavior intervention to be and the use of a particular intervention with the labor intensity of the intervention (Kaff et al., 2007). 
Table 1

Research Findings on Teacher Skills and Values Surrounding Behavior Interventions

- Reactive strategies tend to disrupt instructional time,

- Many teachers lack confidence regarding individualized interventions,

- High intensity interventions are rarely used and lack perceived effectiveness,

- Strategies aimed at teaching expectations seem to be the most popular and effective,

- Limited differentiation of academic or behavior instruction,

- Many teachers lack individual intervention skills, causing them to resort to punitive measures,

- Punitive measures are not seen as effective.

So, the more demanding an intervention is of teacher's time the more likely a teacher is to see the intervention as ineffective and not use it. The result is that many commonly recommended supports aren't used or trusted by educators due to their labor intensity. When these challenges to implementation are coupled with the difficulty of changing a child's learned behavior, the list of behavior supports available narrows. This challenge makes exploring low-intensity and research-based supports that can improve behavior and academic achievement especially valuable.

\section{Statement of the Research Problem}

As students continue to arrive at school grappling with pervasive and complex social issues, the need for strategies to prevent and address the academic and behavior problems that will often ensue grows (Collins \& Arthur, 2007; Nolle, Guerino, Dinkes, \& Chandler, 2007; Skiba \& Peterson, 2000). In response to these needs, federal policy has required educators to implement positive behavior support, when the behavior of a student with an IEP is interfering with learning. This policy has placed significant demands on educators, requiring behavior support skills and time beyond that which many instructors feel comfortable. In order to meet these legal and ethical demands, there is a need to develop interventions that address the complex needs of students, the 
significant legal requirements, and the implementation constraints of educators around behavior support in a general education classroom setting.

The efficacy of positive behavior support is well established (Carr et al., 2002, Sugai et al., 2000). The question now is not "if" behavior interventions can change student behavior, but "how" to implement behavior interventions in a general education classroom setting. Increasing the capacity of teachers to use research-based practices is a critical component of implementing behavior supports in classrooms. Precorrection, the focus of this dissertation, is a highly-regarded behavior support strategy based on instructional principles of re-teaching and antecedent prompting (Colvin, Sugai, \& Patching, 1993). This makes examining how to increase the use of the strategy an valuable piece of research.

\section{Significance of the Research Problem}

Teachers today face growing demands, including a legal and ethical requirement to meet the behavioral needs of students. Not only are teachers expected to individualize instruction for a growing range of students, they are also expected to provide supports for the growing range of behavioral, emotional, and physical needs of students. In many instances these needs will exceed the ability of educators. When teachers are unable to prevent problem behavior they may be more likely resort to punitive discipline practices, such as verbal reprimands, time-outs, office discipline referrals, and suspension. Unfortunately, there is little evidence that this practice improves student behavior and often places students at greater risk (Couvillon, 2006; Skiba, 2002). Research has shown that teachers prefer prevention-based supports, and generally view supports based on 
positive reinforcement as more acceptable than punishment-based interventions (Iwata, Rolider, \& Dozier, 2009; Jones \& Lungaro, 2000). Yet, often, there remains a gap between what teachers would prefer to do and what happens in a busy classroom when students engage in problem behavior.

The correlation between problem behavior and this gap in instructional capacity may help explain why teachers report that "uncivil" behavior is increasing to the point that it is a threat to effective learning (Skiba \& Peterson, 2000). Teachers report instances of simple disrespect, noncompliance, poor peer interactions, cursing, making fun of one another, grabbing, pushing and being off-task as common occurrences in their classrooms (Collins \& Arthur, 2007; Nolle et al., 2007). Unfortunately, many teachers feel that they are unable to prevent these behaviors from disrupting their classroom routines (Baker, 2005). California administrators confirm the reports of teachers: four out of five school administrators in California ranked student discipline and behavior management as a concern (EdSource, 2012).

According to Harrison and Vannest (2012) "externalizing behaviors are the greatest behavioral concern of teachers and the most frequent reason for ODR (office discipline referrals" (p. 61). Routine minor behaviors related to self-control seem to be particularly pervasive. Their effort to identify the most common behavior problems according to teachers found that just under $30 \%$ of children were almost always or often generally distracted, $15 \%$ of children often exhibited excessive motion, and $12 \%$ were almost always distracted during lectures and lacked concentration. Confirming this prevalence of externalizing behavior at the classroom level, Snider (2002) identified 
distractibility in $73 \%$ of children observed. In Harrison and Vannest's research teachers also reported high rates of problem behavior associated with compliance. This research confirms the ability of educators to work with students that lack self-control and struggle to follow directions is becoming an important skill for educators.

Even, early childhood teachers are reaching out for more training on behavior management (Kupersmidt, Bryant, \& Willoughby, 2000; Rimm-Kaufman, Pianta, \& Cox, 2000). Early child care providers continue to list coping with challenging behaviors as their number one need for additional training, technical assistance, and support (Dunlap et al., 2006). According to Hauqing and Kaiser (2003) $12 \%$ of preschoolers have behavior that is impairing their learning; and in low-income preschools, estimates may be as high as $31 \%$ of preschoolers struggling with internalizing disorders and $57 \%$ exhibiting externalizing problems. The high rates of problem behavior of these young students certainly challenges the notion that students are coming to school ready to learn.

In order to comply with legal mandates to provide students with disabilities a free and appropriate public education in the least restrictive environment, schools are required to include students with Emotional Disturbance (ED) and other challenging behaviors in general education settings (Cheney \& Barringer, 1995; Collins \& Arthur, 2007; Main \& Hammond, 2008; McCurdy, Mannella, \& Eldridge, 2003; McLeskey, Henry \& Hodges, 1999). Students with Emotional Disturbance typically require more attention, individualized strategies, and often do not respond to typical classroom management practices. Although students with ED make up one to five percent of the student population, they often make up more than half of the school's discipline referrals (Sugai, 
Sprague, Horner, \& Walker, 2000; Taylor-Greene \& Kartub, 2000). This helps explain why children with behavioral difficulties are often considered to be among the most difficult students to include in regular classrooms (Avramidis \& Norwich, 2002; Croll \& Moses, 2000; Hodkinson, 2006).

Impact of problem behavior. Problem behaviors contribute to disruptive school environments that can lead to an increase in emotional stress for students, and ultimately impacting achievement (Payne, Gottfredson, \& Gottfredson, 2003; Wehby, Lane \& Falk; 2003). Persistent minor problem behaviors will often interfere with a teacher's ability to teach class effectively, which will impede learning (DeVoe et al., 2003; Gottfredson \& Gottfredson, 2001; Valenti, 2011). As The National School Climate Council has pointed out, student achievement is impacted when the learning environment does not allow students to feel safe, cared for, supported, and gently encouraged to learn (Cohen et al., Pickeral, 2009).

Teachers often cite behavior management issues as one of the most daunting aspects of their jobs, resulting in emotional and physical stress (Liu, 2005). Behavior management challenges have repeatedly been shown to be a significant factor in the stress and burnout of both novice and experienced teachers (Martin et al., 1999). Teachers are also three times more likely than students to be victims of violence resulting from extreme challenging behaviors (Kondrasuk, Greene, Waggoner, Edwards, \& Nayak-Rhodes, 2005). The combination of stress, frustration, and risk of injury explains why Ingersoll (2001) found that nearly one-third of teachers leaving the profession cited behavior management issues as their primary reason for leaving the classroom. 
Student misbehavior appears to be especially stressful for new educators (Markow, Kim, Liebman, 2007). Novice teachers report low confidence in their abilities to effectively manage student behavior (Hertzog, 2002; Meister \& Melnick, 2003; Smart \& Igo, 2010). This is not an issue unique to the United States of America: The Australian Education Union (n.d.) national survey of 1,200 beginning teachers identified behavior management as the second most significant concern for new teachers. The emotional toll student problem behavior can have on new teachers may be one reason nearly one quarter of teachers leave the profession within five years (Hertzog, 2002; Ingersoll, 2001).

\section{Methods and Research Questions}

The independent variable in this project was a brief, individualized training with elementary teachers struggling to prevent student problem behavior. This training helped each teacher analyze the problem behavior of a child on whom they wish to focus. Having analyzed this behavior, the training then helped them define a desired behavior. Next, the teacher created and practiced a precorrective prompt, to remind the student of the desired behavior. Finally, the teacher practiced delivering specific praise--typically a valuable reinforcement with elementary students. Utilizing a multiple baseline across teachers research method, this research project aimed to answer two questions:

1. How does a brief teacher training on precorrection and praise paired with regular feedback impact teacher behavior, as measured by use of precorrection, praise and reprimands?

2. How do changes in the teacher's use of precorrection and praise impact student on-task behavior? 


\section{Definitions of Key Concepts}

A precorrection plan, as explained by Colvin, Sugai and Patching (1993), is a seven-step intervention plan. The seven steps are (a) Identify the context and problem behavior, (b) Define the expected behavior, (c) Systematically modify the context, (d) Rehearse the desired behavior, (e) Prompt the expected behavior, (f) Provide strong reinforcements for the desired behavior, and (g) Monitor student progress. Table 2 is a sample precorrection plan adapted from Colvin, Sugai and Patching (1993).

Table 2

Sample Precorrection Plan Steps in a Precorrection Plan

1. Identify the context and the predictable behavior Intervention

Teacher and researcher identify the context (instructional period) linked to low academic engagement and increased problem behavior.

2. Specify expected Academic engagement is operationally defined behaviors

3. Systematically modify the context

Teacher and researcher identify the optimal environmental modifications that will elicit the expected behaviors

4. Conduct behavior Teacher and researcher agree on the best time and method to have the rehearsals student rehearse the behavior

5. Provide strong reinforcement for Teacher will verbally praise and/or deliver an acknowledgement (PBS expected behaviors

6. Prompt expected ticket) contingent upon a demonstration of academic engagement. behaviors Teacher and researcher agree on a prompting plan daily use during instruction

7. Monitor the plan Researcher and teacher will meet weekly to review outcome data Adapted from: Precorrection: An instructional approach for managing predictable problem behaviors. Colvin, G., Sugai, G., \& Patching, B. (1993). 


\section{Chapter 2: Literature Review}

The PBIS framework helps schools implement an instructional approach to behavior supports by focusing on designing effective environments and providing direct instruction of desired behaviors. Similarly, a precorrection plan is a targeted support that aligns with the universal practices of the PBIS framework. A variety of researchers have demonstrated the effectiveness of precorrection across a range of settings, group sizes, and student demographics. This makes closely examining the research methods used in this and the prior precorrection research worthwhile.

\section{Theoretical Framework}

Behavior supports typically rely on two interconnected paths to behavior change: environmental modifications and teaching new behaviors (Horner, Sugai, Todd \& LewisPalmer, 2000; Sugai et al., 2000). As Crone and Horner (2003) explain, behavior plans should detail strategies for (a) modifying the predictors that set off the problem behavior, (b) teaching an appropriate or alternate behavior and (c) modifying ineffective consequences that have maintained the problem behavior. Supports that modify the predictors and consequences of behavior rely on altering environmental factors, or what is happening around the child. These supports aim to reduce the child's need to use the problem behavior and/or change the value of the problem behavior (Horner et al., 2000). However, even if a plan is able to eliminate the need and value of a problem behavior, replacing a learned behavior with a socially appropriate alternative will require instruction and practice. If this is not done a child may simply replace one problem behavior with another. 
Environmental modification. A learned behavior is a behavior that a person engages in expecting a certain result (Cooper, Heron \& Heward, 2007; Kazdin, 1989; Skinner, 1953). Many behavior supports are designed to alter the connection between a problem behavior and the expected results (Crone \& Horner, 2003). Increasing the value of the desired behavior and decreasing the efficacy of the problem behavior is done by altering the environment around the child (Carr et al., 2002). Environmental alterations focus not only on changing the physical environment, but also on changing how adults and peers around the child behave (Drasgow, 2002; Horner et al., 2000; Sugai et al., 2000). The PBIS framework is designed to create effective school climates by encouraging schools to create consistent discipline practices, a high quality positive acknowledgement system, and consistent, school-wide expectations that are directly taught to students. By designing more effective environments, supports can reduce the need for and value of problem behavior (Sugai et al., 2000).

By altering the learned relationship between an antecedent, a behavior, and a consequence, environmental modifications can change how a student gets what s/he needs (Horner et al., 2000; Wolery, Bailey, \& Sugai, 1988). Additionally, many behavior supports change the consequence a child derives from particular behaviors (Kazdin, 1989; Sugai et al., 2000). Altering the consequences of both desired and problem behavior is an important feature of behavior support planning, that requires careful and disciplined control of the environment around the child. However, without sufficient training, opportunities for practice and feedback, teachers will struggle to control the 
many environmental variables that may be triggering or rewarding a child's problem behavior.

Instruction. Behavior supports are not designed to control a child or to repress the child's needs. Rather, the focus is on teaching prosocial skills that will improve the quality of the child's life (Carr et al., 2002; Sugai et al., 2000; Sugai \& Horner, 2009). Behavior supports are based on the belief that if a child is taught a better and more socially acceptable way to get a need met, the child will be inclined to replace the problem behavior with the preferred behavior. Horner et al. (2000) explain that “...effective behavior support is not just about defining the consequences that will punish or control problem behaviors, but about teaching the student the skills that will make problem behaviors irrelevant and comparatively inefficient" (p. 210). Then the authors concluded:

Teaching is the most powerful behavior support strategy available in schools. Most BSPs should include an instructional objective. We seldom think of teaching new skills as part of behavior support, but recent research suggests that teaching new, adaptive skills is perhaps the single most powerful strategy for producing durable behavior change. (Horner et al., 2010, p. 210) (emphasis added)

As the authors point out, many educators overlook the critical role of teaching news skills in behavior support planning. If educators do not make time to teach a socially appropriate way for children to get their needs met, the child may simply substitute one problem behavior for another. This emphasis on the direct instruction of behavior is consistent with the school-wide PBIS implementation process; a fundamental expectation of this process is that schools make time to directly teach students their expectations across settings (Lewis et al., 2010; Sugai, et al., 2000). 
Learning a new behavior requires instruction and practice. Often, a child's problem behavior has been functioning to effectively get the child's needs met for some time. Changing this pattern of behavior will require direct instruction and rehearsal for the child to learn a more socially appropriate way to get his or her needs met (Crone \& Horner, 2003). In order for the child to learn the connection between a new behavior and its' applications and non-application, the child will require consistent practice under a variety of settings (Cooper et al., 2007).

Educators do not teach comma placement solely by telling students where not to place commas. Similarly, spelling is not taught by telling students all the ways not to spell a word. Unfortunately, this is often how educators respond to problem behavior. Problem behaviors are often seen as deliberate acts by the student, as opposed to academic errors, where good intent by the student is assumed (Colvin \& Sugai, 1988). As a result, social supports have often been addressed through punishments and consequences, rather than teaching prosocial behaviors. Table 3 summarizes Colvin and Sugai’s (1988) work explaining how social behavior problems can be viewed from an instructional perspective, comparable to academic skills. As this table shows, the different assumptions regarding academic and social errors lead to radically different pathways to correcting the errors. Academic error correction tends to focus on reteaching and other antecedent changes, whereas traditional behavior error correction tends to focus on consequences and punishment. However, if educators are able to maintain an instructional view of problem behavior, they can help students change their behavior in much the same way as they help correct academic errors. 
Table 3:

Comparing Procedures for Addressing Academic and Social Problems

\begin{tabular}{|c|c|c|}
\hline $\begin{array}{l}\text { Common procedures for } \\
\text { academic problems }\end{array}$ & $\begin{array}{l}\text { Common procedures for } \\
\text { social problems }\end{array}$ & $\begin{array}{c}\text { An instructional approach to } \\
\text { social problems }\end{array}$ \\
\hline $\begin{array}{l}\text { Assume student has learned } \\
\text { incorrectly. }\end{array}$ & $\begin{array}{l}\text { Assume student refuses to } \\
\text { cooperate }\end{array}$ & $\begin{array}{l}\text { Assume student has incorrectly } \\
\text { learned how to get a need met. }\end{array}$ \\
\hline $\begin{array}{l}\text { Assume student has been taught } \\
\text { incorrectly. }\end{array}$ & $\begin{array}{l}\text { Assume student knows what } \\
\text { is right and has been told } \\
\text { often. }\end{array}$ & $\begin{array}{l}\text { Assume student has been taught } \\
\text { incorrectly. }\end{array}$ \\
\hline $\begin{array}{l}\text { Identify the error pattern or } \\
\text { misrule. }\end{array}$ & $\begin{array}{l}\text { Provide negative } \\
\text { consequences. }\end{array}$ & $\begin{array}{l}\text { Identify functional relationship } \\
\text { between behavior and environment. }\end{array}$ \\
\hline Identify the desired skill. & $\begin{array}{l}\text { Provide more negative } \\
\text { consequences. }\end{array}$ & $\begin{array}{l}\text { Identify expected or acceptable } \\
\text { behaviors. }\end{array}$ \\
\hline $\begin{array}{l}\text { Modify examples and lessons to } \\
\text { focus on skill and reduce } \\
\text { opportunity for practice of error. }\end{array}$ & Refer for outside support & $\begin{array}{l}\text { Modify environment to increase } \\
\text { expected behaviors and reduce } \\
\text { inappropriate behaviors. }\end{array}$ \\
\hline $\begin{array}{l}\text { Teach and provide increased } \\
\text { practice of rule }\end{array}$ & & $\begin{array}{l}\text { Teach and provide opportunities to } \\
\text { practice expected behaviors. }\end{array}$ \\
\hline $\begin{array}{l}\text { Provide feedback so correct } \\
\text { responses are strongly reinforced. }\end{array}$ & $\begin{array}{l}\text { Provide more negative } \\
\text { consequences. }\end{array}$ & $\begin{array}{l}\text { Provide feedback so correct } \\
\text { responses are strongly reinforced. }\end{array}$ \\
\hline Assess and monitor progress & $\begin{array}{l}\text { Assume student has } \\
\text { "learned" lesson and will } \\
\text { behave in future. }\end{array}$ & Assess and monitor progress \\
\hline $\begin{array}{l}\text { Integrate skill with academic goals } \\
\text { and curriculum }\end{array}$ & $\begin{array}{l}\text { Withdraw student from } \\
\text { normal context }\end{array}$ & $\begin{array}{l}\text { Generalize the desired behaviors } \\
\text { into the school day. }\end{array}$ \\
\hline
\end{tabular}

\section{Review of the Research Literature}

Much like the process educators use to prevent predictable academic errors, precorrection is a systematic way of anticipating and preventing predictable problem behavior (Colvin et al., 1993; Crosby, Jolivette \& Patterson, 2006). To review, there are seven steps to a precorrection plan (see Table 2). First, the intervention team identifies the context and problem behavior. Then, the team defines the expected behavior. Having 
defined the behavior, the team systematically modified the environment. Precorrection plans stress the need for student to have the opportunity to rehearse the desired behavior. Upon implementation, the teacher prompts the expected behavior and provides strong reinforcements for the desired behavior. Finally, the support team monitors student progress.

Beyond maintaining an instructional approach to behavior interventions, the second critical element of a precorrection plan is a shift from consequence-based correction to antecedent prompting (Colvin et al., 1993). Precorrection shifts the teacher's focus from office discipline referrals, suspensions, or other negative consequences, to instruction and prompting (Crosby, Jolivette \& Patterson, 2006). This shift from more common behavior management practices of reacting to a problem behavior with sanctions or negative consequences, and instead focuses on identifying, teaching, prompting, and reinforcing a more socially acceptable behavior.

Colvin et al. (1993) provides a comparison of the traditional practice of correcting problem behavior after it has occurred, to precorrection, or reminding the student of the expectations before the problem behavior occurs (see Table 4). The authors explain that this approach has the potential to deliver a number of desirable outcomes. (a) serious problem behavior may be prevented, (b) students who have been labeled as at-risk may be directed toward more appropriate and normal levels of functioning, (c) the behavior of students may be strengthened and occasions for appropriate modeling may be increased, and (d) improvement in student behavior may be maintained. Precorrection focuses on the use of teacher input and on empowering 
children by teaching them how to get their needs met in more socially appropriate ways (Colvin et al., 1993). The use of precorrection addresses one of the most common criticisms of traditional punishment-driven responses to problem behavior: that at best, punishment teaches a child what not to do, but fails to teach them how to get their needs met (Maag, 2001).

Table 4:

Comparison Between Correction and Precorrection Procedures

\begin{tabular}{ll}
\hline \multicolumn{1}{c}{ Correction } & \multicolumn{1}{c}{ Precorrection } \\
\hline Reactive & Proactive \\
Maysequences are Manipulated & Antecedents are manipulated \\
& $\begin{array}{l}\text { May lead to positive teacher student } \\
\text { Interactions }\end{array}$ \\
Focuses on inappropriate behavior & $\begin{array}{l}\text { Focuses on appropriate behavior } \\
\text { May lead to escalating behavior }\end{array}$ \\
$\begin{array}{l}\text { Focuses on immediate events } \\
\text { Note. Taken from: Colvin, G., Sugai, G., \& Patching, B. (1993). Precorrection: An instructional } \\
\text { approach for managing predictable problem behaviors. Intervention in School and Clinic, 28, 143-150. }\end{array}$
\end{tabular}

Precorrection has been used to effectively improve the behavior of students across a variety of ages, sample sizes, behavior intensities, skills, and settings. In Stormont and Reinke's (2009) discussion of research-based practices that teachers can effectively implement, the authors explain that:

Precorrective statements can be used across any setting and are very helpful for all children. These instructional and proactive statements are especially important for young children who have not learned these types of behavioral routines and for children who struggle with behavioral expectations due to inconsistent environmental expectations and/or within-child characteristics that make it challenging for them to be successful when transitioning from one setting to another. (p. 27) 
The effectiveness of precorrection across subjects and settings led the authors to conclude that precorrection should be seen as a universal support that can improve the behavior of all students (Stormont \& Reinke 2009).

Initial research demonstrating the effectiveness of precorrection began with a focus on large group and non-classroom settings. Colvin, Sugai, Good and Lee (1997) first used precorrection to improve school-wide transitions. A brief, fifteen-minute staff training, with minimal follow up, was effective in reducing problem behavior at transitions throughout the school, traditionally one of the most problematic times of the day. Lewis, Colvin and Sugai (2000) then found that precorrection reduced the problem behavior of elementary students at recess. The authors were encouraged "that a relatively simple intervention was effective in promoting generalized social responding beyond the training setting, the classroom, to a setting that is typically replete with challenging behavior" (p. 118). This research shows that precorrection can be used to address group, or even school-wide, behavior problems.

De Pry and Sugai (2002) targeted a group of sixth graders exhibiting problem behavior. Applying all seven steps of a precorrection plan resulted in a significant improvement in behavior. In addition to reducing problem behavior, the teacher described the intervention as both valid and effective, and recommended it to others. Demonstrating precorrection as an instructional strategy, Miao, Darch, and Rabren (2002) used precorrection to improve reading performance for students with mild learning disabilities. By using precorrection to improve reading performance, the 
researchers demonstrated that this support can be used for behavior supports, and is also a strategy for academic support.

Faul, Stepensky, and Simonsen (2011) explored the relationship between teacher prompting and off-task behavior for two middle school students. The authors concluded: "To be clear, these results suggest that providing one prompt at the beginning of class may result in a decrease in off-task behavior immediately following the prompt" (p. 52). The researchers also noted comments by teachers that academic performance improved when the student was prompted, and they were eager for the study to end so they could consistently use prompting with their students.

Stormont, Smith, and Lewis (2007) began using precorrection strategies to improve the interactions of three Head Start teachers who were struggling with student behavior. According to the authors, when the teacher delivered a precorrection at the beginning of a lesson both the student and teacher seemed to engage in more appropriate behavior. The authors concluded: "Overall, through the use of a relatively simple intervention each of the three teachers was able to reduce overall rates of student problem behavior during a small group setting” (p. 287). Covington-Smith, Lewis, and Stormont (2011) continued to focus on students in Head Start classes in their follow-up study. For this study, they trained teachers in the use of precorrection and praise to improve the engagement of a focus student with low rates of on-task behavior. The authors explained that "after teachers began to use these strategies all three children who demonstrated problem behavior improved in their overall behavior; children's on-task behavior improved and their aggression decreased"(p.12). The authors also noted a marked 
decrease in the use of reprimands across all three teachers, and found encouraging maintenance findings.

Other researchers coupled prompting and strong reinforcement to teach desired behavior to students engaging in frequent problem behavior. For example, Gena (2006) researched the impact of prompting as a correction procedure for four students with Autism. She was able to conclude it may be effective in increasing the social initiations toward classmates, as well as increasing responses to peer initiations. Flood et al. (2002) also used prompting practices to reduce the off-task behavior of students with ADHD. Crockett and Hagopian (2006) even modified the prompting procedure to support a student with intellectual disabilities, deafness, and severe problem behavior during demand situations. The strategy reduced the problem behavior that was allowing the student to avoid assigned tasks, to the point that the student's task completion went from an average of 1.5 highly difficult tasks per observation to an average of 6.2 tasks per observation. Combined, the authors cited in this paragraph, used precorrection steps to improve the behavior of students with Autism, ADHD, Emotional Disturbance, and intellectual disabilities.

In sum, precorrection has been effectively used to impact behavior across a range of settings, group sizes, and student demographics. It was used to support school-wide behaviors, small groups of students, targeted students within a class, and individuals. It has also been used to impact Head Start students, middle school students, students with moderate disabilities, students with severe disabilities, and general education students. The effectiveness of precorrection with such a diverse range of students and settings 
suggests that precorrection may be a highly durable and transferable behavior support strategy.

\section{Critique of Research}

Precorrection has often been described as a form of behavioral prompting (Colvin et al., 1997; Lewis, Colvin, \& Sugai, 2000). Recent researchers have come to use the terms precorrection and prompting as largely interchangeable terms (Faul et al., 2012; Simonsen, Myers \& DeLuca 2010; Stormont et al., 2007). This may help explain why researchers have described precorrection as a universal support (Stormont \& Reinke, 2009; Stormont et al., 2007). Yet, the precorrection research is largely based on students in need of additional support (Covington-Smith et al., 2011; Miao et al., 2002; Stormont et al., 2007). Precorrection, in its various forms, has been shown to be a valuable behavior support for students engaging in high rates of problem behavior. As discussed in the previous chapter, implementing behavior supports in a general education classroom often poses a number of challenges. Fortunately, a precorrection plan may address many of these hurdles.

As Ratcliff, et al. (2011) found reactive strategies tend to disrupt instruction. However, a precorrection plan is prevention-based, so it is likely less disruptive to instruction. Many teachers view behavior supports that are labor-intensive as ineffective, and so they are rarely used (Kaff et al., 2007). Fortunately, a precorrection plan is a minimally labor-intensive support. Also, precorrection builds on common instructional practices, so it has the potential to increase teacher confidence in their ability to utilize behavior supports by building on existing instructional skills. 
Rather than engaging in supports that remove the child from the learning context, a precorrection plan maintains an instructional focus and re-teaches students that did not respond to universal instruction. Because precorrection is a low-labor-intensity, antecedent- and instruction-driven support, it shows greater promise for implementation then more labor-intensive supports. This may explain why, when Covington-Smith et al. (2011) surveyed the three teachers in their research implementing precorrection practices, overall the teachers "strongly agreed" (the highest possible rating) that precorrection was (a) teacher-friendly and simple to implement, (b) effective and efficient for reducing minor problem behavior, (c) useful and would therefore continue its use, (d) worth recommending and sharing with others, (e) worth using in additional setting (one teacher rated this response four out of five possible), (f) beneficial for students with challenging behavior, and (g) successful overall. Similarly, when De Pry and Sugai (2002) surveyed the teacher in their study, the teacher felt the precorrection plan was an effective and efficient way to reduce minor problem behavior, recommended these strategies for others, and planned to use the support again. Finally, the three teachers surveyed in Stormont et al.'s research (2007) also rated the practice positively.

Precorrection has been demonstrated to be an effective behavioral support across a range of settings in the school day. The precorrection process aligns with traditional instructional practices focusing on teaching desired behaviors rather than stopping problem behaviors. This alignment with instructional practices, social validity, and effectiveness points to a need to explore how the use of precorrection by teachers can be increased. 


\section{Review of the Methodological Literature}

The research documenting the potential efficacy of precorrection made exploring interventions that can increase teacher use of precorrection a valuable avenue of research. This section reviews the research methods used in the prior precorrection literature and their application this to project. The precorrection research discussed earlier in this chapter utilized multiple baseline design. Consistent with this, the current research utilized a multiple baseline across teachers research design. The purpose of multiple baseline research is to verify a functional relationship between a behavior and an intervention (O’Neill, McDonnell, Billingsley, \& Jenson, 2011). By collecting data frequently, over an extended period of time, researchers are able to make better conclusions about the immediacy, consistency, and degree of effect the independent variable has on the dependent variables (O'Neill et al., 2011). In this research, the independent variable was a brief training that utilized five of the steps in a precorrection plan: analyzing a child's problem behavior, identifying desired behaviors, prompting students, delivering a meaningful reinforcement, and regular feedback to monitor progress. The dependent variables were teacher use of precorrection, reprimands, and praise, and then how any changes subsequently impact rates of on-task behavior by students of focus.

The strength of multiple baseline research is the quality and quantity of data documenting the impact of the intervention on a particular subject. However, because this form of research relies so heavily on a case-study approach, it can be difficult to make conclusions regarding how the support may transfer to other students or settings 
(Cooper et al., 2007). For this reason, multiple baseline research relies on replication (Horner et al., 2005). To demonstrate the experimental control necessary to establish a functional relationship, the intervention was replicated across four teachers which increased the reliability of the impact of the independent variable and so alternative explanations for any changes in behavior can best be eliminated.

Initially Colvin et al. (1997) and then Lewis et al. (2000) used multiple baseline research to measure the behavior of students in common areas. Later, De Pry and Sugai (2002) and then Miao et al (2002) used a multiple baseline research design to measure the impact of precorrection on students in classroom and small group settings. Subsequent research has remained focused on using multiple baseline research to measure changes in student behavior in classrooms (Covington-Smith et al., 2011; Stormont et al., 2007).

Much of the previously cited precorrection research gathered data across a single baseline and a single intervention phase. Others also incorporated a mixed method approach incorporating teacher behavior ratings or staff surveys with single case methods (see Covington-Smith et al., 2011). Next, the researchers replicated the intervention across three or more settings, students or times. For example, Lewis et al. (2000) replicated the precorrection intervention prior to three different recess periods. Like prior researchers, the current research utilized sequential baseline phases, staggering the length of time each teacher-student dyad spent in the baseline stage.

In prior precorrection research, the number of sessions ranged from thirteen sessions (Faul et al. 2011) to fifty-three sessions (Simonsen et al., 2010). However, most of the researchers used sessions at or below twenty. Similarly, the length of each session 
varied from thirteen minutes (Simonsen et al., 2010) to forty-five minutes (DePry \& Sugai, 2002). With most the researchers using sessions at twenty minutes or below. Consistent with this prior research, direct observation was used for 26 sessions. Each session will be twenty minutes.

This research replicated the critical elements of research done by CovingtonSmith et al. (2011), examining the impact of a one-on-one teacher training on the use of precorrection on teacher and student behavior. In 2011, these researchers used a teacher training lasting up to ninety minutes to increase the use of precorrection and praise by Head Start teachers and the on-task behavior of individual students identified as having low levels of appropriate behavior. Their research suggests teachers can quickly be trained in the use of precorrection and praise. This project extended this line of research beyond Head Start classrooms into traditional general education elementary classrooms.

Table 5, below, compares the research methods used by Covington-Smith et al. (2011) with the methods used here. As this table shows, Stormont et al., (2007) first trained Head Start teachers to use precorrection as a classroom management tool, which reduced problem behavior for students in small group circle settings. Then in 2011, they used the training to help Head Start teachers increase the on-task behavior of targeted individual students in need of additional support. The current research focused on using precorrection and praise to change the behavior of targeted students as Covington-Smith et al. did in 2011. 
Table 5:

Methods Comparisons of Precorrection Training Research

\begin{tabular}{|c|c|c|c|}
\hline & $\begin{array}{l}\text { Stormont, Covington- } \\
\text { Smith and Lewis (2007) }\end{array}$ & $\begin{array}{l}\text { Covington-Smith, Lewis and } \\
\text { Stormont (2011) }\end{array}$ & Bindreiff (2017) \\
\hline $\begin{array}{l}\text { Teacher } \\
\text { Participants }\end{array}$ & $\begin{array}{l}3 \text { Head Start teachers } \\
\text { using more reprimands } \\
\text { than specific praise }\end{array}$ & $\begin{array}{l}3 \text { Head Start teachers with low } \\
\text { rates of praise and high rates of } \\
\text { reprimands }\end{array}$ & $\begin{array}{l}4 \text { elementary teachers } \\
\text { with high rates of office } \\
\text { discipline referrals }\end{array}$ \\
\hline $\begin{array}{l}\text { Student } \\
\text { Participants }\end{array}$ & $\begin{array}{l}\text { Small groups ( } 7 \text { to } 9 \\
\text { students) of Head Start } \\
\text { students }\end{array}$ & $\begin{array}{l}\text { Teachers nominated } 3 \text { students } \\
\text { with low levels of appropriate } \\
\text { social skills and high rates of } \\
\text { problem behaviors }\end{array}$ & $\begin{array}{l}\text { Teachers nominated } 3 \\
\text { students with low levels } \\
\text { of appropriate social skills } \\
\text { and high rates of problem } \\
\text { behaviors }\end{array}$ \\
\hline Setting & $\begin{array}{l}\text { Teacher directed small } \\
\text { group setting }\end{array}$ & $\begin{array}{l}\text { Teacher directed large group } \\
\text { activity (circle greeting time) }\end{array}$ & $\begin{array}{l}\text { Teacher directed large } \\
\text { group activity }\end{array}$ \\
\hline $\begin{array}{l}\text { Teacher } \\
\text { behavior } \\
\text { measures }\end{array}$ & $\begin{array}{l}\text { Precorrection, specific } \\
\text { behavioral praise, } \\
\text { reprimands }\end{array}$ & $\begin{array}{l}\text { Precorrection, specific } \\
\text { behavioral praise, reprimands }\end{array}$ & $\begin{array}{l}\text { Precorrection, specific } \\
\text { behavioral praise, } \\
\text { reprimands }\end{array}$ \\
\hline $\begin{array}{l}\text { Student } \\
\text { behavior } \\
\text { measures }\end{array}$ & $\begin{array}{l}\text { Problem behavior per } \\
\text { minute by whole group }\end{array}$ & $\begin{array}{l}\text { On task behavior and } \\
\text { aggression }\end{array}$ & On-task behavior \\
\hline $\begin{array}{l}\text { Social } \\
\text { validity }\end{array}$ & $\begin{array}{l}7 \text { question } 5 \text { point Likert } \\
\text { scale }\end{array}$ & 7 question 5 point Likert scale & $\begin{array}{l}7 \text { question } 5 \text { point Likert } \\
\text { scale }\end{array}$ \\
\hline Intervention & $\begin{array}{l}\text { Individual 30-minute } \\
\text { training with each teacher } \\
\text { to instruct and practice } \\
\text { the use of precorrection } \\
\text { and specific praise. Daily } \\
\text { feedback on use of each } \\
\text { intervention }\end{array}$ & $\begin{array}{l}\text { Up to } 90 \text {-minute individual } \\
\text { instruction and practice on the } \\
\text { use of precorrection and } \\
\text { specific praise. Then Daily } \\
\text { feedback on the use of the } \\
\text { intervention. }\end{array}$ & $\begin{array}{l}\text { Up to } 90 \text {-minute } \\
\text { individual instruction and } \\
\text { practice on the use of } \\
\text { precorrection and specific } \\
\text { praise. Daily feedback on } \\
\text { the use of the } \\
\text { intervention. }\end{array}$ \\
\hline Design & $\begin{array}{l}\text { Single subject multiple } \\
\text { baseline across teachers }\end{array}$ & $\begin{array}{l}\text { Single subject multiple baseline } \\
\text { across teachers }\end{array}$ & $\begin{array}{l}\text { Single subject multiple } \\
\text { baseline across teachers }\end{array}$ \\
\hline Limitations & $\begin{array}{l}\text { Need to corroborate } \\
\text { findings. Inability to } \\
\text { disaggregate individual } \\
\text { impact of precorrection } \\
\text { and praise statements. } \\
\text { Inability to disaggregate } \\
\text { impact on specific } \\
\text { children. }\end{array}$ & $\begin{array}{l}\text { Included only Head Start } \\
\text { teachers. Exploring the impact } \\
\text { in different settings, long term } \\
\text { effects. Which strategies } \\
\text { impacted student behavior the } \\
\text { most? }\end{array}$ & $\begin{array}{l}\text { Included only elementary } \\
\text { teachers. No long term } \\
\text { effects measured. Which } \\
\text { strategies impacted } \\
\text { student behavior the } \\
\text { most? }\end{array}$ \\
\hline
\end{tabular}

\section{Summary of the Research Literature and Application to Study}


Throughout the PBIS framework there is an emphasis on an instructional approach to behavior (Carr et al., 2002; Lewis et al., 2010). Precorrection is a behavior intervention strategy that aligns with this instructional approach by utilizing instructional principles to reteach students and prevent problem behavior (Colvin et al., 1993). Researchers have used precorrection interventions to improve the behavior of individuals (Crockett \& Hegelian, 2006), student pairs (Miao, et al.,2002), small groups of students (Stormont et al., 2007), entire classes (De Pry \& Sugai, 2002; Faul et al., 2012; Flood et al., 2002; Gena, 2006; Simonsen et al., 2010), and schools (Colvin et al., 1997; Lewis et al., 2000). Researchers have used precorrection to reduce problem behavior, reduce selfinjurious behavior (Crockett \& Hegelian, 2006), increase engagement (Faul et al., 2002; Flood et al., 2002; Miao, et al., 2002), and improve reading scores (Miao et al. 2002). Additionally, researchers have gathered feedback showing that teachers consider precorrection a socially valid intervention that they can continue to use and will share with others. The consistent success of precorrection in reducing problem behavior and improving engagement makes further research into how teachers can be trained to incorporate this strategy into their practice worthwhile. 


\section{Chapter 3: Research Methods}

This research systematically replicated the research published by Stormont et al., (2007) and then by Covington-Smith et al. (2011). These researchers demonstrated how a brief individual training on precorrection and praise impacted the instructional practices of Head Start teachers. This research extended their findings by exploring how a brief individual training on precorrection and praise impacted the instructional practices of elementary teachers and the behavior of targeted elementary students. Utilizing a multiple baseline across teachers research design, this project aimed to answer two questions: (1) How does a brief teacher training on precorrection and praise paired with regular feedback impact teacher behavior, as measured by use of precorrection, praise and reprimands and (2) How do changes in the use of precorrection and praise by teacher impact the on-task behavior of targeted students?

The independent variable for this project was a brief individualized training with elementary teachers, who have students with a history of problem behavior and low rates of on-task behavior. The purpose of the training was to understand if teachers with a history of having students with high rates of problem behavior or in need of additional training on classroom management could effectively incorporate the precorrection process into their instruction and to measure the subsequent impact on student behavior. This training began by guiding each teacher through an analysis of the problem behavior for the identified student in their class. Once the problem behavior was identified, the researcher and each teacher discussed PBIS principles, shifting the focus to desired behaviors and developing a clear vision of their expectations during math. Once the 
teachers were able to describe their expectations in measurable and observable terms, the teacher created and practiced precorrective statements which oriented the student to the desired behavior during math instruction, a time when off-task behavior had been likely to occur. Then, the researcher and teacher discussed the value of specific praise and identified specific praise statements that may reinforce the on-task behavior of students. The training did not discourage the use of reprimands, rather focused on teaching the value of precorrection. During the intervention phase, each teacher received daily feedback on their use of precorrective statements, praise, and reprimands. As Table 6 shows, this model of teacher training utilized five of the seven steps as outlined by Colvin et al., (1993).

Table 6:

Comparing a Precorrection Plan with Teacher Training Model Steps in a Precorrection Plan (Colvin, Sugai \& Steps in Teacher Training (Stormont, Patching, 1993) Covington-Smith \& Lewis, 2007)

1. Identify the context and the predictable behavior Identify the context and the predictable behavior

2. Specify expected behaviors Specify expected behaviors

3. Systematically modify the context

4. Conduct behavior rehearsals

5. Provide strong reinforcement for expected Provide specific behavioral praise behaviors

6. Prompt expected behaviors Prompt expected behaviors

7. Monitor the plan Monitor the plan

\section{Research Method}

This research relied on an analysis of discrete student and teacher behaviors gathered through direct observation. A single case research methodology was used to identify any functional relationships between the independent and dependent variables (Horner et al., 2005). By replicating the use of a brief training across four teachers, any potential relationships between the training and teacher behavior, and then on student 
behavior can more confidently be understood. By exploring the impact of a brief intervention on elementary teachers in grades 2, 3, 4 and 5 this research provides insights into how to train elementary teachers in a research based practice.

\section{Participants}

Four elementary school teachers, from three Title I elementary schools, were selected based on an analysis of office discipline referral data and input from the school's administration. The researcher met with site administrations to review office discipline referral data from the previous school year and staffing to identify a pool of teachers that may benefit from additional training on classroom management. The researcher then met with potential teachers offering them a chance to participate in a research study aimed to improve the behavior of students with high rates of off-task behavior. A total of four teachers declined, four others were willing, but not selected due to scheduling or other conflicts. Detailed demographic data was gathered, including grade level assignment, education level, years of experience, gender, ethnicity, and race.

The selection of student participants followed a 3-step process beginning with teacher nomination, followed by direct observation, and ending with the completion of a brief functional assessment. Teacher participants nominated students in their class who displayed high rates of problem behavior, particularly off-task behavior. Based on teacher recommendations, the researcher reviewed the academic records, behavioral records, Individualized Education Program (IEP) documentation (if available), and/or behavior contracts of the nominated students. Next, the researcher conducted direct observations

of the students in their classroom, including measures of on-task behavior using duration 
recording, for up to 5 days (range 3 to 5 days). A data decision rule was included which mandated that the student be at or below $50 \%$ of the time on-task for at least three of the five observation days. Following these observations, the researcher met with each teacher to complete a brief Functional Assessment Checklist for Teachers and Staff for the candidate student (March et al., 2000). This was used for each nominated student to identify the function of the child's behavior. Preference was given to those students with low rates of on-task behavior for attention-seeking purposes as this better aligns with precorrection and praise statements and the increased adult attention they bring.

Following the identification of teachers and students, the next criteria for participation was receiving informed consent and assent from all parties; teachers, parents, and students. Identified teachers met with site administration and the researcher to discuss the project, their potential role, and what would be required of them. Participating teachers who had a potential research participant in their room, completed an informed consent agreement. Then, the families of the identified students were contacted to obtain written informed consent. Once this was obtained, students reviewed and voluntarily signed an assent form. District and site leaders were made aware of the proposed research and granted approval. Appendix A includes a sample letter for parental consent, student assent, and teacher consent. All candidates and their families consented. However, if consent by a candidate student's teacher or family, or assent by the student, was not obtained, the student would not have participated in the study and would have been replaced with an alternative candidate using the criteria outlined above. 


\section{Setting}

The study was completed at three different large Title I elementary schools, located in northern California. Observations were conducted in the morning, during whole class math instruction. Data collectors were positioned so they were able to observe the teacher's behavior, as well as, the focus student. Each of the classrooms had twenty-four students, the maximum capacity for Title 1 schools in the district. While each teacher was working with district adopted textbooks, each of the teachers had a unique instructional style. Two of the teachers had highly interactive teaching styles, one relied on lecture and independent work, the fourth on small group instruction and centers. These differences were most evident in terms of the frequency with which they interacted with their students both positively and negatively. However, all were following the district adopted material and pacing calendar.

Each of these schools had been implementing PBIS for over three years and were considered implementing Tier 1 PBIS based on their Tiered Fidelity Inventory scores (Algozzine et al, 2014). Each school had completed a new year "kick off" within two months of the intervention. This was used to teach all students the school wide expectations in each setting. The three schools each had the same "Big 3" expectations of safety, respect and responsibility. Based on these expectations, each school had been using a weekly schoolwide raffle as an acknowledgement system to recognize and reinforce the prosocial behaviors students engaged in. The four classrooms delivered reward tickets for good behavior that were incorporated into a school wide recognition system. Additionally, the second, third and fourth grade classrooms offered team points for groups or rows of students when their team was demonstrating desired behavior. 
Finally, all three schools were using a district developed student information system to track student referrals and suspensions to monitor student problem behavior.

\section{Procedures}

Two weeks prior to beginning student observations, the data collectors practiced gathering observational data on precorrection, praise and reprimands (see Table 7) by teachers and on-task behavior of a student in general education elementary classrooms with teachers and students who were not participating in the research. The data collectors were college students working toward Board Certified Behavior Analyst (BCBA) certification or a teaching credential. The benchmark for interobserver agreement (IOA) was set at $80 \%$ or above (Covington-Smith et al., 2011). Once this benchmark had been met for a period of three consecutive days, the data collector(s) began collecting baseline data on research participants. IOA was checked throughout the baseline and treatment phases. The IOA for teacher behaviors was calculated by dividing the total number of agreements by the total number of agreements and disagreements, then multiplying by 100\% (Cooper et al., 2007). The IOA for student on-task behavior was calculated by dividing the agreed-upon time on-task by the total observed time on-task and multiplying by $100 \%$. IOA was established once for every five days of observation, or approximately $20 \%$ of the sample. IOA never fell below the $80 \%$ benchmark over the course of research. However, if at any time during the research, the IOA had fallen below $80 \%$, data collection would have ceased and additional training would have been initiated.

Intervention. Once a stable baseline of student and teacher behavior was established, the researcher met individually with each classroom teacher. The intervention implementation was staggered across teachers, consistent with the guidelines 
for using a multiple baseline design (O’Neill et al., 2011). The teacher training lasted up to ninety minutes, and began with a verbal explanation of the importance of precorrection and specific praise. Appendix $\mathrm{C}$ is a worksheet used to create the precorrective and specific praise statements each teacher was comfortable using.

Using the student's referral information and observations, the researcher utilized informal dialogue to guide each teacher through the development of a precorrection statement. The first step was to discuss the student's problem behavior and identify what behaviors the teacher would like to see instead. Once this behavior was clearly identified, the researcher and teacher developed precorrective statements that fit the setting. The goal was to develop a precorrective prompt that re-taught the student one of the school-wide behavioral expectations that had been established as part of the school's implementation of SW-PBIS (Sugai et al., 2000). The teacher and researcher role played examples and non-examples of general praise, behavior specific praise, precorrective statements, and specific precorrective statements (see Table 7 for a detailed definition of each term).

Next, they rehearsed examples and non-examples of delivering different types of praise and precorrections, until the teacher demonstrated a high comfort level with their application; through rehearsal and verbal affirmation of their readiness. Once the teacher demonstrated proficiency with these statements the researcher and teacher developed specific praise statements that the teacher was proficient using in the classroom setting. Teachers were then instructed to deliver a class-wide precorrective statement at the beginning of the whole class math activity, to orient the students to the expectation in that 
setting, and then after whole class instruction, to prepare the student for what would happen next. Additional use of precorrection during the instructional period was at the teacher's discretion, based on behavior patterns identified during the problem-solving process. Teachers were encouraged to deliver praise as often as appropriate. This completed the teacher training.

The second part of the intervention was to provide each teacher with feedback regarding the use of precorrective statements, praise, and reprimands. Feedback was provided using daily emails. This email did not use any identifying information about the teacher or student. Each teacher received a daily email that included data on their use of precorrection, praise and reprimands. In this email, the researcher also asked if there were any questions or concerns. Any questions or concerns were answered via email, prior to the following days data collection. If a teacher had requested an in-person discussion to discuss the strategies or ask questions this would have been granted, but no meeting was requested.

Implementation fidelity is a concern within single-subject research because interventions tend to be applied over time (Horner et al., 2005). For this research documentation of implementation was measured through the direct measurement of the use of precorrection and praise over the course of the research. Additionally, verbal confirmation, rehearsal and completion of the handout in Appendix C demonstrated that the training covered the outlined materials and action steps. 


\section{Instruments and Measures}

For this replication study the goal was to use measures consistent with CovingtonSmith, et al. (2011). Teacher behaviors such as precorrection, praise and reprimands were recorded using event recording. Each instance of precorrection and reprimand was recorded as either general or specific (the definitions of each are included in Table 7). These behaviors were recorded as "general" when delivered to the class, other students or not specifically to the focus student and "specific" when delivered directly to the focus student, with student directly identified by name. For example, specific precorrection was recorded when teacher said, "Student's name, remember being responsible means working quietly". Each praise statement was recorded as general when the praise was delivered without stating the specific behavior being praised. When the specific behavior was stated, it was recorded as behavior specific praise. Finally, each praise statement delivered specifically to the focus student was recorded as student specific.

Student on-task behavior was measured continuously using duration recording and then converted to a percentage of the observation period that the student was on-task. Duration recording allows for documentation of the exact amount of time the student was on-task rather than interval recording which would only allow for an estimate (O’Neill et al., 2011). Data collectors used a stopwatch to record the time each student met the operational definition of "on-task". At the earliest onset of student on-task behavior data collectors began the stopwatch; then, when the student stopped meeting the operational definition of on-task behavior, the timer was stopped until the student resumed the ontask behaviors. Table 7 defines these measures in detail using the definitions consistent 
with Covington-Smith et al. (2011). Appendix B includes a sample of the data recording

tool that was used to record the frequency of identified teacher behaviors and the duration

of student on-task behavior.

Table 7

Behavior Categories and Operational Definitions

\begin{tabular}{|c|c|c|}
\hline Categories & Definitions & Measure \\
\hline $\begin{array}{l}\text { Precorrective } \\
\text { statement }\end{array}$ & $\begin{array}{l}\text { A precorrective statement is a statement that prompts or } \\
\text { engages a student in desired behavior before problem } \\
\text { behavior occurs. These statements are planned, teacher } \\
\text { directed, and prepare students for a setting by explaining } \\
\text { the desired behavior before starting a task or entering a } \\
\text { new setting. }\end{array}$ & $\begin{array}{l}\text { Specific or } \\
\text { General } \\
\text { Event Recording }\end{array}$ \\
\hline $\begin{array}{l}\text { Behavior-specific } \\
\text { praise }\end{array}$ & $\begin{array}{l}\text { A behavior-specific praise statement is a verbal } \\
\text { comment indicating approval of student behavior that } \\
\text { specifies the behavior that meets approval. }\end{array}$ & Event Recording \\
\hline $\begin{array}{l}\text { Nonspecific } \\
\text { behavioral praise }\end{array}$ & $\begin{array}{l}\text { A nonspecific behavioral praise statement is defined as a } \\
\text { verbal comment indicating approval of student behavior } \\
\text { without stating the specific behavior that meets approval } \\
\text { (e.g., great job, super work). }\end{array}$ & Event Recording \\
\hline Reprimand & $\begin{array}{l}\text { A reprimand is defined as a verbal comment and/or } \\
\text { negative statement indicating disapproval of students' } \\
\text { academic or social behavior. Reprimand statements also } \\
\text { included any comment stated in a negative and/or loud } \\
\text { tone of voice. }\end{array}$ & Event Recording \\
\hline On task & $\begin{array}{l}\text { On-task behavior is defined as observable behavior that } \\
\text { reflects compliance with the demands of the setting and } \\
\text { activity. On-task behavior is recorded as observed when } \\
\text { the target student is participating in the activity, } \\
\text { following instructions and showing appropriate physical } \\
\text { behavior toward others and self. }\end{array}$ & $\begin{array}{l}\text { Duration } \\
\text { Recording }\end{array}$ \\
\hline
\end{tabular}

Note: adapted from Covington-Smith, S. C., Lewis, T., and Stormont, M. (2011). The effectiveness of two universal behavioral supports for children with externalizing behavior in Head Start classrooms. Journal of Positive Behavior Interventions, 13, 133-143.

Social validity was measured using a seven-item checklist based on an assessment used by Stormont et al. (2007) to measure teacher satisfaction of precorrection interventions. This checklist measured teachers' perceptions of the intervention using a 
5-point Likert-type scale. The following scores were used: $1=$ strongly disagree; $2=$ disagree somewhat; $3=$ agree; $4=$ agree somewhat; and $5=$ strongly agree. The questionnaires were completed by each teacher upon completion of the study. The seven items included on the checklist were:

1. Overall, I feel comfortable with the intervention and consider it to be teacherfriendly (it did not take a lot of time or require additional resources) and was simple to implement.

2. The intervention proved to be an effective and efficient method for reducing minor behavioral problems.

3. I will continue to use the intervention.

4. I will recommend and share the intervention with others.

5. I will use the intervention in additional/other settings.

6. I feel this intervention was beneficial for my students with challenging behavior.

7. Overall, the intervention was successful.

\section{Role of the Researcher}

The researcher was responsible for training teachers in the implementation of the intervention and served as the alternate data collector for interobserver agreement. The researcher had no known biases or relationships with the students or teachers at the school.

\section{Data Collection and Analysis}

Teacher and student behavior was analyzed visually for trend, level, and variability (O'Neill et al., 2011; Scruggs \& Mastropieri, 1986; Wolery, Bailey, \& Sugai, 1988). These visual analyses were used to understand the impact of the training on teacher and student behavior. The frequency of the use of precorrections, praise and reprimands were analyzed by mean, range and trend. Comparing the baseline and intervention mean use of precorrection, praise and reprimands allowed for comparison of 
the overall use of these statements during each stage and to understand the impact or level of change. Level was analyzed to understand the immediacy of any changes in teacher behavior following the intervention. Similarly, trend over the course of the intervention stage was monitored to understand whether the pattern of behavior was continuing to increase, decrease or had stabilized. Finally, the variability of precorrection, praise or reprimand use was analyzed by comparing the range of usage in each phase. The variability was observed as the highest and lowest usage of a behavior within each phase.

The use of specific precorrection, praise and reprimands was analyzed to understand if the intervention changed the frequency or types of interaction the teacher had with the particular student of focus. In addition to analyzing the level, trend and variability of changes in the use of precorrection, praise and reprimands by each teacher, the ratio of precorrection-to-reprimands and praise-to-reprimands was calculated. This was used to understand if increasing the use of precorrection resulted in a decrease in the use of reprimands. Similarly, by comparing praise-to-reprimand ratios changes in the type of student-teacher interactions that occurred could be analyzed. The ratio of precorrection-to-reprimands was calculated by dividing the mean use of precorrections in each stage by the mean use of reprimands in that stage. The ratio of praise-to-reprimands was calculated by dividing the mean use of praise in each stage by the mean use of reprimands in that stage.

Social validity. Social validity data was analyzed by calculating the average and range of scores on the Likert survey discussed previously. The social validity scores 
were first analyzed for each teacher individually to understand the strengths and weaknesses of the intervention for each teacher. Then, the combined scores of the four teachers were analyzed by mean and range across teachers to identify trends and patterns. Finally, these social validity scores were compared with the previous research to understand how these responses fit in the broader context of research.

On-task behavior. In addition to analyzing how the training impacted teacher behavior, data was analyzed to understand how changes in teacher behavior subsequently impacted student behavior. The percent of the observation that each focus student was on-task was analyzed for level, trend and variability to understand the stability of the data collected and the impact of the supports on the student's behavior. Variability was analyzed by examining the range of on-task behavior for each student. The trend of each student's on-task behavior was visually analyzed by examining the patterns of on-task behavior over the course of research. Particular focus was on the immediacy of change in the student's behavior following the implementation of the intervention and for patterns emerging over the intervention stage to understand the stability of the changes in on-task behavior.

FACTS. Over the course of the screening process the researcher and teacher completed a FACTS interview to better understand the function or motivation of each focus student's behavior (March et al., 2000). The FACTS interview format allowed the teacher and researcher to problem solve and develop a hypothesis of the function of each student's off-task behavior. While the function of the student's behavior was not validated experimentally, the FACTS is widely used research based functional 
assessment tool used to develop behavior supports for students in need of additional support (McIntosh et al., 2008). The FACTS data was paired with changes in the on-task behavior of each student (see Table 12). The purpose of this was to understand if there was any relationship between the function of the students off-task behavior, the intervention and changes in student behavior. For example, to understand if changes in the on-task behavior of a student seeking to avoid peers had behavior change differences in level, trend or variability than students off-task to seek peer attention. 


\section{Chapter 4: Results}

\section{Introduction}

This research set out to answer two questions: (1) How does a brief teacher training on precorrection and praise paired with regular feedback impact teacher behavior, as measured by use of precorrection, praise and reprimands? (2) How do changes in the use of precorrection and praise by teacher impact the on-task behavior of targeted students? Four elementary teachers and one student from each class participated in this research. Each teacher and student dyad was from a Title I elementary school $(N=$ 3 schools), grades $2-5$.

\section{Analysis of Data}

Consistent with single case research, changes in teachers' and students' behaviors

were analyzed for level, trend, and variability (Cooper et al., 2007). The purpose of this visual analysis was to understand if the participant's behavior changed in a meaningful way and if so, to what extent can changes be attributed to the independent variable? After the data was analyzed within and across phases for each participant the data was analyzed across participants. As O'Neill et al. (2011) explain, the level of change compares the mean performance within each phase. Additionally, the level of change was analyzed by comparing the immediacy of effect as each teacher-student dyad transitioned from the baseline stage to the intervention stage. The trend was analyzed using a visual analysis, noting whether changes in teacher or student behavior remained flat, increased or decreased within each phase. Variability was analyzed using a visual 
analysis, to compare how much the data in each stage vary in comparison to the overall mean (O’Neill et al., 2011).

Question one asked: How does a brief teacher training on precorrection and praise, paired with regular feedback, impact teacher behavior? This question was answered using three measures. First, by comparing event recording of precorrection, praise, and reprimand statements delivered during the baseline and intervention stages. These changes were used as evidence of how the intervention impacted the new skills taught to the teachers. Secondly, the number of student-specific interactions defined as a precorrection, praise, or reprimand statement delivered exclusively to the student of focus, during baseline and intervention stages, was compared. This data was used to explore how the use of precorrection and praise impacted the individual interactions between the student and the teacher. Finally, the ratios of precorrection-to-reprimands and praise-to-reprimands were calculated. Combined these three measures informed the impact of a brief training on precorrection and praise to elementary teachers.

The second question asked: How do changes in the use of precorrection and praise by teachers impact the on-task behavior of targeted students? This question was answered by comparing the percent of time the student was on-task. The level, trend and variability of the on-task behavior was examined to understand the immediacy and stability of changes in student behavior. This data provided further understanding of the impact of changes in the use of precorrection, praise and reprimands by a general education elementary teacher had on a student in their class. 


\section{Presentation of Results}

Figure 1 summarizes the changes in teacher behavior, regarding the use of precorrection, praise and reprimands. Across the four teachers, the use of precorrection increased by $107 \%$, from 6.51 to 13.49 per observation. The mean use of praise increased from 15.79 to 19.71 , a $25 \%$ increase on average, for the four teachers. The use of reprimands decreased by $30 \%$ for the four teachers, from 6.53 to 4.57 reprimands per observation.

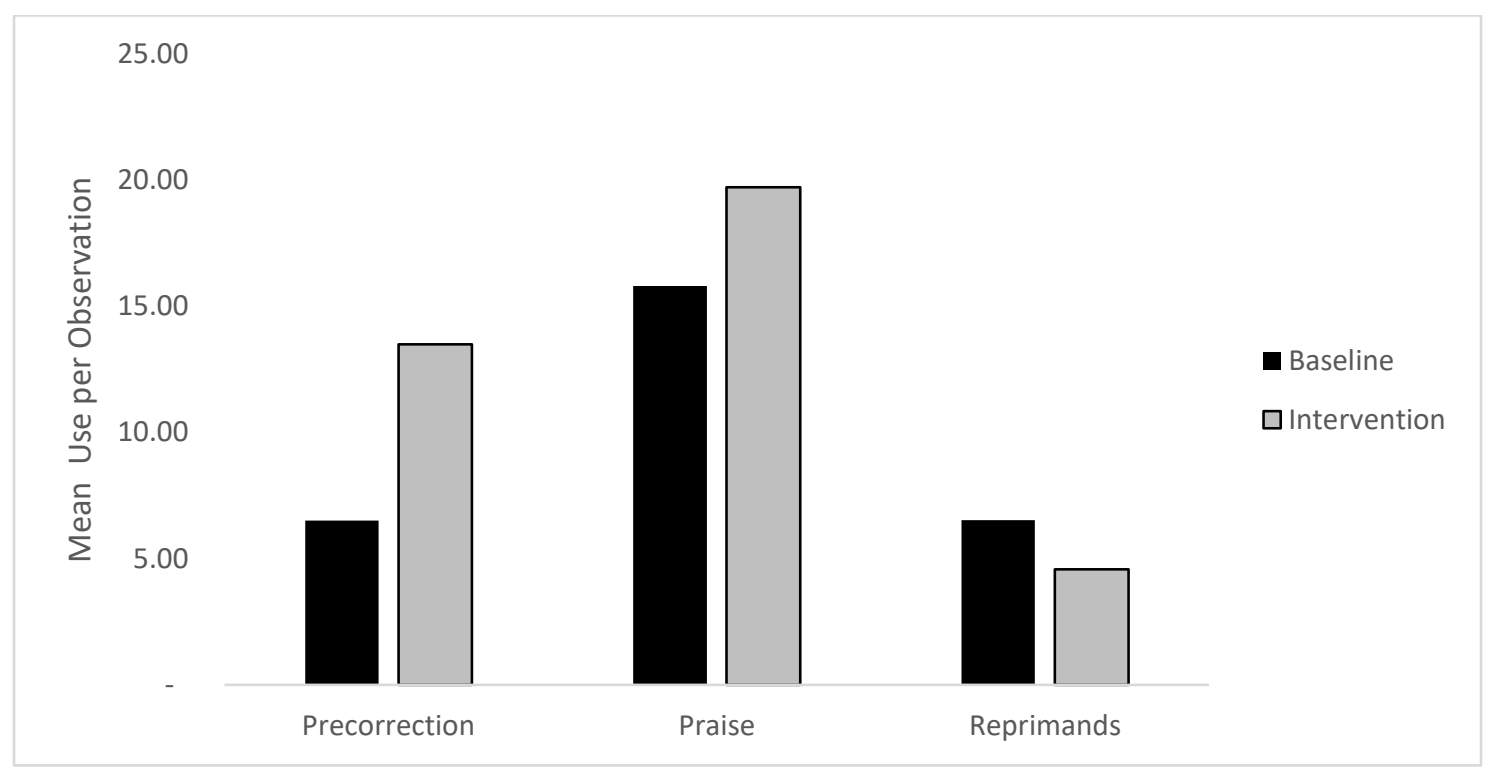

Figure 1. Mean number of precorrection, praise and reprimand statements across teachers.

The mean baseline and intervention rates of precorrection and praise delivered by the four teachers can be seen in Table 8. All four teachers increased their use of precorrection, the degree of change by the teachers was at least $39 \%$ and one teacher increased her use by $256 \%$. Teachers one and four showed strong improvement in their use of praise, and the second teacher made a slight increase. Teacher three had a high use 
of praise during the baseline stage, yet experienced a decrease during the intervention stage of 5\%. These changes were coupled with decreased use of reprimands for three of the four teachers. The changes in teacher behavior will be discussed in greater detail below.

Table 8

Mean use of Precorrection, Praise, Reprimands and Student On-task (Question 1)

\begin{tabular}{|c|c|c|c|c|}
\hline Measure & $\begin{array}{l}\text { Teacher } \\
\text { One }\end{array}$ & $\begin{array}{l}\text { Teacher } \\
\text { Two }\end{array}$ & Teacher Three & $\begin{array}{l}\text { Teacher } \\
\text { Four }\end{array}$ \\
\hline Baseline Precorrection* & 3.17 & 10.29 & 9.25 & 3.33 \\
\hline Intervention & 8.83 & 20.38 & 12.88 & 11.87 \\
\hline Precorrection & & & & \\
\hline Percent Change & $179 \%$ & $98 \%$ & $39 \%$ & $256 \%$ \\
\hline Baseline Praise* & 7.5 & 25.17 & 23.25 & 7.22 \\
\hline Intervention Praise & 11.5 & 27.00 & 22.13 & 18.20 \\
\hline Percent Change & $53 \%$ & $7 \%$ & $-5 \%$ & $152 \%$ \\
\hline Baseline Reprimands* & 3.17 & .57 & 13.25 & 9.11 \\
\hline Intervention Reprimands & 2.5 & 2.00 & 5.63 & 8.13 \\
\hline Percent Change & $-21 \%$ & $251 \%$ & $-58 \%$ & $-11 \%$ \\
\hline $\begin{array}{l}\text { Baseline On-Task } \\
\text { Behavior }\end{array}$ & $44 \%$ & $50 \%$ & $28 \%$ & $51 \%$ \\
\hline $\begin{array}{l}\text { Intervention On-task } \\
\text { Behavior }\end{array}$ & $65 \%$ & $69 \%$ & $65 \%$ & $79 \%$ \\
\hline Percent Change & $47 \%$ & $37 \%$ & $137 \%$ & $55 \%$ \\
\hline
\end{tabular}

In reference to the second research question, Figure 2 shows how the changes in teacher behavior impacted the on-task behavior of each focus student. All the students improved on-task behavior by at least $37 \%$ and the highest improvement was $137 \%$. The changes in teacher behaviors resulted in an average increase of on-task behavior by target 
students by $83 \%$. This increased on-task behavior resulted in an average of 7 minutes and 9 seconds additional on-task behavior per twenty minutes of observation.

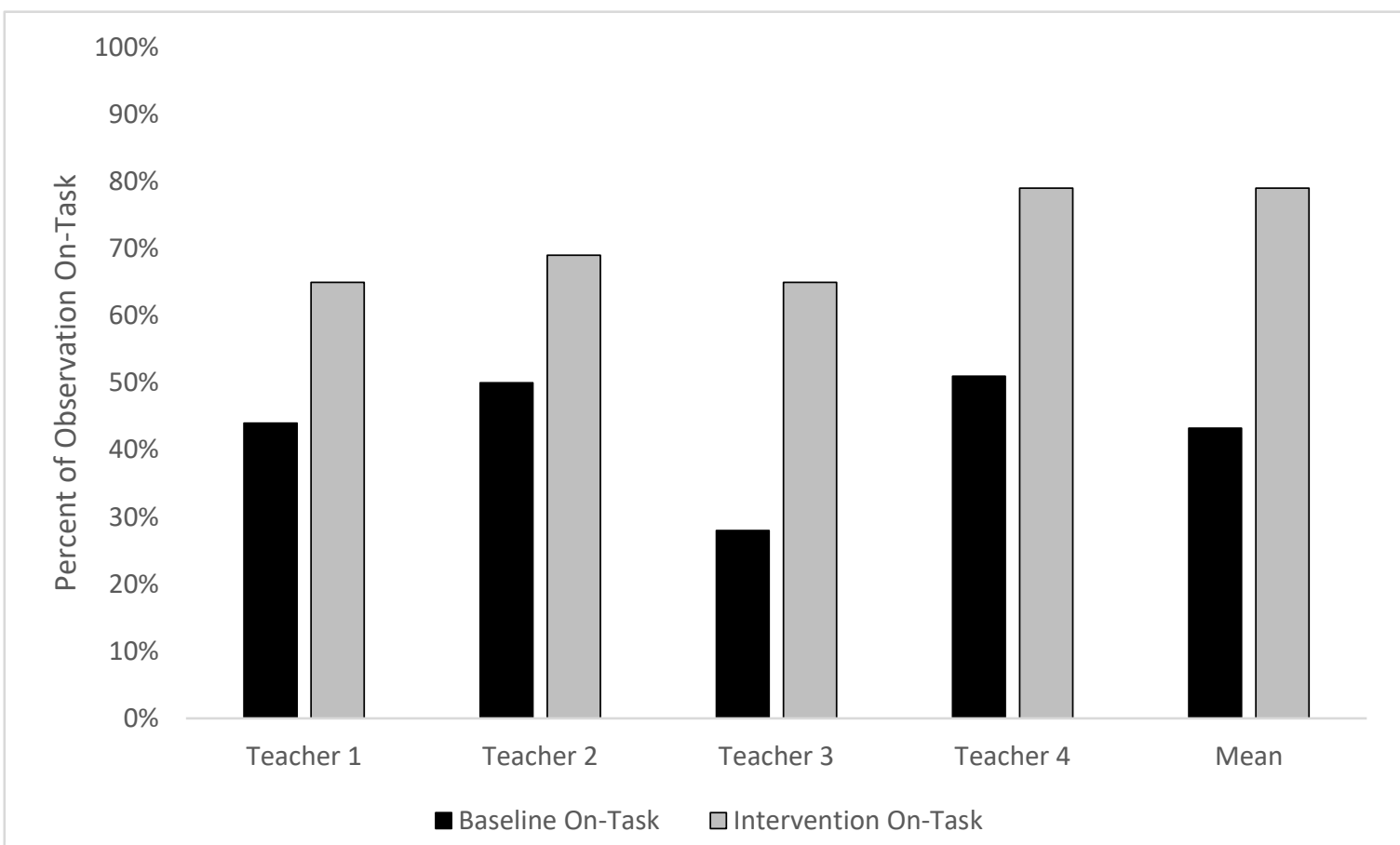

Figure 2 in reference to question 2, mean percentage of observation focus student was on on-task.

Figure 3 displays the daily on-task behavior of each focus student. As this figure shows, there was variation between students in the immediacy by which each began to increase their on-task behavior following the intervention. Similarly, the stability of data varied for each student. For example, the fourth grader showed a sharp increase in ontask behavior immediately following the intervention, suggesting a strong immediacy of effect (O’Neill et al., 2011). Then after 12 days the fourth grader's on-task behavior began to flatten. In contrast, the second grader's on-task behavior did not show as strong of an immediate effect and the trend for her progress had a gradual, increase before also plateauing over the final few days of data collection. These differences will be discussed in more detail below. 


\section{Student On-Task Behavior}

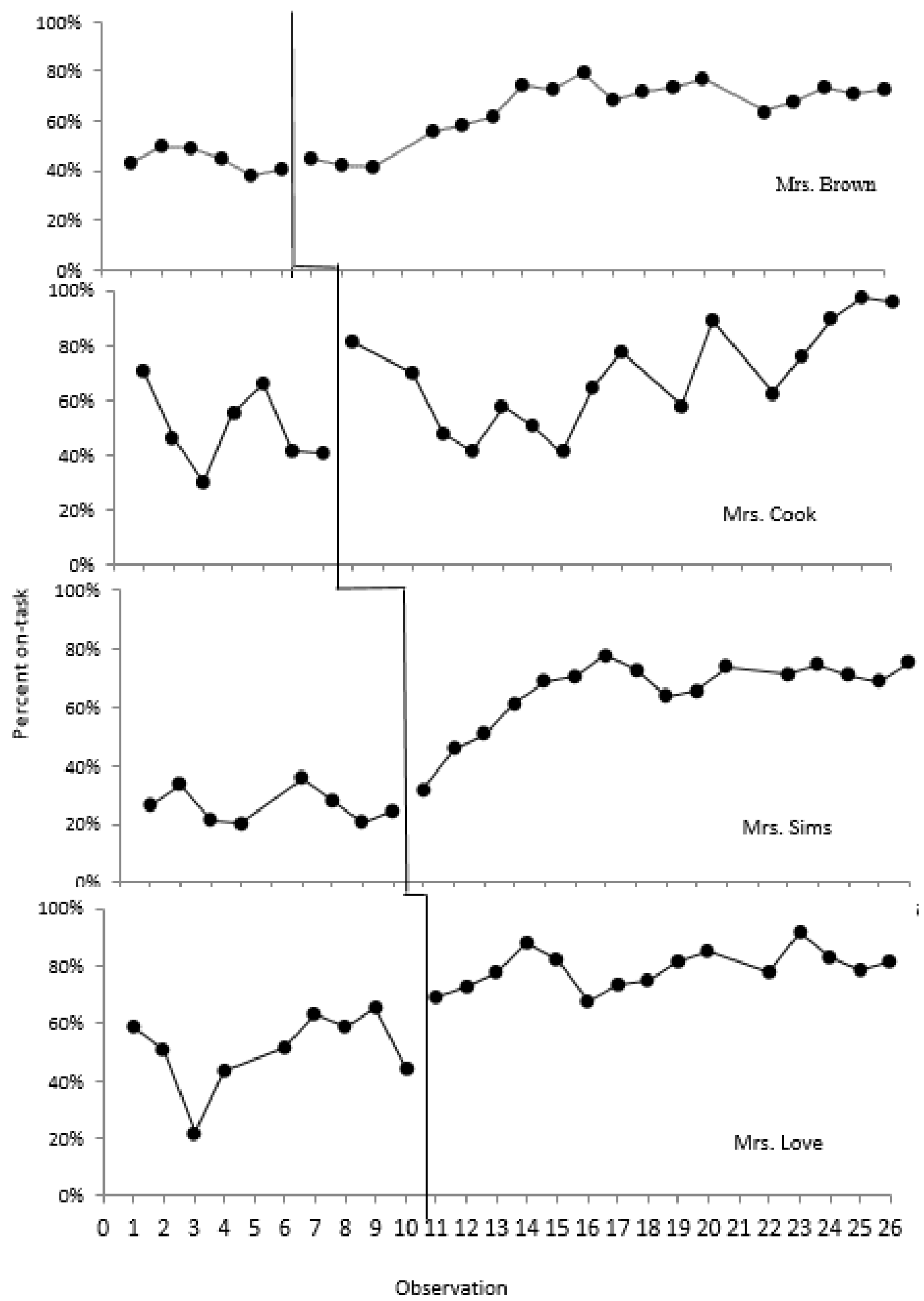

Figure 3 in reference to research question 2, daily percent of observation focus student was on-task. 
Teacher and student dyad 1. Mrs. Brown taught fourth grade at a year-round Title I elementary school. She was identified as a candidate for this research through a review of 2014-2015 discipline data for the school and through conversations with the administrative team. Mrs. Brown was among the top five in disciplinary referrals at her school during the previous year. Mrs. Brown has taught for 23 years, completed her bachelor's degree, and identifies herself as a Caucasian. Prior to beginning the research, her classroom was observed five times to obverse candidate students. Over the course of these observations and discussion, Mrs. Brown repeatedly expressed concerns about the low on-task behavior of her class as a whole. The observations prior to beginning the research suggest a teaching style that relied on lecture and independent seat work by the students. This lower level of teacher-student interaction may have contributed to the generally lower rates of precorrection, praise and reprimands over the course of this research.

In Mrs. Brown's fourth grade class, the focus student was a Hispanic female who had been identified as an English Language Learner. Prior to beginning the research, the student was observed on five occasions. Over those observations, she was on-task from a low of $30 \%$ of the observations to a high of $65 \%$ of the time. In four of the five observations, she was academically engaged less than $50 \%$ of the time. Mrs. Brown and the researcher met to complete a brief Functional Assessment Checklist for Teachers and Staff (FACTS) (March et al., 2000). At this meeting, Mrs. Brown felt confident that the student was most likely to become disruptive and off-task in order to access peer attention, when transitioning to direct instruction activities. The teacher also reported that 
the student was in need of glasses, which she began wearing during the course of this research.

Figure 4 shows Mrs. Brown's use of precorrection, praise, and reprimands throughout this research. On average, Mrs. Brown's use of precorrective statements (general and specific combined) was 3.17 per twenty-minute observation period during baseline. This increased to an average of 8.83 precorrective statements per observation during the intervention stage. This was an increase of $179 \%$, adding 5.67 statements per twenty minutes of class time. As Figure 4 shows, Mrs. Brown's use of precorrections did not immediately increase, but the second day of intervention jumped to 12 precorrection statements. During the intervention stage, her use of precorrections was variable, ranging from two statements to a high of 18 precorrections in twenty minutes. Over the last five days of observation Mrs. Brown's use of precorrection was below her average on four of the five days, with one day above her average at 16 precorrections. In comparison to the

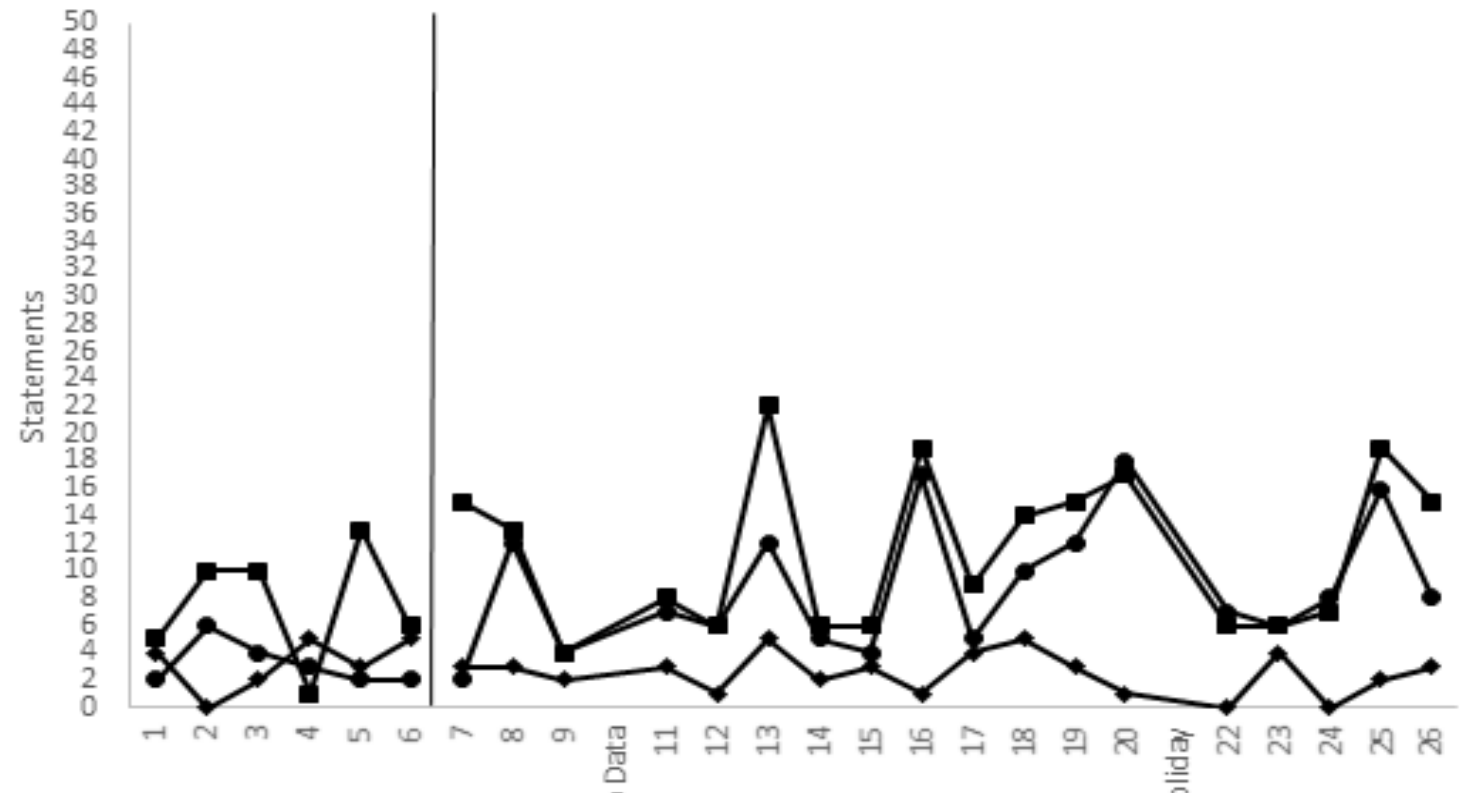

Figure 4 observation results for teacher and student 1. 
other three teachers Mrs. Brown had the most variability in her behavior, frequently having two or three days below her average, then a spike well above her average. Over the course of the research, Mrs. Brown disclosed some personal health issues which may have contributed to this variability.

During the baseline stage, Mrs. Brown was also variable in her use of praise statements (general and specific) with a high of 13 and a low of 1 . This variability resulted in an average of 7.5 praise statements per observation. The median data point for her baseline praise statements was 8. Following the training, Mrs. Brown's use of praise quickly jumped and maintained an average of over 11.5 praise statements per twenty minutes, a 53\% increase. However, over the course of the project, Mrs. Brown's use of praise statements remained variable, ranging from a low of 4 statements to a high of twenty-two per observation. Over the last five days of observation, Mrs. Brown had three days of praise statements well below her mean paired with two days well above the mean. This trend was consistent with the rest of the observation days. Some factors that may have contributed to the variability in Mrs. Brown's behavior were her health challenges and teaching style whereby many observations had limited student-teacher interactions.

In the baseline stage, Mrs. Brown used 3.17 reprimands (general and specific) per twenty minutes of observation. Over the course of the intervention stage this dropped to an average of 2.5 reprimands per observation, which was a decrease of $21 \%$. The range of reprimands over the intervention stage was mostly stable, ranging from five to zero. Similar to her use of precorrection and praise over the final five days, her use of 
reprimands varied daily, with 3 days near the average and two days without any reprimands. During the baseline stage, Mrs. Brown had a precorrection-to-reprimand ratio of 1 to 1 . Meaning on average, for every precorrection statement delivered she would deliver a reprimand statement. Following the intervention, the ratio of precorrections-to-reprimands was 3.53 precorrections per reprimand, an increase of more than $250 \%$. During the baseline stage, Mrs. Brown's praise-to-reprimand ratio was 2.37 praise statements per reprimand. Following the training, her ratio of praise-to-reprimands grew to 4.6 praise statements per reprimand. This rate is much more in line with the 5 to 1 praise-to-reprimand ratio often recommended (Flora, 2000; Gottman, 1994; Gottman \& Levenson 1992; Wheatley, 2015).

Data was also gathered on Mrs. Brown's interactions specifically with the student of focus. Each time Mrs. Brown would deliver precorrections, praise, or reprimands solely to the student of focus, it was recorded. Figure 5 shows how these interactions changed as a result of the training. As this graph shows, Mrs. Brown increased all her interactions with the target student. Her use of precorrections to the target student increased from .17 precorrections per observation to .44 . Similarly, praise increased from .5 to .69 . The increased teacher attention also resulted in increased reprimands, nearly doubling from .17 to .33 . Overall, consistent with her teaching style, there was not a great deal of student-teacher interaction. However, data suggests that as a result of this intervention, Mrs. Brown did increase all types of interactions she had with the student of focus. 


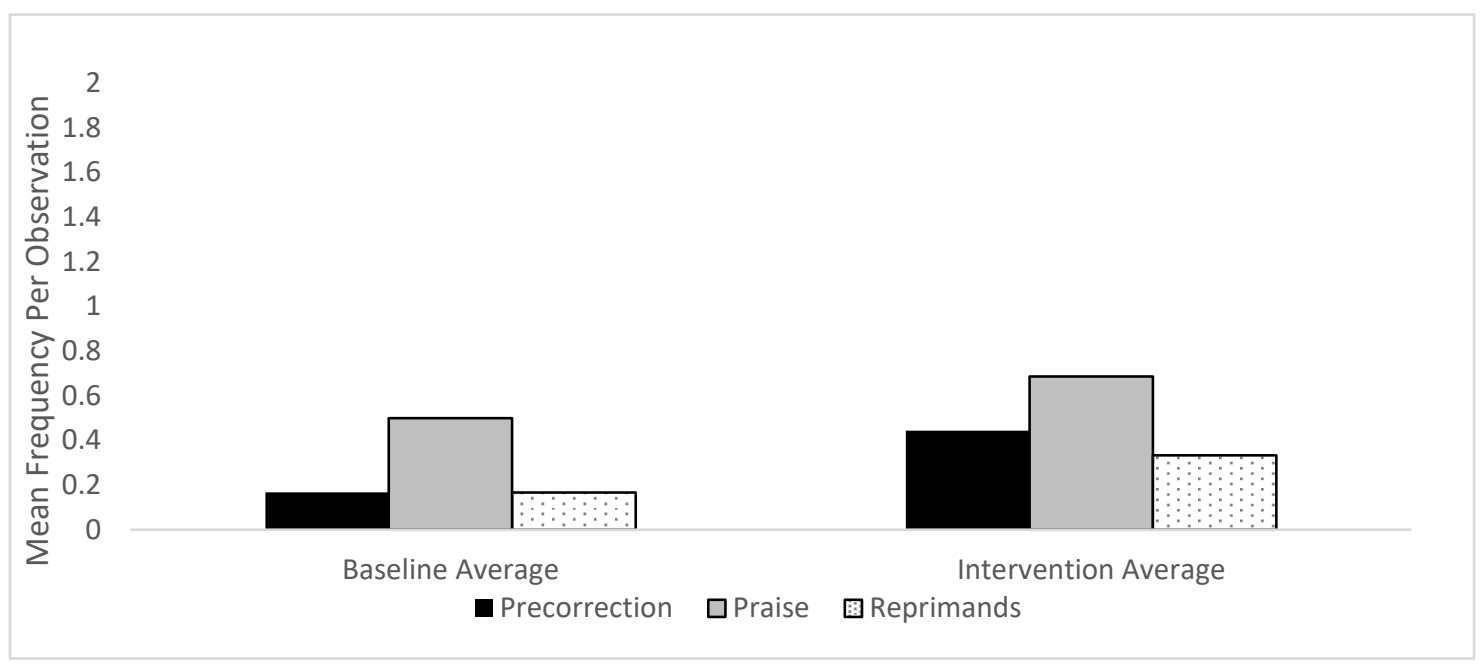

Figure 5 Mean statements delivered by Mrs. Brown directly to the student of focus

In the baseline stage, the focus student was on-task an average of $44 \%$ of every twenty minutes of observation. During the intervention stage, the student's on-task behavior increased to an average of $65 \%$ of the twenty minutes of observation. As can be seen in Figure 3, the student's rate of on-task behavior made steady improvement during the first six days of intervention observation, climbing to $61 \%$. Overall on-task behavior increased by $47 \%$ from the baseline stage, which was an additional 4 minutes and 12 seconds of on-task behavior per twenty minutes of observation. It is worth noting that on the $15^{\text {th }}$ day of observation the student began wearing glasses. On this day, her on-task behavior jumped by over two minutes and remained high for the remainder of the study. Over the course of the intervention stage, the student's on-task behavior made steady improvement from a low of $41 \%$ to a peak of $77 \%$, with an average of $65 \%$ per twentyminute observation. Over the final five days of data collection, on-task behavior entered a flattened trend, which was near the mean and slightly below her peak.

Teacher and student dyad 2. The second teacher, Mrs. Cook, was in her first year of teaching at a public school, after teaching for two years in a private Catholic 
elementary school. She was teaching a fifth-grade class and was identified as a candidate for this research through a recommendation by her administrative team. The recommendation was based on the high number of students with problematic behavior histories in her class, as well as, it being her first-year teaching in public school. She had completed her bachelor's degree and identifies herself as a Caucasian woman. Prior to beginning the research, her classroom was observed four times by the researcher. These observations focused on observing candidate students and measuring their on-task behavior. Mrs. Cook's highly interactive and engaging teaching style lead to variable practices and activities from day to day, for example many lessons were delivered with highly interactive lectures and small group work, other days focused more on independent assignments that complimented the lectures and discussions. This teaching style may have contributed to some of the variations in her data sample.

In Mrs. Cook's fifth grade class, the focus student was a Caucasian male, who was new to the school, and had a history of problem behavior at his previous school. The student had been complaining of others picking on him, and was engaging in little ontask behavior. Prior to beginning the research, the student was observed on four occasions. Over those observations, his level of on-task behavior never exceeded $36 \%$, with a low of $16 \%$. Following these observations, Mrs. Cook and the researcher met to complete a FACTS (March et al., 2000). The focus of this assessment was to understand the student's reluctance to participate in classroom activities, other than art. The work he was producing was of low quality and completion was minimal. The teacher reported that the student would go so far to avoid these activities as to crawl under his desk. The 
teacher and researcher concluded, with confidence, that during peer interactions the student would engage in off-task behaviors primarily to avoid peers and secondarily as a means to avoid non-preferred tasks.

Figure 6 summarizes Mrs. Cook's use of precorrection, praise and reprimands over the course of this research. On average, Mrs. Cook's use of precorrective statements was 10.29 per twenty minutes during the baseline stage. This increased to an average of 20.38 general and specific precorrective statements per observation during the intervention stage. This was an increase of $98 \%$, adding 10.09 statements to twenty minutes of observation. As Figure 6 shows, Mrs. Cook's use of precorrections immediately jumped to 36 precorrections following the intervention. During the intervention stage, her use of precorrections was variable, ranging from 15 statements to a high of 36 precorrections in twenty minutes. Over the last five days of observation, Mrs. Cook's use of precorrection was consistently within 3.5 statements of her average of 20.38 .

During the baseline stage, use of praise statements was high, ranging from 16 to 28 praise statements per observation, resulting in an average of 25.17 . Following the training, Mrs. Cook's use of praise remained stable and high, averaging 27 praise statements per twenty minutes, a 7\% increase. As Figure 6 shows, over the course of the project, Mrs. Cook's use of praise statements was variable, but consistently high ranging from a low of thirteen statements to a high of thirty-four. 


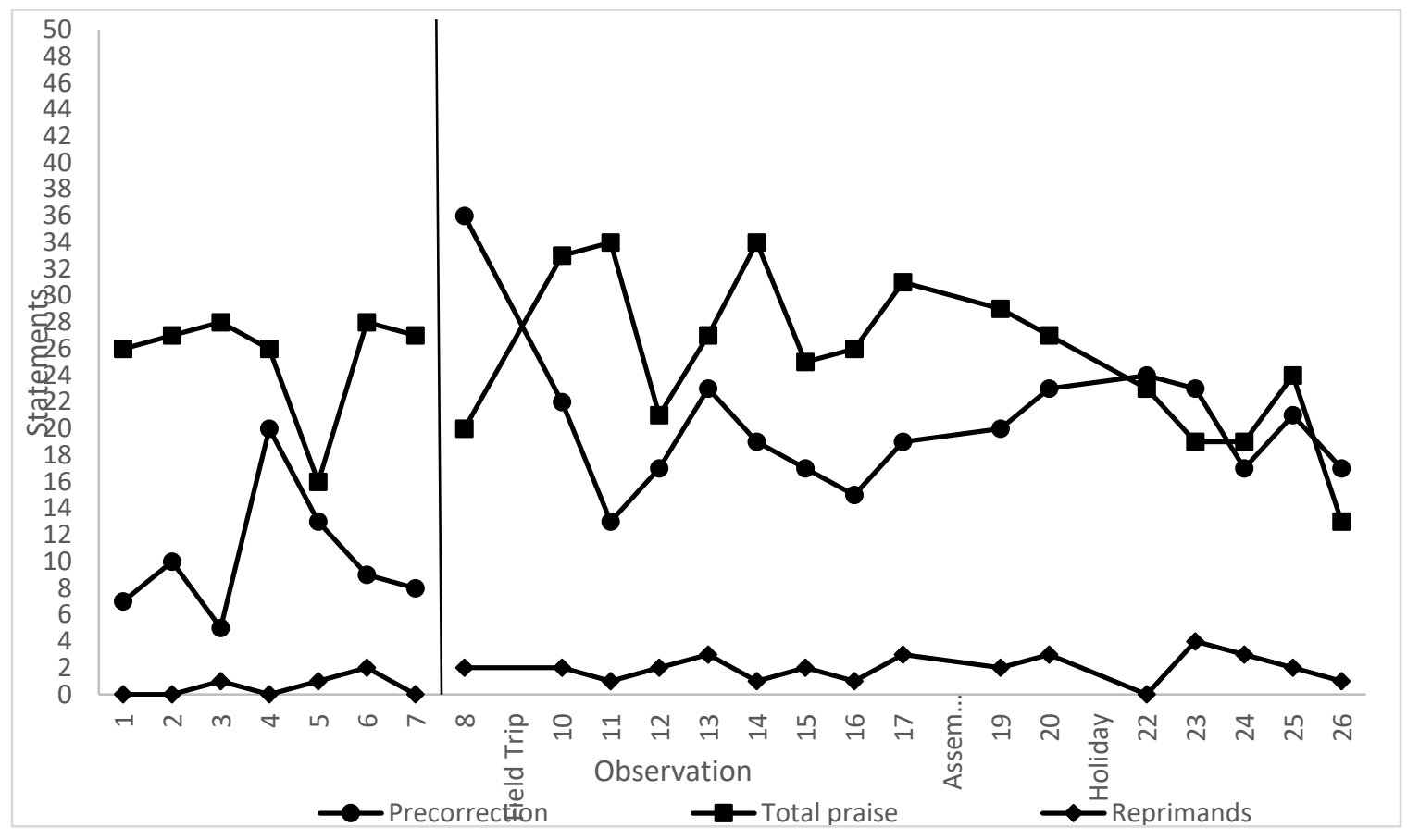

Figure 6 observation results for teacher and student 2 .

Mrs. Cook's use of reprimands was low during baseline stage, delivering an average of .57 reprimands per twenty minutes of observation. Over the seventeen days of intervention, her use of reprimands increased, to an average of 2 reprimands per twenty minutes of observation. While still well below other participants, the use of reprimands nearly quadrupled from .57 during baseline to 2.0 during the intervention stage. Overall, her low rates of reprimands were stable ranging from zero to a high of 4 .

The rare use of reprimands during the baseline stage did result in lower precorrection-to-reprimand and praise-to-reprimand ratios during the intervention stage. Mrs. Cook's ratio of precorrections-to-reprimands during the baseline stage was an impressive 18 precorrections per reprimand. Despite nearly doubling her use of precorrections during the intervention stage, her ratio of precorrections-to-reprimands fell to 10.19 precorrections per reprimand. In the baseline stage, Mrs. Cook had a ratio of 
praise-to-reprimands of just over 44. This ratio fell to 13.5 during the intervention stage, but still more than triple the recommendation of 5 to 1 (Flora, 2000; Gottman, 1994;

Gottman \& Levenson 1992; Wheatley, 2015). In summary, Mrs. Cook’s use of precorrections increased, her use of praise largely remained steady, and her use of reprimands remained low, but did increase. The increase in the use of reprimands caused the ratios of praise-to-reprimands and precorrections-to-reprimands to drop noticeably. Yet, her rates of precorrections, praise, and reprimands were all above the other three participants.

Observational data was gathered regarding Mrs. Cook's interactions directly to the student of focus. Each time Mrs. Cook would deliver precorrections, praise, or reprimands solely to the student of focus, it was recorded. Figure 7 shows how these interactions changed following the training. As this graph shows, Mrs. Cook increased all her interactions with the target student. Her use of precorrections to the target student increased from .29 precorrections per observation to 1.44 . Similarly, praise increased from 1.3 to 1.44. Mrs. Cook did not reprimand the focus student specifically in baseline, yet during the intervention stage reprimands increased to an average of .44 reprimands per observation. In the intervention stage, all the measured types of interactions with the focus student increased, especially specific precorrection statements. 


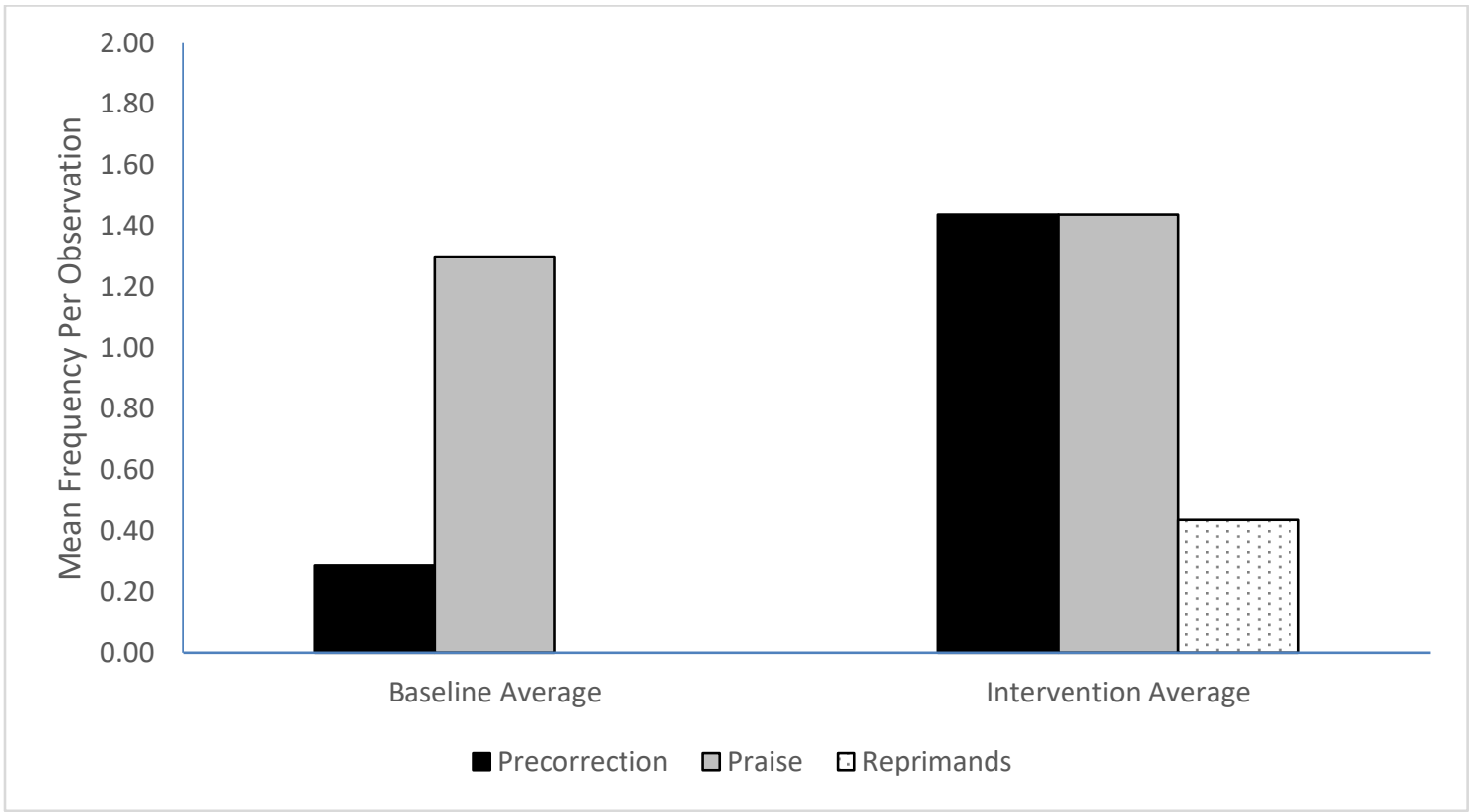

Figure 7 mean statements delivered by Mrs. Cook directly to the student of focus.

Both during the baseline and intervention phases the on-task behavior of the focus student was variable over the course of this research (see Table 3). However, he did increase his on-task behavior throughout the observations. In the baseline stage, the focus student was on-task an average of $50 \%$ of every twenty minutes of observation, ranging from a low of $30 \%$ to a high of $71 \%$. This jumped to $81 \%$ the first day following intervention. Over the course of the intervention stage, the student's on-task behavior made steady improvement, from a low of $41 \%$ to a peak of $97 \%$, with an average of $69 \%$ per twenty-minutes of observation. Despite the variability, the student's rate of on-task behavior increased $37 \%$ above the baseline mean. Which was an additional 3 minutes and 48 seconds of on-task behavior per twenty minutes of observation. Over the course of 
the 16 days of intervention data collection, this increased on-task behavior gave the student the opportunity to access an additional 59 minutes and 49 seconds of instruction.

Teacher and student dyad 3. Mrs. Sims taught second grade at a Title I elementary school. She was identified as a candidate for this research through a review of 2014-2015 discipline data, and conversations with the administrative team. In the previous year, Mrs. Sims' had a number of severe behavior problems, coupled with her limited teaching experience were factors that made her a candidate for this research. Mrs. Sims had begun her second year of teaching, after having completed her bachelor's degree, and identifies herself as a Caucasian. Prior to beginning the research, her classroom was observed three times, to measure the on-task behavior of candidate students. Much of her instruction during the observation was done leading small group interventions during math, which seemed to increase her interactions with students.

In Mrs. Sims' second grade class, the focus student was an African American male that was experiencing persistent and pervasive behavior problems that, only two months into the school year, were escalating. This behavior had caused him to be referred to the administration as a student in need of additional support. Prior to beginning the research, the student was observed on three occasions, and during those observations his level of on-task behavior never exceeded $17 \%$, with low of $11 \%$. Following the observations, Mrs. Sims and the researcher met to complete a brief functional assessment (March et al., 2000). It was reported that the student had been getting into fights, becoming aggressive with peers, and was consistently defiant and disruptive. He would make noises, get out of his seat, and touch peers on a minute by 
minute basis. His defiance was described as medium-to-high and increasing. Based on this assessment, the teacher felt that whether the student was working in groups, with the whole class, or alone, he would become disruptive in order to get peer attention.

Figure 8 summarizes Mrs. Sims's use of precorrection, praise and reprimands over the course of this research. On average, Mrs. Sims's use of general and specific precorrective statements during baseline was 9.25, with a downward trend. However, following the intervention training, her use of precorrection quickly rose, ultimately averaging 12.88 precorrection statements per observation. This was an increase of 39\%, adding 3.62 statements per twenty minutes of class time. As Figure 8 shows, her use of the precorrection statements remained very stable during the intervention stage, ranging from 7 to a high of 16. After the first three days of intervention, Mrs. Sims was

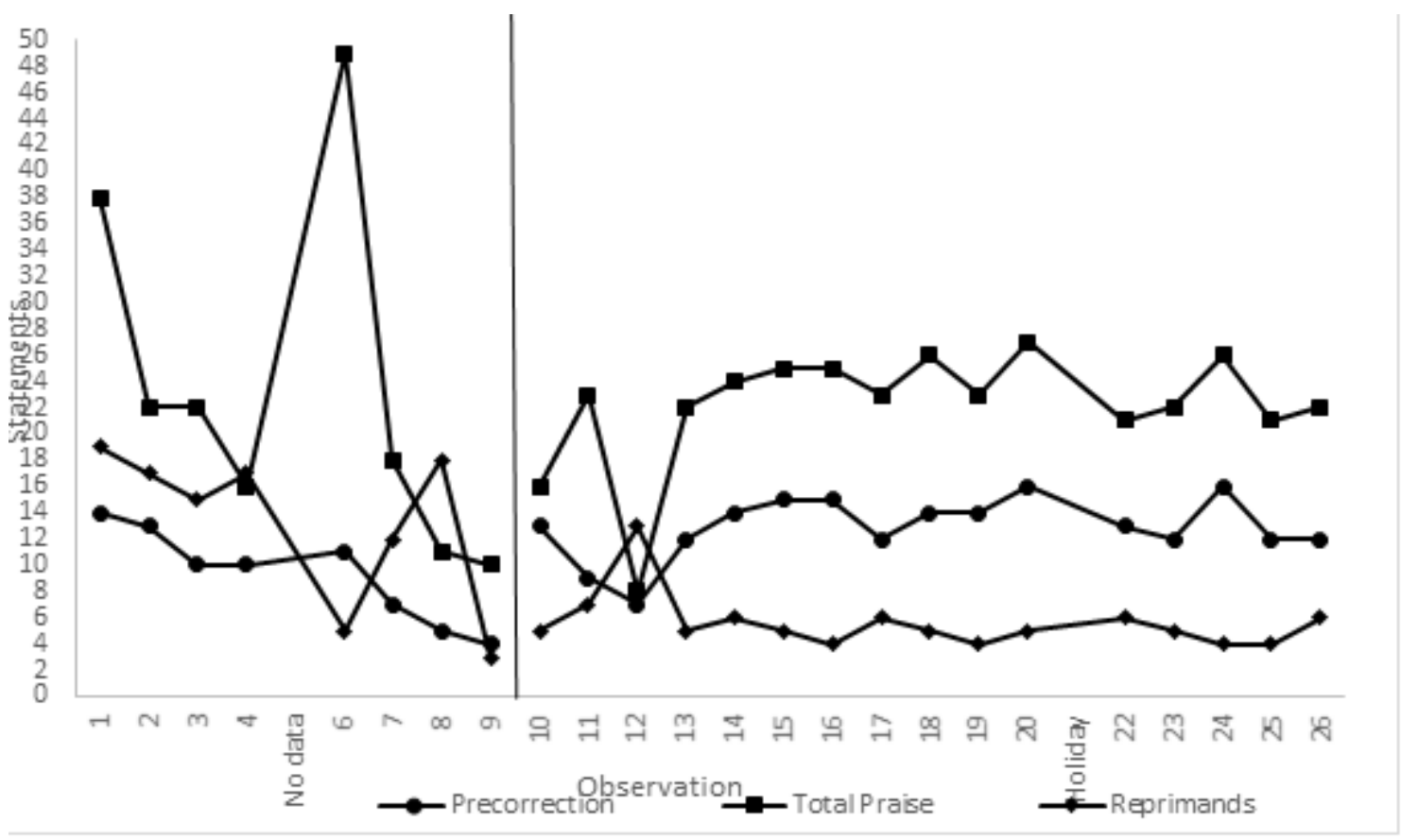

Figure 8 observation results for teacher and student 3 . 
consistent in her use of the statements, and was within just over 3 statements of the average for the remainder of the research.

During the baseline stage, Mrs. Sims was delivering high rates of praise to students, but had a downward trend (See Figure 8). Her use of praise peaked at fortynine statements, but had dropped to ten statements over the last two days of baseline data collection. This resulted in a wide range of baseline praise statements (from 10 to 49), ultimately averaging 23.25 praise statements per observation. The range of praise statements during baseline had two important outliers, on day 1 and day 6 Mrs. Sims delivered 38 and then 49 praise statements respectively. Without these two outliers, her mean praise statement delivery would have been 16.50. It is unclear from the data what caused such increases in praise statements on those days. During intervention, her mean use of praise decreased by 1.13 statements, to an average of 22.13 , a $5 \%$ decrease. However, use of praise statements was more stable, ranging between 21 and 27 for all but two of the intervention observations. If the two outlier data points were removed her use praise over the course of the research would have shown a $5 \%$ increase.

Mrs. Sims' use of reprimand statements was high in the early stages, delivering over fifteen reprimands on five of the nine baseline days. This resulted in an average of 13.25 reprimands per observation. This number dropped in the intervention stage by over 7.5 statements per observation, to an average of 5.63 reprimands per observation, which was a $58 \%$ reduction. She was consistent in this behavior change, with only one day above ten reprimands. 
During the baseline stage, her ratio of precorrections-to-reprimands was .70 precorrections per reprimand. Following the brief training, the ratio became 2.29 precorrections for each reprimand, a change of $228 \%$. While the mean usage of praise did decrease, her use of reprimands decreased even further. During the baseline stage, her ratio of praise-to-reprimands was 1.75 praise statements per reprimand. During the intervention stage, the ratio grew to 3.93 per reprimand, a $124 \%$ increase, which is more in line with research recommendations.

Each time Mrs. Sims would deliver precorrections, praise, or reprimands solely to the student of focus, it was recorded. As Figure 9 shows, the teacher did not precorrect the student specifically during the baseline stage. Then during the sixteen days of intervention, Mrs. Sims precorrected the target student an average of one time each observation. Mrs. Sims went from not precorrecting the focus student for nine days during the baseline stage to precorrecting him regularly during the intervention stage.

While she did not precorrect the focus student at all during baseline, she did frequently deliver reprimand statements to him, twice reprimanding him five times in twenty minutes and averaging 1.8 student specific reprimands per observation. Following the training, the use of reprimand statements to the focus student dropped, delivering a total of seventeen reprimands over the sixteen days of intervention, averaging 1.2 statements per observation. The use of praise statements to the focus student also increased by $218 \%$ from .44 praise statements per observation to 1.41 praise statements per observation. On average following the training Mrs. Sims added one 
student specific precorrection and one student specific praise statement per observation and reduced her reprimands to the focus student by more than one-third.

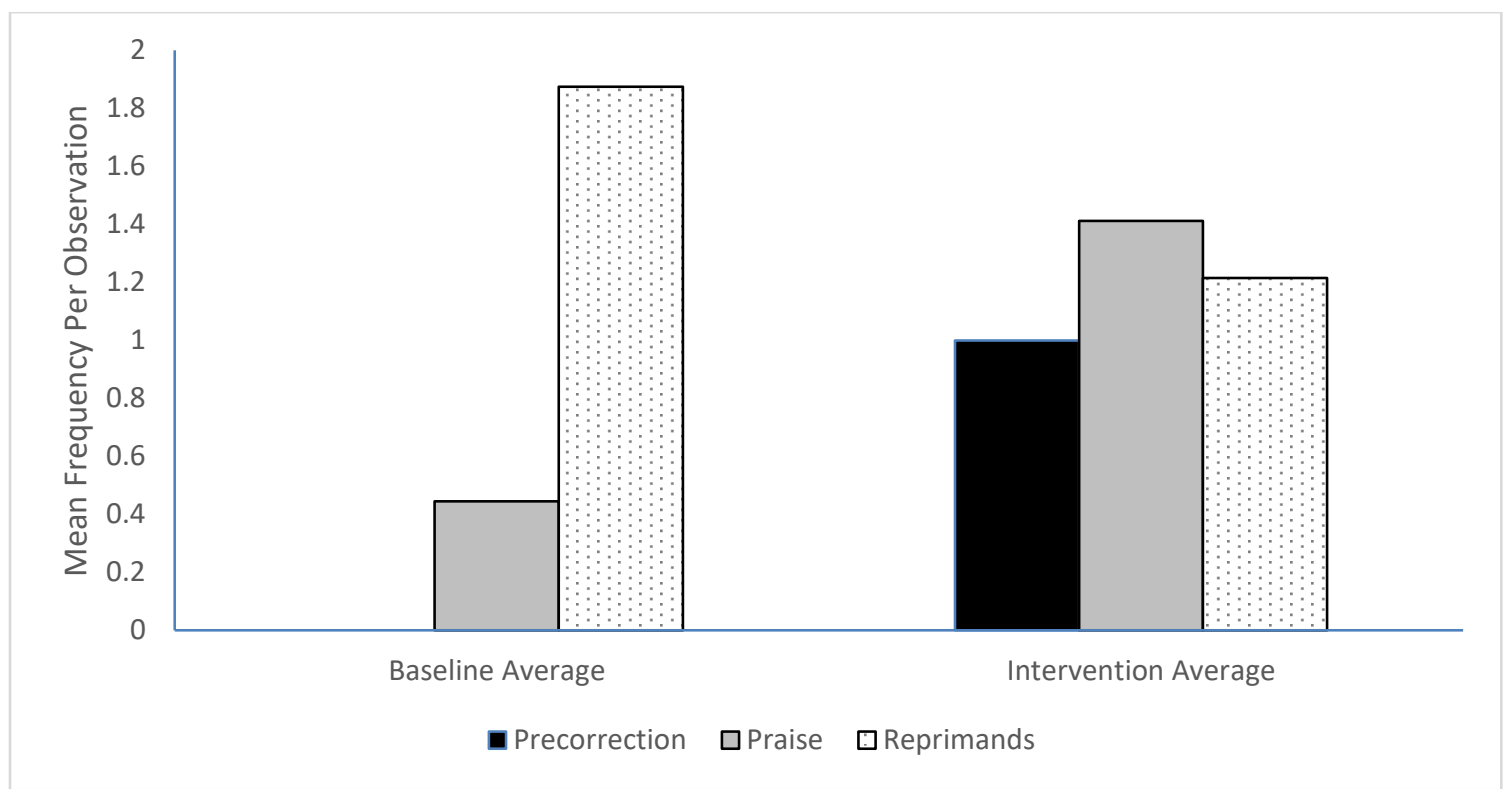

Figure 9 mean statements delivered by Mrs. Sims directly to the student of focus.

The on-task behavior of the focus student in Mrs. Sims' class was consistently low during the baseline stage. However, his on-task behavior increased throughout the course of this research. In the baseline stage, the focus student was on-task an average of $28 \%$ of every twenty minutes of observation, ranging from a low of $20 \%$ to a high of $36 \%$. Following the intervention, the student made consistent progress in his on-task behavior (see Figure 3), resulting in an average on-task rate of $65 \%$ of the observation, ranging from $32 \%$ to $78 \%$. This is an increase of 7 minutes and 24 seconds of on-task behavior per twenty minutes of observation. The student's rate of on-task behavior increased $137 \%$ from the baseline stage, his on-task behavior peaked at $78 \%$ of the 
observation, and four of the last five days of observation was on-task over $75 \%$ of the observation.

Teacher and student dyad 4. Mrs. Love taught third grade at a Title I elementary school. During the previous year, she had the most office discipline referrals in the school and classroom management was identified as a priority in her performance review. Mrs. Love was also beginning her second year as a teacher, after having added her teaching credential to a bachelor's degree, and identifies herself as multiethnic. Prior to beginning the research, her classroom was observed five times by the researcher. These focused on observing candidate students and gathering data about their on-task behavior. During these observations, it was noted Mrs. Love appeared to be struggling and was eager to receive additional support. Mrs. Love had difficulty guiding her class through transitions and her use of lengthy and highly personal reprimands was frequent. She reported her classroom management practices were not effective, and she was struggling to manage the curriculum demands amongst pervasive problem behavior across students. Despite these struggles, Mrs. Love seemed to be striving for a highly engaging teaching style that led to variable practices and activities from day to day.

In Mrs. Love's third grade class the focus student was an African American male, who was experiencing persistent problem behavior and had been referred to the administration as a student in need of additional support. Prior to beginning the research, the student was observed on four occasions and during those observations his level of ontask behavior did not exceed $23 \%$, with a low of $15 \%$. Following the observations, Mrs. Love and the researcher met to complete a brief Functional Assessment (March et al., 
2000). This assessment focused on the student's disruptive off-task behavior during whole-class instruction and transitions. When the class would transition to a new activity, the student would seek out peers, becoming slow to engage in the academic material and unable to sustain his focus when he did. The teacher concluded this behavior was largely driven by his need to get peer attention. However, she also felt his significant academic deficits were a factor causing him to avoid work.

Figure 10 summarizes Mrs. Love's use of precorrection, praise and reprimands over the course of this research. Mrs. Love averaged 3.33 general and specific precorrections per observation during the baseline stage. However, this average was aided by her teacher evaluation day (day 8), where she delivered twelve precorrections. Without this outlier, she averaged 2.25 precorrections per twenty minutes, and for these nine days the range was zero to four. After a lengthy intervention meeting and practicing praise and precorrection statements for just under ninety minutes, Mrs. Love made some dramatic changes to her teaching practices. Immediately following the intervention, her use of precorrections jumped to thirteen and remained above ten for all but one day. This resulted in a $256 \%$ increase, to an average of 11.87 precorrection statements per observation. As Figure 10 shows, her use of precorrections was stable, ranging from 9 to 16 over the intervention stage.

During the baseline stage, Mrs. Love was delivering 7.2 praise statements to students. The use of praise was low and variable ranging from 10 statements per observation to a low of 1 statement in twenty minutes. Following the intervention, Mrs. Love' use of praise statements increased to an average of 18.2 praise statements per 
observation. This was a $152 \%$ increase. Figure 10 shows the use of praise remained variable ranging from 13 to a high of 26 . However, over the final five days of observation Mrs. Love's use of praise was more stable, with all five days within three statements of her average.

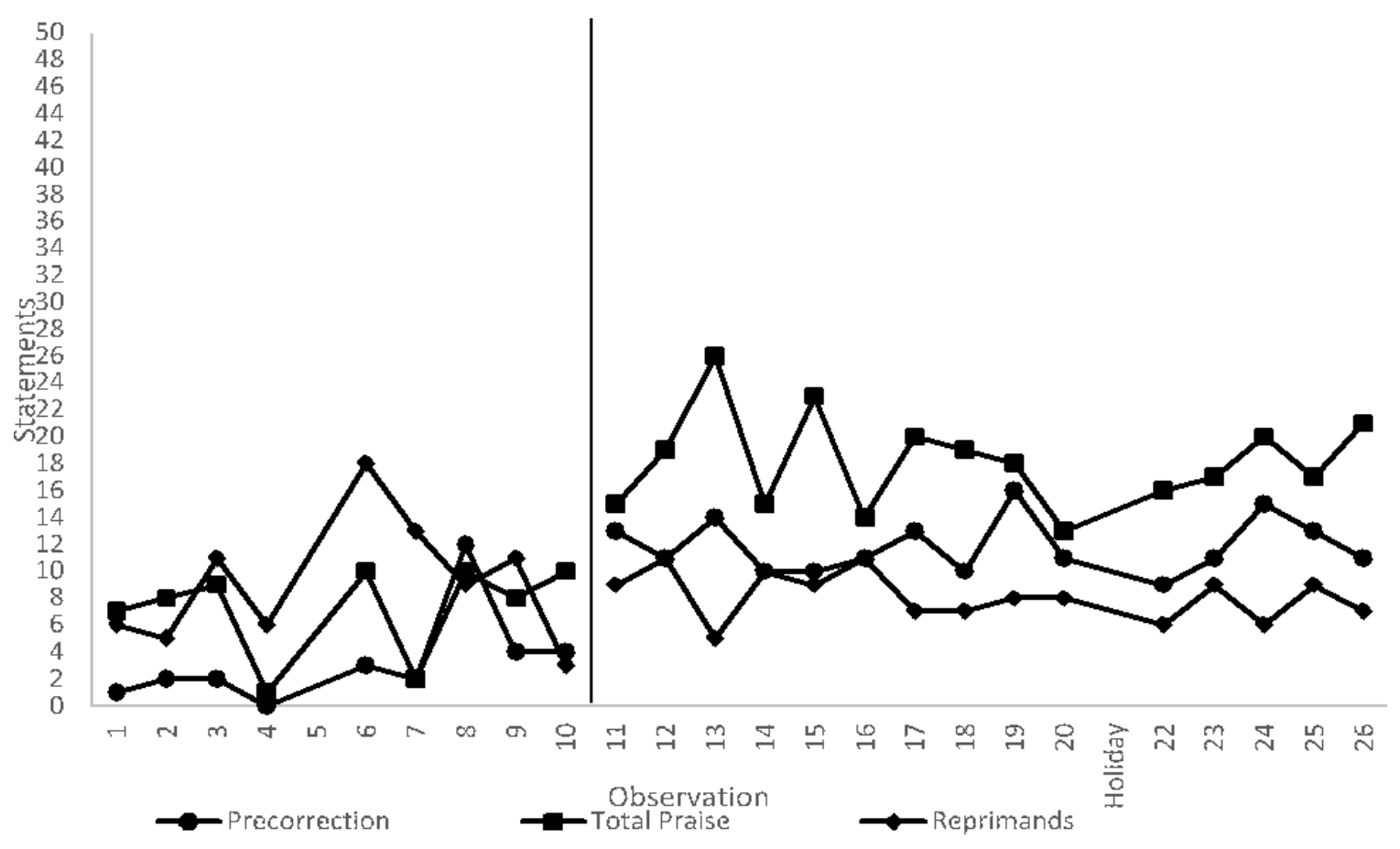

Figure 10 Observation results for teach and student 4

Mrs. Love's use of reprimand statements was high in the baseline stage and only dropped slightly during the intervention stage. During the baseline stage, Mrs. Love averaged 9.11 reprimands per twenty minutes of observation, and this decreased to 8.13 during the intervention stage. While the average only changed slightly, the use of reprimands was more stable. During the intervention stage, reprimands ranged from a low of five to a high of eleven. In four of the last five days, Mrs. Love's use of reprimands was slightly below her average. During the baseline stage, her ratio of precorrections-to-reprimands was .37 precorrections per reprimand, which meant that she 
was delivering nearly three reprimands for every precorrection. This shifted to 1.46 precorrections per reprimand, a change of just under $300 \%$. Similarly, her ratio of praiseto-reprimands shifted from .79 praise statements per reprimand to 2.24 , a $182 \%$ change in behavior.

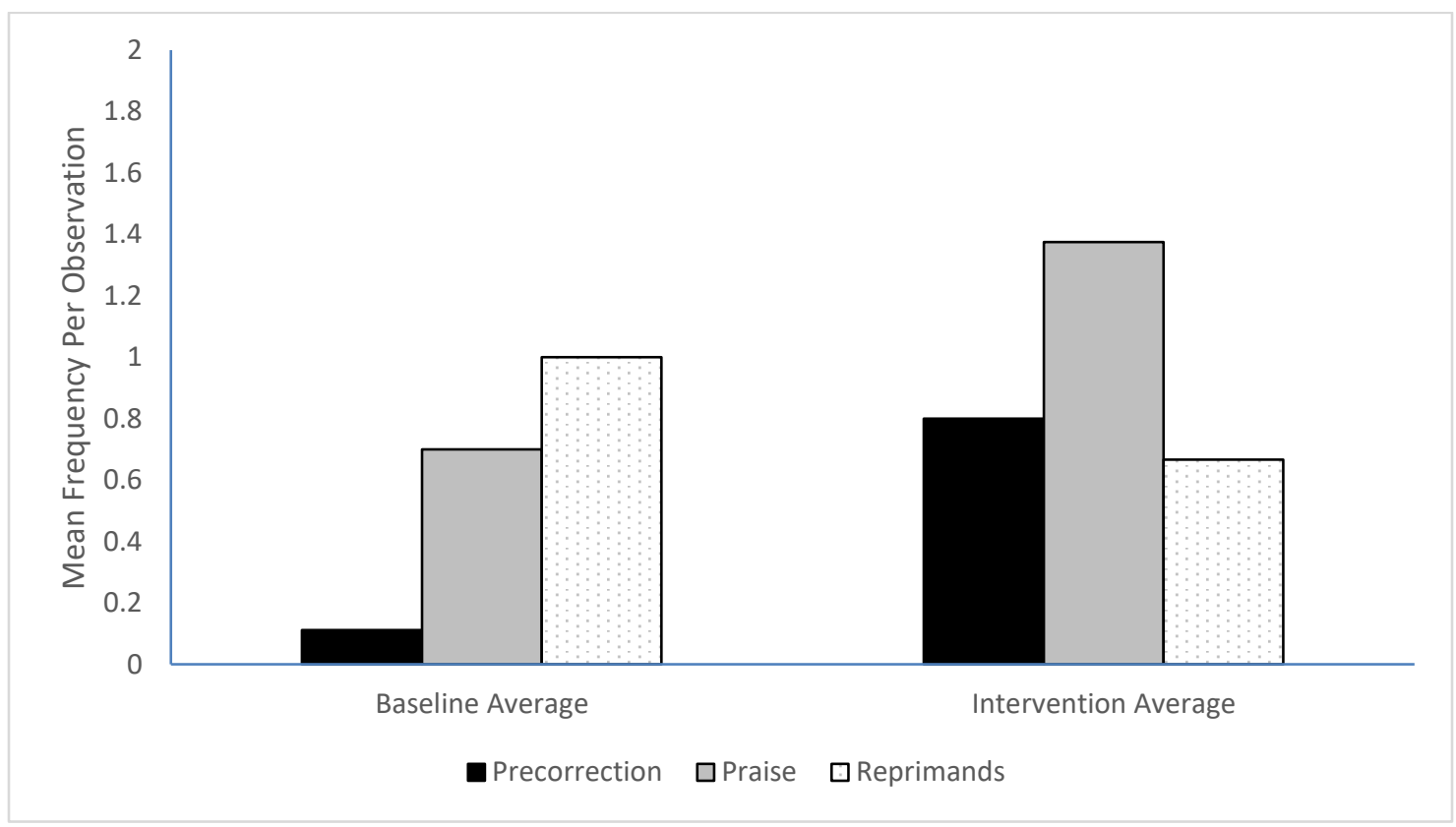

Figure 11 mean statements delivered by Mrs. Love directly to the student of focus.

Observational data was gathered about Mrs. Love's interactions directly to the student of focus. Figure 11 shows that Mrs. Love increased her positive interactions with the target student. In the baseline stage, she gave the student one student specific precorrection in ten days of observation. In the intervention stage, she was delivering an average of .8 student specific precorrections per observation. She also went from delivering less than one (.7) student specific praise statements per observation to averaging 1.38 student specific praise statements per observation. During the baseline 
stage Mrs. Love was reprimanding the focus student an average of once each observation, after the intervention this dropped by $1 / 3$ to .67 reprimands per observation.

The on-task behavior of the focus student in Mrs. Love's class was variable. Baseline on-task behavior ranged from $22 \%$ to $65 \%$ of the observations, which resulted in an average on-task behavior of 51\%. Following the intervention, the student made stable progress in his on-task behavior (see Figure 3), resulting in being on-task for an average of $77 \%$ of the observation. Overall, the student remained variable in his on-task behavior, ranging from a low of $43 \%$ and peaking at $92 \%$. This high of $92 \%$ occurred once over the final five days, the other four days he was within $2 \%$ of the mean, suggesting he may be stabilizing his on-task behavior. The student's rate of on-task behavior resulted in an overall $55 \%$ increase in on-task from the baseline stage. As a result of this increase, time on-task increased by 5 minutes and 15 seconds per observation.

Interobserver agreement (IOA). Interobserver agreement was established prior to beginning this research, two weeks prior to beginning data collection the data collectors and the researcher jointly observed classrooms similar to those of the research setting. In total, twelve twenty-minute observations were observed jointly by the two data collectors and the researcher to develop consistency and fluency with the data collection process. When the three parties exceeded $80 \%$ IOA for three consecutive observations, research was ready to begin.

Over the course of the research interobserver agreement data was gathered by the researcher for $20 \%$ of the sample. On average, the rate of interobserver agreement 
between the data collectors and the researcher was $96 \%$ for student on-task behavior, with a range of $89 \%$ to $100 \%$. The average IOA for precorrection was $92 \%$, with a range of $82 \%$ to $100 \%$. The IOA for general praise statements was $93 \%$, with a range of $86 \%$ to $100 \%$ and the IOA for reprimand statements averaged $93 \%$, with a range of $80 \%$ to $100 \%$. Over these four data categories the average IOA rate was $93 \%$, well above the predetermined benchmark of $80 \%$.

Social validity. The four teachers each completed a brief, seven-question Likert Scale survey at the conclusion of the research project. The survey was emailed to the teachers and returned within a week. A Likert scale was used to gather information from the teacher with $1=$ strongly disagree; 2 = disagree somewhat; $3=$ agree; $4=$ agree somewhat and $5=$ strongly agree. As Table 9 shows, the teachers strongly agreed that this intervention was teacher-friendly and effective, they will use it again in other settings, and they will recommend it with others. Two of the teachers "agreed somewhat" about the effectiveness of these interventions with challenging students and felt that it was successful overall. The average score for the seven questions was 4.8 out of a 5.0 possible, suggesting that the four teachers felt the intervention held a high degree of social validity.

Demographic data. The four teachers participating in this research had many similar demographic characteristics. Table 10 summarizes the background information gathered on each participating teacher. All four of the teachers identified themselves as females with Bachelor's degrees. One teacher identified herself as multiethnic, the other three as Caucasian. While most of the teachers were new to the profession Mrs. Brown 
Table 9

Social Validity Survey Results

\begin{tabular}{|c|c|c|c|c|c|}
\hline Question & $\begin{array}{l}\text { Fourth } \\
\text { Grade }\end{array}$ & $\begin{array}{l}\text { Fifth } \\
\text { Grade }\end{array}$ & $\begin{array}{l}\text { Second } \\
\text { Grade }\end{array}$ & $\begin{array}{l}\text { Third } \\
\text { Grade }\end{array}$ & Mean \\
\hline $\begin{array}{l}\text { Overall, I feel comfortable with the intervention and } \\
\text { consider it to be teacher-friendly (it did not take a } \\
\text { lot of time or require additional resources) and was } \\
\text { simple to implement. }\end{array}$ & 5 & 5 & 5 & 5 & 5 \\
\hline $\begin{array}{l}\text { The intervention proved to be an effective and } \\
\text { efficient method for reducing minor behavioral } \\
\text { problems }\end{array}$ & 5 & 4 & 5 & 5 & 4.75 \\
\hline I will continue to use the intervention. & 5 & 5 & 5 & 5 & 5 \\
\hline $\begin{array}{l}\text { I will recommend and share the intervention with } \\
\text { others. }\end{array}$ & 5 & 5 & 5 & 5 & 5 \\
\hline $\begin{array}{l}\text { I will use the intervention in additional/other } \\
\text { settings. }\end{array}$ & 5 & 5 & 5 & 5 & 5 \\
\hline $\begin{array}{l}\text { I feel this intervention was beneficial for my } \\
\text { students with challenging behavior. }\end{array}$ & 5 & 4 & 4 & 5 & 4.5 \\
\hline Overall, the intervention was successful. & 5 & 4 & 4 & 4 & 4.25 \\
\hline Average & 5.0 & 4.6 & 4.7 & 4.9 & 4.8 \\
\hline
\end{tabular}

had taught for 23 years. Mrs. Cook was in her third-year teaching, however it was her first year in public school, after spending the previous two at a private school. Finally, the teachers taught a range of grades across the elementary school continuum. All four teachers were working at Title 1 schools with diverse populations economically, racially and ethnically as well as linguistically. Mrs. Brown, the most experienced teacher in the research, rated the intervention with the highest social validity of the four participants. There were no other observed differences in how the teachers responded to the data collection or interventions over the course of the research. 
Table 10

Demographic Data of Participating Teachers

\begin{tabular}{lllll}
\hline & Mrs. Brown & Mrs. Cook & Mrs. Sims & Mrs. Love \\
\hline Race/Ethnicity & Caucasian & Caucasian & Caucasian & Multiethnic \\
Gender & Female & Female & Female & Female \\
Education & Bachelor's & Bachelor's & Bachelor's & Bachelor's \\
Years' experience & 23 & 3 & 2 & 2 \\
Grade Taught & 4 & 5 & 2 & 3 \\
\hline
\end{tabular}

\section{Interpretation of Findings}

The first research question was intended to understand if a brief individual teacher training on precorrection and praise would increase the use of these practices by elementary school teachers. The second question examined if changes in the use of these practices impacted the on-task behavior of the identified at-risk student in the class. The data shows that the four teachers in this study improved their use of precorrection, and three of the four increased their use of praise. Similarly, three of the teachers decreased their use of reprimands. In all four cases, the student's rate of on-task behavior increased. Also, the teachers rated the interventions as highly useful, simple, and effective, suggesting that this was a socially valid intervention.

Changes in teacher behaviors. Table 11 compares the baseline and intervention ratios of precorrection-to-reprimands and then the praise-to-reprimands for the four teachers. The ratios compare the mean use of the precorrection to the mean use of reprimands and then the mean use of praise to the mean use of reprimands. On average, the brief intervention and the subsequent changes in teacher behavior, resulted in an average increase in the ratio of precorrections to reprimands by $184 \%$. Three of the four teachers increased their ratio of precorrection-to-reprimands by at least 228\%. During the baseline stage teachers 1,3 and 4 were as or more likely to reprimand a student than 
as were to precorrect. Following the brief training these three teachers were over two times more likely to precorrect than reprimand.

Table 11

Teacher Precorrection-to-reprimand and Praise-to-reprimand Ratios

\begin{tabular}{lcccc} 
Teacher Precorrection-to-reprimand and Praise-to-reprimand Ratios & & \\
\hline & $\begin{array}{c}\text { Mrs. } \\
\text { Brown }\end{array}$ & $\begin{array}{c}\text { Mrs. } \\
\text { Cook }\end{array}$ & $\begin{array}{c}\text { Mrs. } \\
\text { Sims }\end{array}$ & $\begin{array}{c}\text { Mrs. } \\
\text { Love }\end{array}$ \\
\hline Baseline Precorrection-to-reprimand Ratio & 1.00 & 18.00 & 0.70 & 0.37 \\
Intervention Precorrection Reprimand Ratio & 3.53 & 10.19 & 2.29 & 1.46 \\
Percent Change & & & & $299 \%$ \\
Baseline Praise-to-reprimand Ratio & $253 \%$ & $-43 \%$ & $228 \%$ & 0.79 \\
Intervention Praise-to-reprimand Ratio & 2.37 & 44.04 & 1.75 & 2.24 \\
Percent Change & 4.60 & 13.50 & 3.93 & $182 \%$ \\
\hline
\end{tabular}

Additionally, on average, changes in the use of praise and reprimands resulted in an $83 \%$ increase in the average praise-to-reprimand ratio. Teachers 1,3 and 4 increased their raise of praise-to-reprimands ranging from $94 \%$ to $182 \%$. Mrs. Love made especially strong progress, at the onset of research Mrs. Love was more likely to reprimand than to praise a student. Following the intervention, she was 2.24 times more likely to praise than reprimand. Overall, similar to the precorrection-to-reprimand ratios, these averages were decreased by Mrs. Cook, who was delivering a reprimand only every other day during the baseline stage. Yet, in spite of these increases, her ratios remained well above the other teachers throughout the intervention stages.

Covington-Smith et al. (2011) experienced similar changes in teacher behavior due to their training. The three teachers in their research were described as delivering 
more reprimands than precorrections prior to being trained in precorrection and praise. Then, following their brief training, precorrection increased and use of reprimands was eliminated by all three teachers. The same was true for their use of praise; it was used less than reprimands during baseline, then increased following the training, while reprimands were eliminated.

Changes in student behavior. All four target students experienced improvement in their on-task behavior during observations (see Figure 3). The range of improved ontask behavior for the four students ranged from $38 \%$ to a high of $137 \%$. On average, the four students that were at-risk of needing more intensive behavior, supports due to low on-task behavior increased their on-task behavior by $83 \%$. This increase gave these students the opportunity to access an additional seven minutes and forty-eight seconds of learning per twenty minutes, on average. The student in the third dyad was in the most need of support, following this brief intervention, his on-task behavior improved by over $114 \%$ and as a result site administration no longer considered him a student in need of additional support.

FACTS and student behavior. The researcher met with each teacher prior to beginning research. During this meeting, they completed a Functional Assessment of Checklist for Teachers and Staff (FACTS) (March et al., 2000). The purpose of this assessment was to understand the function of the student of focus' off-task behavior, in order to inform the teacher training and to explore potential relationships between the function of the child's off-task behavior and any changes in their on-task behavior. Table 
12 summarizes the perceived function of each student's off-task behavior and resulting changes in student behavior following intervention. Per the interview results, three of the students appeared to be seeking peer attention and the fourth was seeking to avoid peer attention. The three students seeking peer attention had the largest gains in on-task behavior following the intervention. However, the student avoiding peer attention also increased his on-task behavior by $37 \%$. Much like prompting, precorrection is designed to amplify signals of the availability of reinforcement, which may explain why it contributed to the improved behavior of all four students (Simonsen et al., 2010). However, it may be worth exploring further if effectiveness varies based on function of student behavior.

Table 12

Comparison of FACTS Results with Changes in Student Behavior

\begin{tabular}{lll}
\hline Student & $\begin{array}{l}\text { Perceived Function of } \\
\text { Off-Task Behavior }\end{array}$ & Change in Student On-Task Behavior \\
\hline Student 1 & Gain peer attention & Increased $47 \%$ \\
Student 2 & Avoid peer attention & Increased 37\% \\
Student 3 & Gain peer attention & Increased $137 \%$ \\
Student 4 & Gain peer attention & Increased 55\% \\
\hline
\end{tabular}

\section{Limitations of Study}

Over the course of this research, teacher and student behaviors were influenced by many factors. For example, one of the teachers was having significant personal health problems, one of the students got glasses, and a third was experiencing intense changes in his home life. Each of these--and likely others, that were unknown to this researcher-impacted the behaviors of research participants. It is worth noting that despite these changes, the increased use of precorrection and praise seemed to give the teachers new skills that they could effectively and efficiently use to improve student behavior. 
When evaluating this study, there are several additional limitations that should be kept in mind. This study only included elementary general education teachers, and the findings may not generalize to other teachers or grade levels. In addition, the sample size of this research was small and there was variation in the how the intervention changed teacher behaviors and subsequent student behaviors. This research focused on students atrisk, due to off-task behavior during teacher-directed academic instruction, so the results may not generalize to other settings or students with different behavior profiles. Also, there was no notation of the quality or intensity of each statement. For example, one of the teachers would deliver highly personal, lengthy reprimands reminding the student in detail all the previous errors they had made. However, this was recorded as a single reprimand. As a result of these limitations, no conclusions can be made about the generalizability of the results across teachers, students, or settings.

In the reporting of this data use of general and specific praise statements were combined. This was done because the focus of this research was to get a sense of the impact of a brief training had on teacher's use of these skills more than to differentiate the value of general or specific praise. Additionally, this allowed findings to remain consistent with the reporting methods utilized in prior precorrection research. Finally, the definition of on-task that was used in this research is likely less specific than may be found in other research. However, the definition used here was consistent with the work of Covington-Smith et al. (2011).

Teachers' use of precorrection, praise, and reprimands all changed over the course of the intervention phase. Making it impossible to report which affected student behavior 
the most. Which of these changes, or to what degree each change impacted student ontask behavior, cannot be determined. For example, distinguishing whether the second grader in Mrs. Sims' class made large gains in his on-task behavior due to the reduction in reprimands, the increased praise or the more frequent precorrections was not the intent of this research. For purposes of this research the different strategies (i.e. praise, precorrection) were delivered as a package of interventions that interact, consistent with the precorrection process outlined by Colvin et al. (1993). Also, there are no agreedupon standards for the optimal rates of precorrection or praise across various settings, student characteristics, and types of instruction. This limits the ability to analyze the optimal rates of these practices. 


\section{Chapter 5: Discussion}

\section{Introduction}

As students continue to carry the weight of complex social issues with them to school, the need for evidence-based strategies to prevent and address the academic and behavior problems that will often ensue grows (Baker, 2005; Harrison \& Vannest, 2012). Fortunately, the efficacy of many behavior supports is well established (Carr et al., 2002; Horner et al., 2000). As understanding of the value of positive behavior support grows, a challenge will be to find the best possible avenues to increase the use of research based practices in busy general education classrooms (Cook \& Odom, 2013; Greenwood \& Abbott, 2001). This research focused on how to increase the use of two research based practices, precorrection and praise, by general education elementary teachers in need of additional support preventing student problem behavior.

The problem of practice targeted in this research was a common overreliance on reactive, punitive responses to student misbehavior. Teachers prefer prevention-based supports, and generally view supports based on positive reinforcement as more acceptable than punishment-based supports (Jones \& Lungaro, 2000). Yet, teachers often resort to punitive discipline. Many teachers initially rely on consequences and universal practices, such as proximity, ignoring or redirection, to address problem behavior (Smart \& Igo, 2010; Valenti, 2011). If problem behavior persists, many teachers quickly lose confidence and resort to retreatism or discipline measures (Baker, 2005; Ratcliff et al., 2011). 
There is little evidence that punishment based practices, such as suspension, improve student behavior and they often place students at greater risk (Couvillon, 2006; Skiba, 2002; Skiba \& Peterson, 2000). In practice, it is common for teachers experience a gap between a preference for prevention and a reliance on ineffective punishment. Additionally, many times there is an inverse relationship between teachers' perceived effectiveness of a practice and the labor intensity required to implement a particular practice (Boardman, Argüelles, Vaughn, Hughes, \& Klingner, 2005; Kaff et al., 2007). The result is that many commonly recommended practices aren't used or trusted by educators due to their labor intensity (Kaff et al., 2007).

The work of Ratcliff et al. (2011) highlights how this reliance on reactive strategies can undermine learning. These researchers found that teachers were seventeen times more likely to ignore problem behavior, make neutral comments, or reprimand, than they were to praise student behavior. The authors concluded all these responses (i.e. neutral, ignoring or reprimanding problem behavior after the behavior has occurred) undermine student engagement, because the teacher was having to stop instruction to respond to problem behavior, yet often the behavior didn't cease (Ratcliff et al., 2011). They found, if students are behaving appropriately there tends to be a lack of positive reinforcement and when students engage in problem behavior the common teacher reactions are often inversely related to students' time on-task (Emmer \& Stough, 2001; Ratcliff, Jones, Costner, Savage-Davis \& Hunt, 2010; Stuhlman \& Pianta, 2009). Ratcliff et al. (2011) concluded, "Teachers with fewer management problems did not wait for misbehavior to occur. They created an environment that increased positive student 
behavior and decreased student misbehavior by using instructional strategies that encouraged on task behavior" ( p. 46).

Consistent with these conclusions, the goal of this intervention was to empower teachers so they do not get caught waiting for misbehavior to occur. Instead, to identify when it is likely to occur, to define what they would like to see instead, to teach what they would like to see, to provide an antecedent precorrection and to then recognize when students display the desired behavior. Precorrection is meant to change the instructor's role in the behavior sequence from reacting to the behavior, to prompting desired behavior (Colvin et al., 1993). If teachers can learn to incorporate precorrection into their instruction, they may be better able to prevent problem behavior in a way that better aligns with their beliefs as educators and behavior research (De Pry \& Sugai, 2002; Simonsen et al., 2010).

In order to explore the impact of training teachers to incorporate precorrection and praise into their practices this research systematically replicated research published by Covington-Smith, et al. (2011). These researchers demonstrated how a brief, individual teacher training, with ongoing feedback, on precorrection and praise impacted the instructional practices of Head Start teachers. The current research replicated the efforts of Covington-Smith et al. (2011) by exploring how a similar, brief, individual training on precorrection impacted the instructional practices of elementary teachers in Title I schools and the on-task behavior of targeted students. 


\section{Synthesis of Findings}

Findings from this study indicate that elementary school teachers can learn to change their behavior, from reactive reprimand practices to precorrection and praise. Across the four teachers the mean increase in the use of precorrection was $107 \%$. The range of change in precorrection was from $39 \%$ to $256 \%$. The use of praise by the four teachers increased by $25 \%$ following the training, the changes in use of praise ranged from $-5 \%$ to $152 \%$. Following the training, there was also a marked decrease in the use of reprimands across the teachers. Decreases in the use of reprimands averaged a $30 \%$ reduction across the four teachers. These findings align with the work of CovingtonSmith et al. (2011) and extend the research to elementary settings.

After the teachers began to use these practices, all four students who had been considered at-risk of falling behind academically due to their off-task behavior, improved in their on-task behavior by an average of over $80 \%$. This increase allowed these struggling students the opportunity to access more than an additional seven minutes of learning per twenty minutes of observation. This increase in on-task behavior occurred during math instruction, often one of the most demanding times of the school day. It is also worth noting the diversity of students that these practices impacted. All four of the participants in this research were receiving free or reduced lunch and were enrolled at Title I elementary schools. The four students were from second, third, fourth and fifth grades. Two of the students were African-American males, another was a Caucasian male, and the fourth was a Hispanic female who was also an English language learner. Combined, these students represent a range of cultures, ages, academic skills, and even 
functions of their off-task behavior, yet the intervention appeared to improve the behavior of each.

Data from this study indicates that many of the benefits that Colvin et al. (1993) suggested can occur when teachers adopt a prevention focus did occur over the course of this research (see Table 13). As a result of the training the teachers made a shift from reactive correction of inappropriate behavior to proactive precorrection focused on positive behavior. Then, on-task behavior by students with low rates of on-task behavior increased. Which created additional opportunities for teachers to praise their students.

Covington-Smith et al. (2011) had similar findings in their research, they concluded:

It is also important to note that the changes in teacher behavior after the intervention are much more reflective of positive teacher-child relationships, which is a foundational support for children's development and learning. Specifically, as teachers began to use precorrective statements and behaviorspecific praise, they concurrently reduced their use of reprimand statements. This change is critical to support the development of prosocial skills in the context of positive teacher-student relationships. (p. 141)

Table 13

Comparison between Correction and Precorrection Procedures

\begin{tabular}{ll}
\hline Correction & Precorrection \\
\hline Reactive & Proactive \\
Consequences are Manipulated & Antecedents are manipulated \\
May lead to negative teacher student interactions & May lead to positive teacher student interactions \\
Focuses on inappropriate behavior & \\
May lead to escalating behavior & Focuses on appropriate behavior \\
Focuses on immediate events & May lead to appropriate behavior \\
\hline
\end{tabular}

Taken from: Colvin, G., Sugai, G., \& Patching, B. (1993). Precorrection: An instructional approach for managing predictable problem behaviors. Intervention in School and Clinic, 28, 143-150. 
As Colvin et al (1993) predicted, the shift to precorrection appeared to create the pathway for improved student behavior and more positive student-teacher interactions. Incorporating these two strategies, precorrection and praise, can create a virtuous cycle of positive behaviors. When teachers incorporated precorrection positive behaviors did increase (see Table 13). As these positive behaviors increased teachers had more opportunities to praise students, which increased the likelihood students will continue to do more positive behaviors in the future. In the case of this research, as in CovingtonSmith et al. (2011), the brief training was able to create a shift in the student-teacher relationship from reaction and correction to prevention and praise with a combined seven students with low rates of on-task behavior.

\section{Larger Context}

Simonsen et al., (2010) based their prompting research on the premise that there is a rising number of students engaged in problem behavior in general education classrooms. Yet the skills, desire and confidence of many teachers regarding problem behavior is limited. Due to this growing demand and limited supply of supports the authors felt it is important for research to identify simple practices that require minimal training and effort. These realities caused the authors to conclude precorrection is an ideal strategy for managing student behavior in a general education classroom. Improving the use of research based practices that can be utilized by general education teachers to prevent the rising tide of problem behavior is the larger context of this research. 
Replication findings. This research replicated the work of Covington-Smith et al. (2011), to further explore the impact of a brief training with regular feedback on the instructional practices of elementary teachers. Both studies found strong gains in the use of precorrection and praise by teachers, and in the on-task behavior of the focus student. However, the changes by the Head Start teachers in Covington-Smith et al.'s (2011) research were of a higher percentage. Additionally, all the students in each study made noticeable improvements in their on-task behavior and all seven teachers rated the supports highly in the social validity survey.

The teachers in Covington-Smith et al.'s (2011) work were delivering very low rates of precorrection and praise prior to their training. During the baseline stage of Covington-Smith's research the participating Head Start teachers use of precorrection and praise was almost nonexistent. Combined, the teachers delivered an average of 1.10 precorrections per twenty minutes following the training. Similarly, their use of praise per twenty minutes averaged 1.46 general or specific praise statements following the training. In comparison, the teachers in the current study had precorrection rates ranging from 3.3 to 10.29 and praise rates from 7 to 29 during baseline data collection. The minimal initial usage of precorrection and praise contributed to the dramatic growth the Head Start teachers made when presented as a percentage change. These differences in baseline and outcome precorrection and praise also suggest that the different levels of training received by Head Start and elementary school teachers typically receive likely contributed to the different rates of change. It is likely through a credentialing program and student teaching experiences the elementary teachers in the current study had 
multiple exposures to precorrection and praise. This may not of have been the case with the Head Start teachers.

Also, Covington-Smith et al. (2011) identified candidate teachers using prior observational data that was unavailable to this researcher. In their work, researchers identified candidate teachers by reviewing previous observational data. Rather than relying on discipline data from the previous year and administrative interviews the researchers could rely on direct observation of teacher behavior. The different selection criteria used to identify potential teachers may have also impacted results.

The current research was in elementary schools during math instruction compared to Head Start classrooms during opening circle. It's possible the more rigorous academic setting and content impacted the changes in behavior. Additionally, the researcher was not able to obtain information about the precorrection and praise training materials used by Covington-Smith et al. (2011) and thus this aspect of their training could not be replicated. Any differences in the training delivered would likely impact subsequent results. However, utilizing two different training models suggest there may be multiple training models that can be used to increase the use of precorrection and praise.

When these two research projects are combined some interesting patterns and differences emerge, that are worth examining more closely. While the rates of change differed, the seven teachers participating in the research made noticeable improvements in their instructional practices. These changes resulted in improved on-task behavior in all seven participating students. Similarly, all seven teachers rated the support as socially valid and plan to continue to use it in the future. When these two research projects are 
combined with the larger precorrection research base there is consistent evidence that new and less trained educators can incorporate precorrection and praise into their instructional practices in a variety of situations to improve student behavior with minimal training and feedback.

Precorrection and prevention. Covington-Smith et al. (2011) and the current research support the idea that when teachers shift from corrections to precorrections, the desired behavior of target student(s) increases, which creates more opportunities for meaningful praise from the teacher. Additionally, both projects found a marked decrease in the use of reprimands. The two teachers in this research project that made the largest changes in their behavior were delivering between 1.25 and 3 reprimands for every precorrection, prior to the training. Following the training, the two teachers were delivering between 1.46 and 2.29 precorrections for every reprimand. The teachers in Covington-Smith et al.'s (2011) work were relying, almost exclusively, on reprimands prior to the training. Yet following the training no reprimands were observed. Teachers in both studies were able to change their practices from a reactive focus on misbehavior to a proactive focus on desired behavior.

The teachers in this research were identified as needing additional support in classroom management and as they went through the precorrection planning process having them operationalize their desired behaviors seemed to clarify aspects of their environment and routines that may have been problematic. The process of creating precorrection scripts had the teachers analyze the routine, when and where the problem behavior was most likely to occur. Then, they worked to define the students' desired 
behavior, their classroom expectations and their routines in observable and measurable terms. This process seemed to help these teachers align their own pedagogy outside of the research setting with evidence-based classroom management principles (Morrison, 1979; Simonsen et al., 2008).

Teacher training implications. As Stormont et al. (2007) explained precorrection and praise are not instructional strategies that require extensive professional development time. This research, like the work of Covington-Smith et al (2011), demonstrate that even struggling teachers can apply precorrection and praise practices after a single brief training. While the model used in this research lasted up to ninety minutes, others had success in, as little as, thirty minutes (Colvin et al. 1997; De Pry \& Sugai, 2002). However, when researching evidence-based classroom management practices, Simonsen, et al. (2008) touched on the large research to practice gap when it comes to classroom management practices. The authors concluded:

We must increase our systematic study and understanding of factors that affect adoption of these practices (e.g., educator skill fluency, school/community demographics, administrator commitment). Clearly, giving educators simple access and exposure to these practices through readings, lectures, and one-time professional development events are unlikely to change existing practice. It may be as or more important to consider what organizational supports are needed to maximize the likelihood that classroom management practices will be (a) given priority for adoption, (b) adapted to be contextually and culturally relevant, and (c) implemented with fidelity and durability. (p. 370)

Just as with students, teachers will require practice, feedback, and opportunities for ongoing coaching in order to learn a new behavior, making, the daily feedback of teacher behavior incorporated into this training model especially important. This served 
to provide teachers with feedback, to connect changes in the student behavior with their actions, and served as a reminder of the agreed upon practices. This may explain why, shortly after entering the intervention stage, two of the four teachers mentioned the impact of the daily feedback on their behavior as being helpful.

In similar research, Simonsen et al. (2010) staggered the implementation of the feedback to teachers following a brief training on prompting, opportunities to respond (OTR), and specific praise. While the brief training itself did have an impact, the changes in teacher behavior made much larger gains once researchers began delivering regular feedback to teachers. For example, the training by itself increased the use of prompting from zero prompts per observation, to an average of 1.2 prompts. Once feedback began to be delivered, the rate of prompting shot up another $353 \%$ to 5.43 prompts. In their research, the use of OTR actually decreased by $22 \%$, following the training. However, once feedback was incorporated, the use of OTR doubled. Similarly, the training increased the average use of specific praise by $55 \%$, then feedback increased its use by another $200 \%$. Combined, the inclusion of regular feedback increased the use of the trained skills by an average of $218 \%$ more than the benefits seen from simply training the teachers.

The findings from Simonsen et al. (2010) highlight why regular feedback is an important component to the acquisition of even relatively simple, low labor intensity supports. As Covington-Smith et al. (2011) explain:

For professional development to be effective, three critical variables should be highlighted (Guskey, 2000; Lewis, 2001). First, change is a gradual process for teachers. Second, teachers need to receive regular feedback on student outcomes. Third, continued support and follow-up are necessary after initial training. Once 
the skills are identified that reflect best practices, a clear strategy for systematic and ongoing support should be developed. (p. 142)

This may explain why the researchers included the feedback component in the design of their training with Head Start teachers. In the case of this research, the inclusion of regular feedback and the opportunity for questions was an important factor. Two of the teachers commented that the regular feedback emails were helpful reminders.

Additionally, the daily emails allowed another teacher, Mrs. Cooks to regularly ask clarifying questions.

Simonsen, Fairbanks, Briesch, Myers and Sugai (2008) encouraged researchers to identify the most effective strategies for transferring research into practice to ensure that identified supports are research based, contextually appropriate, implemented with fidelity over time, monitored and enhanced. Future research may compare the impact of a brief training with and without regular feedback or different feedback modalities, in order to understand the value of ongoing support and most effective ways to deliver this support with the limited resources typically available.

Social validity. As Rodriguez, Loman and Horner (2009) explained, despite common concerns regarding student behavior, many educators have questioned the extent to which behavior supports can be implemented with the fidelity needed to elicit meaningful changes in student behavior. Due to these concerns researchers have increasingly emphasized the importance of identifying socially valid behavior support practices. This research surveyed participating teachers using a survey that had been 
used by Stormont et al. (2007) and Covington-Smith et al. (2011). Combining the results of the six teachers in their research with the current research, a clear pattern emerges.

Table 14 summarizes the results of these ten teachers. Combined, all ten teachers were comfortable with the intervention, considered it teacher friendly, and plan to continue to use it in the future. Overall, of the seven questions measuring social validity, the average score was 4.87 out of 5.0 possible. No teacher scored any of the seven questions lower than a four out of five. Combined ten general education teachers have identified precorrection as a socially valid behavior support.

Table 14

Social Validity Survey Results

\begin{tabular}{|c|c|c|c|}
\hline Question & $\begin{array}{c}\text { Current } \\
\text { Research (4) }\end{array}$ & $\begin{array}{l}\text { Covington-Smith } \\
\text { et al. (2011) (3) }\end{array}$ & $\begin{array}{l}\text { Stormont et } \\
\text { al. }(2007)(3)\end{array}$ \\
\hline $\begin{array}{l}\text { Overall, I feel comfortable with the } \\
\text { intervention and consider it to be teacher- } \\
\text { friendly (it did not take a lot of time or require } \\
\text { additional resources) and was simple to } \\
\text { implement? }\end{array}$ & 5.00 & 5.00 & 5.00 \\
\hline $\begin{array}{l}\text { The intervention proved to be an effective and } \\
\text { efficient method for reducing minor } \\
\text { behavioral problems }\end{array}$ & 4.75 & 5.00 & 4.67 \\
\hline I will continue to use the intervention? & 5.00 & 5.00 & 5.00 \\
\hline $\begin{array}{l}\text { I will recommend and share the intervention } \\
\text { with others? }\end{array}$ & 5.00 & 4.67 & 5.00 \\
\hline $\begin{array}{l}\text { I will use the intervention in additional/other } \\
\text { settings? }\end{array}$ & 5.00 & 5.00 & 4.67 \\
\hline $\begin{array}{l}\text { I feel this intervention was beneficial for my } \\
\text { students with challenging behavior? }\end{array}$ & 4.50 & 5.00 & 5.00 \\
\hline Overall, the intervention was successful? & 4.25 & 5.00 & 5.00 \\
\hline Average & 4.79 & 4.95 & 4.90 \\
\hline
\end{tabular}




\section{Research Context}

Since Colvin et al. (1993) explained how shifting from corrections to precorrections can be an effective strategy to prevent problem behavior, the value of precorrection has been explored by a variety of researchers. The current research builds on this base of published research, which is summarized in Table 15. These eleven articles document the use of precorrection across settings, participants, and more. The student participants in these studies ranged in age from 3 to 19 years old, and included general education students with high rates of problem behavior, Head Start students, students with severe Emotional Disturbance, Learning Disabilities, and severe physical disabilities. The first four articles listed on Table 15 targeted students with intense problem behavior. The next three articles appeared to involve students that might be considered at-risk or needing additional support due to problem behavior. Finally, the final four articles are based on research that applied precorrection to school-wide settings, such as an entire class or entire school during recess.

Table 15

Summary of Published Research on Precorrection

\begin{tabular}{|c|c|c|c|c|c|}
\hline Source & Setting & $\begin{array}{l}\text { Group } \\
\text { size }\end{array}$ & Participants & $\begin{array}{l}\text { Independent } \\
\text { Variable }\end{array}$ & $\begin{array}{l}\text { Dependen } \\
\text { t Variable }\end{array}$ \\
\hline $\begin{array}{l}\text { Crockett \& } \\
\text { Hegelian, } \\
2006\end{array}$ & Clinic office & 1 to 1 & $\begin{array}{l}119 \text { year old with } \\
\text { multiple physical } \\
\text { disabilities }\end{array}$ & $\begin{array}{l}3 \text { step Vs. } 1 \\
\text { Step prompts }\end{array}$ & $\begin{array}{l}\text { Self- } \\
\text { injurious } \\
\text { behavior } \\
\text { and tasks } \\
\text { complete } \\
\text { d }\end{array}$ \\
\hline $\begin{array}{l}\text { Simonsen, } \\
\text { Myers \& } \\
\text { DeLuca, } \\
2010\end{array}$ & $\begin{array}{c}\text { Special Day } \\
\text { Class }\end{array}$ & Class & $\begin{array}{c}3 \text { classes, } 15 \text { students } \\
11 \text { to } 18 \text { with } \\
\text { moderate to severe } \\
\text { emotional } \\
\text { disturbances }\end{array}$ & $\begin{array}{l}\text { Training } \\
\text { teachers to } \\
\text { use prompts, } \\
\text { OTR \& } \\
\text { specific praise }\end{array}$ & $\begin{array}{l}\text { Teacher } \\
\text { implemen } \\
\text { tation }\end{array}$ \\
\hline
\end{tabular}




\begin{tabular}{|c|c|c|c|c|c|}
\hline Gena, 2006 & $\begin{array}{l}\text { Pre-k class } \\
\text { during semi } \\
\text { or } \\
\text { unstructured } \\
\text { play time }\end{array}$ & 12 & $\begin{array}{c}\text { Four } 3 \text { and } 4 \text { year } \\
\text { olds with Autism and } \\
\text { behavior difficulties, } \\
\text { excluded from } \\
\text { several settings due } \\
\text { to behavior }\end{array}$ & Prompting & $\begin{array}{l}\text { Initiations } \\
\text { toward } \\
\text { peers }\end{array}$ \\
\hline $\begin{array}{l}\text { Faul, } \\
\text { Stepensky, } \\
\text { \& Simonsen, } \\
2012\end{array}$ & $\begin{array}{c}\text { Urban } \\
\text { general } \\
\text { education } \\
\text { Classroom }\end{array}$ & $\begin{array}{l}\text { Whole } \\
\text { Class }\end{array}$ & $\begin{array}{l}2 \text { Middle Schoolers } \\
\text { with high levels of } \\
\text { off task behavior and } \\
\text { didn't respond to tier } \\
2\end{array}$ & $\begin{array}{l}\text { Antecedent } \\
\text { Prompt }\end{array}$ & $\begin{array}{l}\text { On and } \\
\text { off task } \\
\text { behavior }\end{array}$ \\
\hline $\begin{array}{l}\text { Flood, } \\
\text { Wilder, } \\
\text { Flood \& } \\
\text { Masuda, } \\
2002\end{array}$ & $\begin{array}{l}\text { Simulated } \\
\text { classroom }\end{array}$ & Class & $\begin{array}{c}310 \text { year olds with } \\
\text { ADHD and off task } \\
\text { behavior }\end{array}$ & $\begin{array}{l}\text { Differential } \\
\text { peer } \\
\text { reinforcement }\end{array}$ & $\begin{array}{l}\text { Off task } \\
\text { behavior } \\
\& \text { work } \\
\text { completio } \\
\mathrm{n}\end{array}$ \\
\hline $\begin{array}{l}\text { Miao, Darch } \\
\& \text { Rabren, } \\
2002\end{array}$ & $\begin{array}{c}\text { Resource } \\
\text { Room small } \\
\text { group reading } \\
\text { lessons }\end{array}$ & Pairs & $\begin{array}{c}6 \text { 1st graders with } \\
\text { mild disabilities, } \\
\text { behavior and learning } \\
\text { problems }\end{array}$ & Precorrection & $\begin{array}{l}\text { Correct } \\
\text { responses } \\
\text { \& on task } \\
\text { behavior }\end{array}$ \\
\hline $\begin{array}{l}\text { Covington } \\
\text { Smith, } \\
\text { Lewis, \& } \\
\text { Stormont. } \\
2011\end{array}$ & $\begin{array}{c}\text { Teacher } \\
\text { directed large } \\
\text { group activity }\end{array}$ & $\begin{array}{l}\text { Large } \\
\text { groups }\end{array}$ & $\begin{array}{l}3 \text { Head Start Students } \\
\text { with low levels of } \\
\text { appropriate social } \\
\text { skills and high rates } \\
\text { problem behavior }\end{array}$ & $\begin{array}{l}\text { Precorrection } \\
\text { and specific } \\
\text { praise }\end{array}$ & $\begin{array}{l}\text { Externaliz } \\
\text { ing } \\
\text { problem } \\
\text { behavior }\end{array}$ \\
\hline $\begin{array}{l}\text { Stormont, } \\
\text { Covington- } \\
\text { Smith, \& } \\
\text { Lewis, 2007 }\end{array}$ & $\begin{array}{l}\text { Head start } \\
\text { classroom, } \\
\text { teacher lead } \\
\text { small group }\end{array}$ & $\begin{array}{l}\text { Small } \\
\text { groups }\end{array}$ & $\begin{array}{l}\text { Teachers using more } \\
\text { reprimands than } \\
\text { praise }\end{array}$ & $\begin{array}{l}\text { Precorrection } \\
\text { and specific } \\
\text { praise }\end{array}$ & $\begin{array}{l}\text { Student } \\
\text { problem } \\
\text { behavior }\end{array}$ \\
\hline $\begin{array}{l}\text { De Pry \& } \\
\text { Sugai, } 2002\end{array}$ & $\begin{array}{l}\text { Sixth grade } \\
\text { social studies }\end{array}$ & Class & $\begin{array}{l}26 \text { Sixth Grade } \\
\text { students }\end{array}$ & $\begin{array}{l}\text { Active } \\
\text { supervision } \\
\text { and } \\
\text { precorrection }\end{array}$ & $\begin{array}{l}\text { Minor } \\
\text { behaviora } \\
1 \\
\text { incidents }\end{array}$ \\
\hline $\begin{array}{l}\text { Lewis, } \\
\text { Colvin \& } \\
\text { Sugai, } 2000\end{array}$ & $\begin{array}{c}\text { Recess and } \\
\text { prior to }\end{array}$ & $\begin{array}{l}\text { School } \\
\text { wide }\end{array}$ & $\begin{array}{l}475 \text { 1st thru 6th } \\
\text { graders }\end{array}$ & $\begin{array}{l}\text { Active } \\
\text { supervision } \\
\text { and } \\
\text { precorrection }\end{array}$ & $\begin{array}{l}\text { Problem } \\
\text { behavior }\end{array}$ \\
\hline $\begin{array}{l}\text { Colvin, } \\
\text { Sugai, } \\
\text { Good, \& } \\
\text { Lee, } 1997\end{array}$ & $\begin{array}{l}\text { School } \\
\text { common } \\
\text { areas }\end{array}$ & $\begin{array}{l}\text { School } \\
\text { wide }\end{array}$ & $\begin{array}{c}4,5001 \text { st thru } 6 \text { th } \\
\text { graders }\end{array}$ & $\begin{array}{l}\text { Active } \\
\text { supervision } \\
\text { and } \\
\text { precorrection }\end{array}$ & $\begin{array}{l}\text { Problem } \\
\text { Behavior }\end{array}$ \\
\hline
\end{tabular}

Evidence-based practice potential. As Simonsen et al. (2008) explained it is important for research to focus on evaluating new or under-researched classroom 
management strategies. This was a focus of the current research. Over the course of this research eleven research articles that documented the potential effectiveness of precorrection were identified (see Table 16). This growing base of research demonstrating the effectiveness of precorrection, suggests there may be value in researching the merits of precorrection as an evidence-based practice. However, it is not the intent of this paper to analyze the merits of precorrection as an evidence-based practice in detail. Instead, to suggest as the research base around precorrection continues to grow a systematic evaluation of this research may provide valuable guidance.

Horner et al. (2005) outlined a criteria for considering a practice as evidencebased when utilizing multiple baseline research. The researchers explained:

Single-subject research documents a practice as evidence-based when (a) the practice is operationally defined; (b) the context in which the practice is to be used is defined; (c) the practice is implemented with fidelity; (d) results from single-subject research document the practice to be functionally related to change in dependent measures; and (e) the experimental effects are replicated across a sufficient number of studies, researchers, and participants to allow confidence in the findings. (p.175)

When examining the precorrection research base, there are a total of eleven published research articles including twenty-two students, as well as an entire class and two schoolwide populations. These articles consistently establish a functional relationship between precorrection and a change in valuable outcomes (Horner et al., 2005).

Precorrection has been implemented across a wide range of contexts and populations. Interestingly, while this range suggests precorrection is durable, it may hinder establishing it as an evidence-based practice. Future research may need to consider how to define the context, populations, and specific outcomes to which precorrection is best applied. Colvin et al. (1993) originally defined precorrection as a 
seven-step, problem-solving process. However, it has often been applied in subsequent research as simply a precorrective statement; others have paired it with environmental modifications such as peer reinforcement or active supervision. Future research may need to examine the parameters of precorrection, its application and more closely examine how it aligns with evidence based practice criterion.

\section{Implications}

Predictable problem behavior. Per referral data from the Technical Assistance Center on Positive Behavioral Interventions and Supports, $58 \%$ of the minor, teachermanaged referrals at elementary schools are for defiance, disrespect, or disruption (Gion, McIntosh, \& Horner, 2014). These also make up just under half of the major, officemanaged referrals. In middle school $60 \%$ of the teacher-managed referrals are for these behaviors. Similarly, teachers report instances of simple disrespect, noncompliance, poor peer interactions, cursing, making fun of one another, grabbing, pushing, and being offtask as common occurrences in their classrooms (Harrison \& Vannest, 2012; Nolle, et al., 2007). As De Pry and Sugai (2002) explain:

Teachers often spend inordinate amounts of time responding to minor behavioral incidents that disrupt or interfere with instructional activities. Often, these behaviors are not so severe that they must involve office or administrative staff, but they typically consume significant amounts of the teachers' instructional time. (p. 262)

Fortunately, these predictable, nonaggressive problem behaviors are what the use of

precorrection has reduced repeatedly in research (Covington-Smith et al., 2011; De Pry \& Sugai, 2002; Simonsen et al., 2010). It may be worth exploring if increasing the use of 
the problem-solving process in a precorrection plan may be a low-intensity way for teachers to be better prepared to prevent these predictable problem behaviors.

Additionally, it is not uncommon for researchers to recommend providing students with re-teaching and additional practice prior to implementing targeted interventions (Borgmeier \& Rodriguez, 2015; Crone \& Horner, 2003). Delivering precorrection statements is based on the assumption that the behavior being prompted has been taught and that the child, group, class, or school simply need a reminder as they are entering a setting where that expected behavior is to be utilized. Precorrection may be a skill teachers utilize as a first response to problem behavior, providing elements of reteaching and additional practice.

Implementation of supports. The nature of a busy general education classroom, with twenty-five or more students, pacing calendars, and the numerous other competing demands on educators, makes the implementation of research based practices a challenge. Considering these limitations, the ability of teachers to quickly learn and effectively implement precorrection is exciting. As discussed previously, two of the most common concerns about behavior supports are (a) Are the resources available to implement research based behavior supports (Hieneman, et al., 2005; Nelson et al., 1999; Reid \& Nelson, 2002)? And (b) Do school site personnel have the skills necessary to implement behavior interventions (Allday et al., 2011; Conroy et al., 2000; Gresham \& Quinn, 1999; Reid \& Nelson, 2002)? The precorrection training involved in this research is a lowlabor-intensity process that doesn't require any additional resources and builds on the 
instructional skills of educators, allowing them to quickly incorporate these practices into their instruction.

Considerations for future research. This research focused on building the capacity of general education elementary school teachers to prevent problem behavior. By providing a brief training and ongoing feedback on precorrection and praise the teachers in this research were able to incorporate these research based practices into their instruction. As a result of this research potentially new areas of research have emerged.

The ratio of praise-to-reprimands is frequently discussed topic in professional development programs and has value as an indicator of classroom climate (Flora, 2000; Gottman \& Levenson, 1992). Similarly, it may be useful for future research to explore to what extent the ratio of precorrections-to-reprimands may be an indicator of the learning climate in classrooms. The widespread concerns teachers have about responding to problem behavior and the challenge of responding to this behavior in a constructive manner makes shifting the focus of educators to prevention valuable. Understanding if the ratio of precorrection-to-reprimands can be used as a measure to monitor prevention efforts and/or a teaching tool could be valuable information for educators and educational leaders.

When Rodriguez, Loman and Borgmeier (2016) researched the use of Tier two interventions they found wide differences in implementation and the identification of critical features of many interventions. This inconsistency can limit the potential impact of interventions and complicates implementation. In order to improve the implementation of behavior supports more clearly defining the implementation steps, 
providing high quality training on the support and consistently and clearly identifying the critical features of a support will improve the ability of professionals to get the maximum utility of an intervention. There is a need for future research to identify the critical features and training requirements of precorrection.

This research provided insight into the importance of ongoing feedback and opportunities for questions while educators are working to acquire a new skill. Examining how school districts can better incorporate this in professional development could be an area of research that improves the quality and efficacy of professional development programs (Stokes \& Baer, 1977) Future research could explore the impact of trainings with and without feedback. Additionally, there could be value in exploring the effectiveness of different modes of feedback and support, such as in person, groups, virtually, etc. Understanding the value of ongoing feedback and opportunities for questions, as well as, how to effectively provide it could be valuable research for educational leaders and teacher credentialing programs.

In the future, it may be worth considering how precorrections can be varied to help teachers prevent problem behavior class wide or individually. Can the delivery method of precorrection be varied to meet the needs of students with more intense problem behavior? How can other research based practices, such as active supervision, most effectively be layered on top of precorrection for students in need of additional supports? Considering the limitations many educators feel when addressing problem behavior, rather than attempting to teach a different strategy for each type of problem behavior, teaching educators the problem-solving process in precorrection and how to 
apply it to a variety of settings may improve the social validity and implementation of behavior supports.

Conclusion. The problem of practice this research focused on was an overreliance on reactive and punitive responses to problem behavior by many educators. precorrection and praise are simple and low-labor-intensity antecedent and consequence manipulations, only requiring the teacher to deliver a one-sentence, verbal reminder beforehand and a similarly brief specific praise statement as a consequence. Providing professional development and support to utilize precorrection and praise is an effective way to increase the use of these skills. According to social validity survey results, precorrection can increase teacher confidence in behavior supports. Additionally, precorrection is a durable strategy that can be used in different settings and with a range of students. This may provide teachers with critical skills that reduce their need to resort to punitive measures that are typically not seen as effective.

Precorrection aligns with many of the popular ideas being researched and expanded upon in business, economics, sales, and social psychology. As influential social psychologists Martin, Goldstein and Cialdini (2014) explain in The Small Big: Small Changes that Spark Big Influence, decision makers need to identify what small changes can be made that will net the greatest change. This is especially true in education regarding problem behavior, where resources are scarce and demand is great. Precorrection also aligns with what Thaler and Sunstein (2009) describe as a nudge, or a subtle change that results in noticeable shifts in human behavior. Similarly, precorrection is a practice that aligns with what highly regarded behavioral psychologists 
Embry and Biglan (2008) describe as a kernel for behavior change. These kernels are described as small units of behavioral influence that underlie effective prevention and treatment. As these diverse researchers agree, there is value in finding and maximizing the use of low-intensity supports that yield large results. Precorrection and praise, like "nudges" or "kernels", are small investments that educators can make that yield large returns. 


\section{Bibliography}

Abidin, R. R., \& Kmetz, C. A. (1997). Teacher-student interactions as predicted by teaching stress and the perceived quality of the student-teacher relationship. Retrieved from http://eric.ed.gov/?id=ED413330

Abidin, R. R., \& Robinson, L. L. (2002). Stress, biases, or professionalism what drives teachers' referral Judgments of students with challenging behaviors? Journal of Emotional and Behavioral Disorders, 10, 204-212. doi:10.1177/10634266020100040201

Albin, R. W., Lucyshyn, J. M., Horner, R. H., \& Flannery, K. B. (1996). Contextual fit for behavioral support plans: A model for "goodness of fit." In L. K. Koegel, R. L. Koegel, \& G. Dunlap (Eds.), Positive behavioral support: Including people with difficult behavior in the community, (pp. 81-98). Paul H Brookes Publishing. Baltimore, MD.

Algozzine, B., Barrett, S., Eber, L., George, H., Horner, R., Lewis, T., Putnam, B., Swain-Bradway, J., McIntosh, K., \& Sugai, G (2014). School-wide PBIS Tiered Fidelity Inventory. OSEP Technical Assistance Center on Positive Behavioral Interventions and Supports.

Allday, R., Nelson, J., \& Russel, C. (2011). Classroom-based functional behavioral assessment: Does the literature support high fidelity implementation? Journal of Disability Policy Studies, 22, 140-149.

Armstrong, S. W., \& Kauffman, J. M. (1999). Functional behavioral assessment: Introduction to the series. Behavioral Disorders, 24, 167-181. 
Australian Education Union. (n.d.). AEU national beginning teacher survey results 2006. Retrieved July 3, 2013, from http://www.aeufederal.org.au/Publications/2006/Btsurvey06.html

Avramidis, E., \& Norwich, B. (2002). Teachers' attitudes towards integration/inclusion: A review of the literature. European Journal of Special Needs Education, 17, $129-147$.

Ayers, W. (2004). Teaching the personal and the political: Essays on hope and justice. New York: Teachers College Press.

Baker, J. (2006). Evidence for population-based perspectives on children's behavioral adjustment and needs for service delivery in schools. School Psychology Review, $35,31-46$.

Baker, P. H. (2005). Managing student behavior: How ready are teachers to meet the challenge? American Secondary Education, 33 (3), 51-64.

Bambara, L. M., Nonnemacher, S., \& Kern, L. (2009). Sustaining school-based individualized positive behavior support perceived barriers and enablers. Journal of Positive Behavior Interventions, 11, 161-176. doi:10.1177/1098300708330878

Benazzi, L., Horner, R. H., \& Good, R. H. (2006). Effects of behavior support team composition on the technical adequacy and contextual fit of behavior support plans. Journal of Special Education, 40, 160-170.

Boardman, A. G., Arguielles, M. E., Vaughn, S., Hughes, M. T., \& Klingner, J. (2005). Special education teachers' views of research-based practices. The Journal of 
Special Education, 39(3), 168-180.

http://doi.org/10.1177/00224669050390030401

Borgmeier, C. \& Rodriguez, B.J. (2015). Consequence strategies to change behavior. In F. Brown, J. L. Anderson, \& R. L. De Pry (Eds.), Individual positive behavior supports: A standards-based guide to practices in school and community settings. Baltimore, MD: Paul H. Brookes Publishing.

Bradshaw, C. P., Mitchell, M. M. \& Leaf, P. J. (2010) Examining the effects of SchoolWide Positive Behavioral Interventions and Supports on student outcomes: Results from a randomized controlled effectiveness trial in elementary schools. Journal of Positive Behavior Interventions, 12, 133-148

Carr, E. G., Dunlap, G., Horner, R. H., Koegel, R. L., Turnbull, A. P., Sailor, W., ... Fox, L. (2002). Positive behavior support: Evolution of an applied science. Journal of Positive Behavior Interventions, 4, 4-16.

Cheney, D., \& Barringer, C. (1995). Teacher competence, student diversity, and staff training for the inclusion of middle school students with emotional and behavioral disorders. Journal of Emotional and Behavioral Disorders, 3, 174-182.

Clunies-Ross, P. (2008). Self-reported and actual use of proactive and reactive classroom management strategies and their relationship with teacher stress and student behavior. Educational Psychology, 28, 693-710.

Cohen, J., McCabe, L., Michelli, N. M., \& Pickeral, T. (2009). School climate: Research, policy, practice, and teacher education. The Teachers College Record, 111, 180213. 
Collins, I. J., \& Arthur, L. M. (2007). Examining the implementation of school-wide positive discipline intervention and its impact on teacher beliefs, values and practices. Retrieved July 1, 2013, from http://www.georgiasouthern.edu/etd/archive/fall2007/isreal_j_collins/collins_isrea 1_200708_edd.pdf

Colvin, G., Sugai, G., Good, R. \& Lee, Y.Y. (1997). Using active supervision and precorrection to improve transition behaviors in an elementary school. School Psychology Quarterly School Psychology Quarterly, 12, 344-363.

Colvin, G., \& Sugai, G. (1988). Proactive strategies for managing social behavior problems: An instructional approach. Education \& Treatment of Children, 11, 341.

Colvin, G., Sugai, G., \& Patching, B. (1993). Precorrection: An instructional approach for managing predictable problem behaviors. Intervention in School and Clinic, $28,143-150$.

Conroy, M., Clark, D., Fox, J. J., \& Gable, R. A. (2000). Building competence in FBA: Are we headed in the right direction? Preventing School Failure: Alternative Education for Children and Youth, 44, 169-173.

Cook, B. G., \& Odom, S. L. (2013). Evidence-based practices and implementation science in special education. Exceptional Children, 79, 135-144. http://doi.org/10.1177/001440291307900201

Cook, C. R., Mayer, G. R., Wright, D. B., Kraemer, B., Wallace, M. D., Dart, E., ... Restori, A. (2012). Exploring the link among behavior intervention plans, 
treatment integrity, and student outcomes under natural educational conditions. The Journal of Special Education, 46, 3-16. doi:10.1177/0022466910369941

Cook, C., Wright, D., \& Gale, B. (2007). Establishing and evaluating the substantive adequacy of positive behavioral support plans. Journal of Behavioral Education, 16, 191-206.

Cooper, J. O., Heron, T. E., \& Heward, W. L. (2007). Applied behavior analysis $\left(2^{\text {nd }}\right.$ ed.). New York: Pearson.

Couvillon, M. A. (2006). Measurement and utility of functional behavioral assessments and behavior intervention plans in classrooms for students with emotional and behavioral disorders. University of North Texas. Retrieved from http://digital.library.unt.edu/ark:/67531/metadc5469/m2/1/high_res_d/dissertation .pdf

Covington-Smith, S. C., Lewis, T., \& Stormont, M. (2011). The effectiveness of two universal behavioral supports for children with externalizing behavior in head start classrooms. Journal of Positive Behavior Interventions, 13, 133-143.

Crimmins, D. (2006). Individualized behavioral supports at 15 years: It's still lonely at the top. Research and Practice for Persons with Severe Disabilities, 31, 31-45.

Crockett, J. L., \& Hagopian, L. P. (2006). Prompting procedures as establishing operations for escape-maintained behavior. Behavioral Interventions, 21, 65-71.

Croll, P., \& Moses, D. (2000). Ideologies and utopias: Education professionals' views of inclusion. European Journal of Special Needs Education, 15, 1-12. 
Crone, D. A., \& Horner, R. H. (2003). Building positive behavior support systems in schools: Functional behavioral assessment. New York: The Guilford Press.

Crosby, S., Jolivette, K., \& Patterson, D. (2006). Using precorrection to manage inappropriate academic and social behaviors. Beyond Behavior, 16, 14-17.

De Pry, R. L., \& Sugai, G. (2002). The effect of active supervision and pre-correction on minor behavioral incidents in a sixth grade general education classroom. Journal of Behavioral Education, 11, 255-267. doi:10.1023/A:1021162906622

DeVoe, J. F., Peter, K., Kaufman, P., Miller, A., Noonan, M., Snyder, T. D., \& Baum, K. (2004). Indicators of school crime and safety. Washington, DC: US Government Printing Office.

Drasgow, E. (2002). School-wide behavior support: Legal implications and requirements. Child \& Family Behavior Therapy, 24, 129-45.

Dunlap, G., Strain, P. S., Fox, L., Carta, J. J., Conroy, M., Smith, B. J., ... McCart, A. (2006). Prevention and intervention with young children's challenging behavior: Perspectives regarding current knowledge. Behavioral Disorders, 32, 29-45.

EdSource. (2012). Understanding school discipline in California: Perceptions and practice. Retrieved from: http://edsource.org/wpcontent/publications/Edsource_Student_Discipline_Survey_Exec_Summary_Sept 2012.pdf

Elliott, S. N., Witt, J. C., Kratochwill, T. R., \& Stoiber, K. C. (2002). Selecting and evaluating classroom interventions. In M.R. Shinn, M. R. Walker, H. M., Stoner, G. (Eds.), Interventions for academic and behavior problems II: Preventive and 
remedial approaches, (pp. 243-294). National Association of School

Psychologists: Washington DC, US.

Ellis, J. (2004). Modifications to basic functional analysis procedures in school settings: A selective review. Behavioral Interventions, 19, 205-228.

Embry, D. D., \& Biglan, A. (2008). Evidence-based kernels: Fundamental units of behavioral influence. Clinical Child and Family Psychology Review, 11(3), 75113. http://doi.org/10.1007/s10567-008-0036-X

Emmer, E. T., \& Stough, L. M. (2001). Classroom management: A critical part of educational psychology, with Implications for teacher education. Educational Psychologist, 36, 103-112. http://doi.org/10.1207/S15326985EP3602_5

Etscheidt, S. (2006). Behavioral intervention plans: Pedagogical and legal analysis of issues. Behavioral Disorders, 31, 223-243.

Faul, A., Stepensky, K., \& Simonsen, B. (2011). The effects of prompting appropriate behavior on the off-task behavior of two middle school students. Journal of Positive Behavior Interventions, 14, 47-55.

Flood, W. A., Wilder, D. A., Flood, A. L., \& Masuda, A. (2002). Peer-mediated reinforcement plus prompting as treatment for off-task behavior in children with attention deficit hyperactivity disorder. Journal of Applied Behavior Analysis, 35, 199-204.

Flora, S. R. (2000). Praise's magic reinforcement ratio: Five to one gets the job done. The Behavior Analyst Today, 1(4), 64-69. 
Fuchs, D., Fuchs, L. S., \& Stecker, P. M. (2010). The "blurring” of special education in a new continuum of general education placements and services. Exceptional Children, 76, 301-323.

Gable, R. A., Hendrickson, J. M., \& Smith, C. (1999). Changing discipline policies and practices: Finding a place for functional behavioral assessment in schools. Preventing School Failure, 43, 167-70.

Gena, A. (2006). The effects of prompting and social reinforcement on establishing social interactions with peers during the inclusion of four children with autism in preschool. International Journal of Psychology, 41, 541-554.

Gersten, R. M. (2009). Assisting students struggling with reading: Response to intervention and multi-tier intervention in the primary grades. U.S. Department of Education, National Center for Education Evaluation and Regional Assistance, Institute of Education Sciences.

Greenwood, C. R., \& Abbott, M. (2001). The research to practice gap in special education. Teacher Education and Special Education, 24, 276-289. http://doi.org/10.1177/088840640102400403

Gresham, F. M., \& Quinn, M. M. (1999). Methodological issues in functional analysis: Generalizability to other disability groups. Behavioral Disorders, 24, 119-137.

Gion, C. M., McIntosh, K., \& Horner, R. (2014). Patterns of minor office discipline referrals in schools using SWIS. Retrieved from Positive Behavioral Interventions and Supports, OSEP Technical Assistance Center website: http://www. pbis. 
org/common/pbisresources/publications/Final-ODR-Brief. pdf. Retrieved from http://www.pbis.org/Common/Cms/files/pbisresources/EvalBrief_May2014.pdf

Gottfredson, G. D., \& Gottfredson, D. C. (2001). What schools do to prevent problem behavior and promote safe environments. Journal of Educational and Psychological Consultation, 12, 313-344.

Gottman, J. M., \& Levenson, R. W. (1992). Marital processes predictive of later dissolution: Behavior, psychology, and health. Journal of Personality and Social Psychology, 63, 221-223.

Harrison, J. R., \& Vannest, K. (2012). Common problem behaviors of children and adolescents in general education classrooms in the united states. Journal of Emotional and Behavioral Disorders, 20, 55-64.

Heckaman, K., Conroy, M., Fox, J., \& Chait, A. (2000). Functional assessment-based intervention research on students with or at risk for emotional and behavioral disorders in school settings. Behavioral Disorders, 25, 196-210.

Hertzog, H. S. (2002). “When, how, and who do I ask for help?”: Novices’ perceptions of problems and assistance. Teacher Education Quarterly, 29(3), 25-41.

Hieneman, M., Dunlap, G., \& Kincaid, D. (2005). Positive support strategies for students with behavioral disorders in general education settings. Psychology in the Schools, 42, 779-794.

Hodkinson, A. (2006). Conceptions and misconceptions of inclusive education-one year on: A critical analysis of newly qualified teachers' knowledge and understanding of inclusion. Research in Education, 76, 43-55. 
Horner, R. H., Carr, E. G., Halle, J., McGee, G., Odom, S., \& Wolery, M. (2005). The use of single-subject research to identify evidence-based practice in special education. Exceptional Children, 71, 165-179.

Horner, R. H., Sugai, G., Todd, A.W. \& Lewis-Palmer, T. (2000). Elements of behavior support plans: A technical brief. Exceptionality, 8, 205-215.

Horner, R. H., Sugai, G., Smolkowski, K., Eber, L., Nakasato, J., Todd, A. W., \& Esperanza, J. (2009). A randomized, wait-list controlled effectiveness trial assessing school-wide positive behavior support in elementary schools. Journal of Positive Behavior Interventions, 11, 133-144.

Huaqing, Q. C., \& Kaiser, A. P. (2003). Behavior problems of preschool children from low-income families: Review of the literature. Topics in Early Childhood Special Education, 23, 188-216.

Ingersoll, R. M. (2001). Teacher turnover and teacher shortages: An organizational analysis. American Educational Research Journal, 38, 499-534.

Iwata, B. A., Rolider, N. U., \& Dozier, C. L. (2009). Evaluation of timeout programs through phased withdrawal. Journal of Applied Research in Intellectual Disabilities, 22, 203-209.

Jones, K. M., \& Lungaro, C. J. (2000). Teacher acceptability of functional assessmentderived treatments. Journal of Educational and Psychological Consultation, 11, 323-332. http://doi.org/10.1080/10474412.2000.9669418

Kaff, M. S., Zabel, R. H., \& Milham, M. (2007). Revisiting cost-benefit relationships of behavior management strategies: What special educators say about usefulness, 
intensity, and effectiveness. Preventing School Failure: Alternative Education for Children and Youth, 51, 35-45. http://doi.org/10.3200/PSFL.51.2.35-45

Kapusnick, R. A., \& Hauslein, C. M. (2001). The "silver cup" of differentiated instruction. Kappa Delta Pi Record, 37, 156-159.

Kazdin, A. E. (1989). Behavior modification in applied settings. Pacific Grove, Ca: Brooks/Cole.

Kerr, M. M., \& Nelson, C. M. (2006). Strategies for addressing behavior problems in the classroom. New York: Pearson.

Kondrasuk, J. N., Greene, T., Waggoner, J., Edwards, K., \& Nayak-Rhodes, A. (2005). Violence affecting school employees. Education, 125, 638-647.

Kupersmidt, J. B., Bryant, D., \& Willoughby, M. T. (2000). Prevalence of aggressive behaviors among preschoolers in Head Start and community child care programs. Behavioral Disorders, 26, 42-52.

Lewis, T., Barrett, S., Sugai, G., \& Horner, R. (2010). Blueprint for school-wide positive behavior support training and professional development (Version 3). Washington D.C.: National Technical Assistance Center on Positive Behavioral Interventions and Supports.

Lewis, T., Colvin, G., \& Sugai, G. (2000). The effects of precorrection and active supervision on the recess behavior of elementary students. Education and Treatment of Children, 23, 109-21.

Liu, X. S. (2005). Teachers' perceptions of their jobs: A multilevel analysis of the teacher follow-up survey for 1994-95. Teachers College Record, 107, 985-1003. 
Losen, D. J. (2011). Discipline policies, successful schools, and racial justice. Retrieved July 3, 2013, from http://civilrightsproject.ucla.edu/research/k-12education/school-discipline/discipline-policies-successful-schools-and-racialjustice/NEPC-SchoolDiscipline-Losen-1-PB_FINAL.pdf

Maag, J. W. (2004). Behavior management: From theoretical implications to practical applications. Behavioral Disorders, 30, 185-187.

Main, S., \& Hammond, L. (2008). Best practice or most practiced? Pre-service teachers' beliefs about effective behavior management strategies and reported self-efficacy. Australian Journal of Teacher Education, 33(4), 28-39. http://doi.org/10.14221/ajte.2008v33n4.3

March, R. E., Horner, R. H., Lewis-Palmer, T., Brown, D., Crone, D., Todd, A. W., \& Carr, E. G. (2000). Functional assessment checklist for teachers and staff (FACTS). Eugene, OR: Educational and Community Supports.

Markow, D., Kim, A., Liebman, M. (2007). The Metlife survey of the American teacher: The homework experience. New York, N.Y.: MetLife.

Martin, A. J., Linfoot, K., \& Stephenson, J. (1999). How teachers respond to concerns about misbehavior in their classroom. Psychology in the Schools, 36, 347-358.

Martin, S. J., Goldstein, N., \& Cialdini, R. (2014). The small BIG: Small changes that spark big influence. New York: Grand Central Publishing.

McCurdy, B. L., Mannella, M. C., \& Eldridge, N. (2003). Positive behavior support in urban schools can we prevent the escalation of antisocial behavior? Journal of Positive Behavior Interventions, 5, 158-170. 
McLeskey, J., Henry, D., \& Hodges, D. (1999). Inclusion: What progress is being made across disability categories?. Teaching Exceptional Children, 31(3), 60-64.

Meister, D. G., \& Melnick, S. A. (2003). National new teacher study: Beginning teachers' concerns. Action in Teacher Education, 24(4), 87-94.

Miao, Y., Darch, C., \& Rabren, K. (2002). Use of precorrection strategies to enhance reading performance of students with learning and behavior problems. Journal of Instructional Psychology, 29, 162-174.

Morrison, T. L. (1979). Classroom structure, work involvement, and social climate in elementary school classrooms. Journal of Educational Psychology, 71, 471-477.

Nelson, J., Robert, M.L., Mathur, S.R., Rutherford, R. B. (1999). Has public policy exceeded our knowledge base? A review of the functional behavioral assessment literature. Behavioral Disorders, 24, 169-181.

Nolle, K. L., Guerino, P., Dinkes, R., \& Chandler, K. (2007). Crime, violence, discipline, and safety in US public schools. Findings from the School Survey on Crime and Safety: 2005-06. National Center for Education Statistics. Retrieved from http://www.eric.ed.gov/ERICWebPortal/recordDetail?accno=ED498378

O’Neill, R. E., McDonnell, J. J., Billingsley, F. F., \& Jenson, W. R. (2011). Single case research designs in educational and community settings. Boston, MA: Pearson.

O’Neill, S., \& Stephenson, J. (2009). Teacher involvement in the development of function-based behavior intervention plans for students with challenging behavior. Australasian Journal of Special Education, 33, 6-25. doi:10.1375/ajse.33.1.6 
Payne, A. A., Gottfredson, D. C., \& Gottfredson, G. D. (2003). Schools as communities: The relationships among communal school organization, student bonding, and school disorder. Criminology, 41, 749-778.

Ratcliff, N. J., Jones, C. R., Costner, R. H., Savage-Davis, E., \& Hunt, G. H. (2010). The elephant in the classroom: The impact of misbehavior on classroom climate. Education, 131, 306-314.

Ratcliff, N. J., Jones, C. R., Costner, R. H., \& Savage-Davis, E. (2011). Teacher classroom management behaviors and student time-on-task: Implications for teacher education. Action in Teacher Education, 32(4), 38-51.

Reid, R., \& Nelson, J. R. (2002). The utility, acceptability, and practicality of functional behavioral assessment for students with high-incidence problem behaviors. Remedial and Special Education, 23, 15-23.

Rimm-Kaufman, S. E., Pianta, R. C., \& Cox, M. J. (2000). Teachers’ judgments of problems in the transition to kindergarten. Early Childhood Research Quarterly, 15, 147-166. http://doi.org/10.1016/S0885-2006(00)00049-1

Rodriguez, B. J., Loman, S. L., \& Borgmeier, C. (2016). Tier 2 interventions in positive behavior support: A survey of school implementation. Preventing School Failure: Alternative Education for Children and Youth, 60, 94-105. https://doi.org/10.1080/1045988X.2015.1025354

Rodriguez, B. J., Loman, S. L., \& Horner, R. H. (2009). A preliminary analysis of the effects of coaching feedback on teacher implementation fidelity of First Step to Success. Behavior Analysis in Practice, 2(2), 11-21. 
Rose, L. C., \& Gallup, A. M. (2000) The 32nd annual Phi Delta Kappa/Gallup poll of the public's attitudes toward the public schools. Phi Delta Kappan, 82(1), 41-58.

Scott, T. M., \& McIntyre, J. (2005). An examination of the relation between functional behavior assessment and selected intervention strategies with school-based teams. Journal of Positive Behavior Interventions, 7, 205-215.

Scott, T. M., Liaupsin, C. J., Nelson, C. M., \& Jolivette, K. (2003). Ensuring student success through team-based functional behavioral assessment. Teaching Exceptional Children, 35(5), 16-21.

Scruggs, T. E., \& Mastropieri, M. A. (1996). Teacher perceptions of mainstreaming/inclusion, 1958-1995: A research synthesis. Exceptional Children, $63,59-74$.

Simonsen, B., Fairbanks, S., Briesch, A., Myers, D., \& Sugai, G. (2008). Evidence-based practices in classroom management: Considerations for research to practice. Education and Treatment of Children, 31, 351-380. https://doi.org/10.1353/etc.0.0007

Simonsen, B., Myers, D., \& DeLuca, C., (2010). Teaching teachers to use prompts, opportunities to respond, and specific praise. Teacher Education and Special Education, 33, 300-318.

Skiba, R. J. (2002). Special education and school discipline: A precarious balance. Behavioral Disorders, 27(2), 81-97.

Skiba, R. J., \& Peterson, R. L. (2000). School discipline at a crossroads: From zero tolerance to early response. Exceptional Children, 66, 335-396. 
Skinner, B. F. (1953). Science and human behavior. New York: Macmillan.

Smart, J. B., \& Igo, L. B. (2010). A grounded theory of behavior management strategy selection, implementation, and perceived effectiveness reported by first-year elementary teachers. The Elementary School Journal, 110, 567-584.

Snider, S. L. (2002). Tics and problem behaviors in schoolchildren: Prevalence, characterization, and associations. Pediatrics, 110, 331-336.

Solnick, M. D., \& Ardoin, S. P. (2010). A quantitative review of functional analysis procedures in public school settings. Education and Treatment of Children, 33, $153-175$.

Stokes, T. F., \& Baer, D. M. (1977). An implicit technology of generalization. Journal of Applied Behavior Analysis, 10, 349-367.

Stormont, M., \& Reinke, W. (2009). The importance of precorrective statements and behavior-specific praise and strategies to increase their use. Beyond Behavior, $18(3), 26-32$.

Stormont, M., Smith, S. C., \& Lewis, T. J. (2007). Teacher implementation of precorrection and praise statements in Head Start classrooms as a component of a program-wide system of positive behavior support. Journal of Behavioral Education, 16, 280-290.

Stoughton, E. H. (2007). "How will I get them to behave?": Pre service teachers reflect on classroom management. Teaching and Teacher Education, 23, 1024-1037. doi:10.1016/j.tate.2006.05.001 
Stuhlman, M. W., \& Pianta, R. C. (2009). Profiles of educational quality in first grade. The Elementary School Journal, 109, 323-342. http://doi.org/10.1086/593936

Sugai, G., \& Horner, R. H. (2009). Responsiveness-to-intervention and school-wide positive behavior supports: Integration of multi-tiered system approaches. Exceptionality, 17, 223-237.

Sugai, G., Horner, R. H., Dunlap, G., Hieneman, M., Lewis, T. J., Nelson, C. M., ... Ruef, M. (2000). Applying positive behavior support and functional behavioral assessment in schools. Journal of Positive Behavior Interventions, 2, 131-143. doi:10.1177/109830070000200302

Sugai, G., Sprague, J. R., Horner, R. H., \& Walker, H. M. (2000). Preventing school violence the use of office discipline referrals to assess and monitor school-wide discipline interventions. Journal of Emotional and Behavioral Disorders, 8, 94101.

Taylor-Greene, S. J., \& Kartub, D. T. (2000). Durable implementation of school-wide behavior support the high five program. Journal of Positive Behavior Interventions, 2, 233-235.

Thaler, R. H., \& Sunstein, C. R. (2009). Nudge: Improving decisions about health, wealth, and happiness. New York: Penguin Books.

Turnbull III, H. R., Wilcox, B. L., Stowe, M., Raper, C., \& Hedges, L. P. (2000). Public policy foundations for positive behavioral interventions, strategies, and supports. Journal of Positive Behavior Interventions, 2, 218-230. 
Tomlinson, C. A. (1999). Mapping a route toward differentiated instruction. Educational Leadership, 57, 12-17.

Valenti, M. W. (2011). Selective supports: An exploratory study of urban educators preferred behavioral interventions. University of Pittsburgh, Pittsburgh, PA. Retrieved from http://d-scholarship.pitt.edu/7079/

Van Acker, R., Boreson, L., Gable, R. A., \& Potterton, T. (2005). Are we on the right course? Lessons learned about current FBA/BIP practices in schools. Journal of Behavioral Education, 14, 35-56.

Wald, J., \& Losen, D. J. (2003). Defining and redirecting a school-to-prison pipeline. New Directions for Youth Development, 99, 9-15.

Wehby, J. H., Lane, K. L., \& Falk, K. B. (2003). Academic instruction for students with emotional and behavioral disorders. Journal of Emotional and Behavioral Disorders, 11, 194-197.

Wheatley, R. (2015). The effectiveness of an intervention designed to increase the positive to negative ratio of instructor interactions during after-school programming. All Graduate Theses and Dissertations. Retrieved from http://digitalcommons.usu.edu/etd/4280

Wolery, M., Bailey, D. B., \& Sugai, G. M. (1988). Effective teaching: Principles and procedures of applied behavior analysis with exceptional students. Boston, MA: Allyn and Bacon.

Yell, M. L., \& Katsiyannis, A. (2000). Functional behavioral assessment and IDEA '97: Legal and practice considerations. Preventing School Failure, 44, 158-62. 


\section{APPENDIX A: CONSENT FORMS}

\section{Parent Informed Consent Form}

Your child is invited to participate in a research study conducted by Dustin Bindreiff, doctoral student in the Graduate School of Education, Portland State University. Through this research, I hope to gather information about the impact of an instructional intervention, precorrection on the academic engagement of students. If your child decides to participate, he or she will be observed for one period per day for up to 30 school days.

Your child's participation in this study will be kept completely confidential. Your child's name will not be on any field notes, surveys, or other data collection materials. The identities of participants will be kept confidential by assigning a code to each participant. Information that links the participants name to the code, as well as other data collection materials, will be kept in the locked filing cabinet in my office.

Participation is entirely voluntary. Your child's decision to participate or not will not affect this/her relationship with XXXX Elementary School, the researcher, or with Portland State University. If your child decides to take part in the study, he or she may choose to withdraw at any time without penalty. Please keep a copy of this letter for your records.

If you have any concerns or problems about your son or daughter's participation in this study or his or her rights as a research subject, please contact Human Subjects Research Review Committee, PO Box 751 (reference HSRRC Proposal \# 153545). Portland, OR. Their phone number is 503-725-2227 and email, hsrrc@pdx.edu. If you have questions about the study, contact Dustin Bindreiff at (917) 710-5848.

Your signature means that you have read and understand the above information and agree that your child has permission to take part in this study. Please understand that you may withdraw your consent at any time without penalty, and that, by signing, you are not waving any claims, rights or remedies. The researcher will provide you with a copy of this form for your own records.

Signature of parent

Date

Signature of the Researcher 


\section{Student Assent Form}

Student's name:

Like you I am a student and am doing some homework about how to help kids, like you, learn. Your parent has said it is okay for you to help me with this project. We want to learn how we can help students learn. If you choose help me with this project, someone will visit your class to take notes on your learning. You will not be asked to do anything extra or new. If you have any questions about what you will be doing, I can explain more.

If you do want to help us with this project, please sign your name on the line below. Remember, you can stop at any time and if you decide not to take part anymore, just let me know.

Signed:

Date: 


\section{Teacher Informed Consent Form}

One of your students has been invited to participate in a research study conducted by Dustin Bindreiff, doctoral student in the Graduate School of Education, Portland State University. Through this research, I hope to gather information about the impact of an instructional intervention, precorrection on the academic engagement of students.

If you decide to participate, there will be a brief training period where you and the researcher, can discuss your concerns and strategies when working with students. Then, you will be observed using the instructional strategies for twenty minutes per day for up to 30 school days in the classroom. Finally, each day you will be given feedback on use of the strategies and have the opportunity to ask questions. Additionally, you will be asked to complete a short 7 seven question rating scale survey.

Your participation in this study will be kept completely confidential. Your name will not be on any field notes, surveys, or other data collection materials. Subject's identities will be kept confidential by assigning a code to each participant. Information that links the participants name to the code, as well as other data collection materials, will be kept in the locked filing cabinet in my office.

Participation is entirely voluntary. Your decision to participate or not will not affect your relationship with XXXX Elementary School, the researcher, or with Portland State University. If your child decides to take part in the study, he or she may choose to withdraw at any time without penalty. Please keep a copy of this letter for your records.

If you have any concerns or problems about your participation in this study or his or her rights as a research subject, please contact Human Subjects Research Review Committee, PO Box 751 (reference HSRRC Proposal \# 153545). Their phone number is 503-7252227 and email, hsrrc@pdx.edu. If you have questions about the study, contact Dustin Bindreiff at (503) 890-2806.

Your signature means that you have read and understand the above information and are willing to participate in this study. Please understand that you may withdraw your consent at any time without penalty, and that, by signing, you are not waving any claims, rights or remedies. The researcher will provide you with a copy of this form for your own records.

Signature of teacher

Date

Signature of the Researcher 


\section{APPENDIX B: DATA COLLECTION FORM}

Date: _Teacher:

Start Time (hrs, mins, sec.): __ Finish Time (hrs, mins, sec.):

Student On-Task Behavior: Student is participating in the activity, following instructions and showing appropriate physical behavior towards others and self.

Time on-task:

Percent of observation on-task:

Setting and Observation Notes:

\begin{tabular}{|l|l|l|}
\hline $\begin{array}{l}\text { Teacher's } \\
\text { Statements }\end{array}$ & 20 minutes Observation Session & Totals \\
\hline $\begin{array}{l}\text { Pre-corrective } \\
\text { statements }\end{array}$ & & \\
\hline $\begin{array}{l}\text { General/Non- } \\
\text { Specific Praise }\end{array}$ & & \\
\hline $\begin{array}{l}\text { Behavior- } \\
\text { specific Praise }\end{array}$ & & \\
\hline $\begin{array}{l}\text { Reprimand } \\
\text { statements }\end{array}$ & & \\
\hline
\end{tabular}

Instruction to the data collectors:

1. General Precorrective Statements are prompts delivered to the whole class, groups, or any individual student (see Table 7 for more detailed definition). Please place a tally mark in corresponding box for every precorrective statement delivered by the teacher. Circle (or underline) the tally mark/s to indicate that the teacher delivered a pre-corrective statement/s to the target student.

2. General/Non-Specific Praise Statements - Place a tally mark in the corresponding box for every general/non specific praise statement (e.g.: "Good job", "Super work", etc.) that the teacher delivers to the whole class, small group or any individual student. Circle (or underline) tally marks to indicate that the praise statement/s was/were delivered to our target student.

3. Behavior-specific Praise Statements - Place a tally mark in the corresponding box for every behavior- specific praise that teacher delivers to the whole class, small group or any individual student. Circle (or underline) tally marks to indicate that the teacher delivered praise statements to our target student.

4. Reprimand statements - Place a tally mark in the corresponding box for every reprimand delivered by the teacher to the whole class, group or any individual student. Circle (or underline) reprimand statements delivered to our target student. 


\section{APPENDIX C: TRAINING TEMPLATE}

Precorrection is a prevention based instructional strategy that often helps teachers prevent predictable problem behavior in their classroom. Precorrection has been used in a variety of settings to work with students engaging in a variety of challenging behaviors. Precorrection can help identify a time when a student, group of students or even a class often have trouble meeting expectations. Once this has been done, we work to clearly identify what behavior you would like to see from the student instead.

Next, we want to develop a precorrective statement that can be delivered to remind the student of the expectation. This statement can then be delivered prior to times when the problem behavior is likely to occur in order to orient the student to the activity and the expectations for that setting. This process has been helpful for many educators as a way to reteach students needing additional instruction is needed to meet expectations. Below is an example of the process. On the next page we can talk more specifically about your class and work to create a precorrective statement that might fit the needs of your students.

\begin{tabular}{|c|c|}
\hline \multicolumn{2}{|c|}{ Sample Precorrection Planning form } \\
\hline Action & Intervention \\
\hline $\begin{array}{l}\text { When and where does the } \\
\text { problem behavior most often } \\
\text { occur? }\end{array}$ & $\begin{array}{l}\text { During whole class instruction, Luke often interrupts } \\
\text { and talks to his neighbors. }\end{array}$ \\
\hline $\begin{array}{l}\text { What behavior would you } \\
\text { like to see from the child } \\
\text { instead? }\end{array}$ & $\begin{array}{l}\text { I would like Luke to stay "on task" meaning his eyes } \\
\text { will be on the teacher or activity. }\end{array}$ \\
\hline $\begin{array}{l}\text { How will you precorrect the } \\
\text { student? }\end{array}$ & $\begin{array}{l}\text { As I prepare to deliver a lesson to the whole class I will } \\
\text { remind the whole class that being responsible means } \\
\text { keeping your eyes on the teacher or task. }\end{array}$ \\
\hline $\begin{array}{l}\text { How will you acknowledge } \\
\text { when the child meets the } \\
\text { expectation? }\end{array}$ & $\begin{array}{l}\text { I will verbally praise the student telling her what } \\
\text { behavior she did that was great. }\end{array}$ \\
\hline
\end{tabular}


In this section focus on your class and (student of focus). Let's spend some discussing the following:

1. When you think about your day and the behavior of when do you think the off-task behavior we have discussed is most likely to occur?

2. What behaviors do you expect from your students at this time?

3. Do you have some ideas about precorrections that might remind of these expectations?

4. Finally, how do you let student's know they are doing a good job in your class?

\begin{tabular}{|l|l|}
\hline \multicolumn{1}{|c|}{ Sample Precorrection Planning form } \\
\hline \multicolumn{1}{|c|}{ Action } & \\
\hline $\begin{array}{l}\text { When and where does the } \\
\text { problem behavior most often } \\
\text { occur? }\end{array}$ & \\
\hline $\begin{array}{l}\text { What behavior would you } \\
\text { like to see from the child } \\
\text { instead? }\end{array}$ & \\
\hline $\begin{array}{l}\text { How will you precorrect the } \\
\text { student? }\end{array}$ & \\
& \\
\hline $\begin{array}{l}\text { How will you acknowledge } \\
\text { when the child meets the } \\
\text { expectation? }\end{array}$ & \\
\hline
\end{tabular}


Providing specific praise

All forms of praise are often valuable to students. Yet, if we can deliver specific praise for a child's behavior the impact is often even greater. For example, a general praise statement such as telling a child "good job", can be made more powerful when we specifically tell the child what behavior they did a good job of doing, for example "good job on correcting your math work.". The impact of praise statements is also increased when it is given as immediately, or as close as possible, to the time when the student engages in the desired behavior.

What are some praise statements you like to use in the classroom?

Do you feel these are specific? Or is there a way we can make these statements more specific?

What are one or two specific praise statements you would like to use in your classroom during whole class instruction?

What are one or two specific praise statements you would like to use in your classroom during independent work time?

Practice is vitally important to learning any new skill. Why don't we take a couple minutes and role play delivering the precorrection and specific praise statements. Would you like to be the student or the teacher to start? 